Universidade de Brasília - UnB

Instituto de Ciências Biológicas

Programa de Pós-Graduação em Ecologia

\title{
Ecologia de Kerodon acrobata (Rodentia: Caviidae) em fragmentos de mata seca associados a afloramentos calcários no Cerrado do Brasil Central
}

\author{
Alexandre de Souza Portella \\ Prof. Dr. Emerson Monteiro Vieira
}

Tese apresentada ao Programa de Pós-Graduação em Ecologia, como requisito parcial para a obtenção do título de Doutor em Ecologia.

Brasília, setembro de 2015. 
ALEXANDRE DE SOUZA PORTELLA

Ecologia de Kerodon acrobata (Rodentia: Caviidae) em fragmentos de mata seca associados a afloramentos calcários no Cerrado do Brasil Central

Tese aprovada junto ao Programa de Pós-Graduação em Ecologia da Universidade de Brasília como requisito parcial para obtenção do título de Doutor em Ecologia

Banca Examinadora:
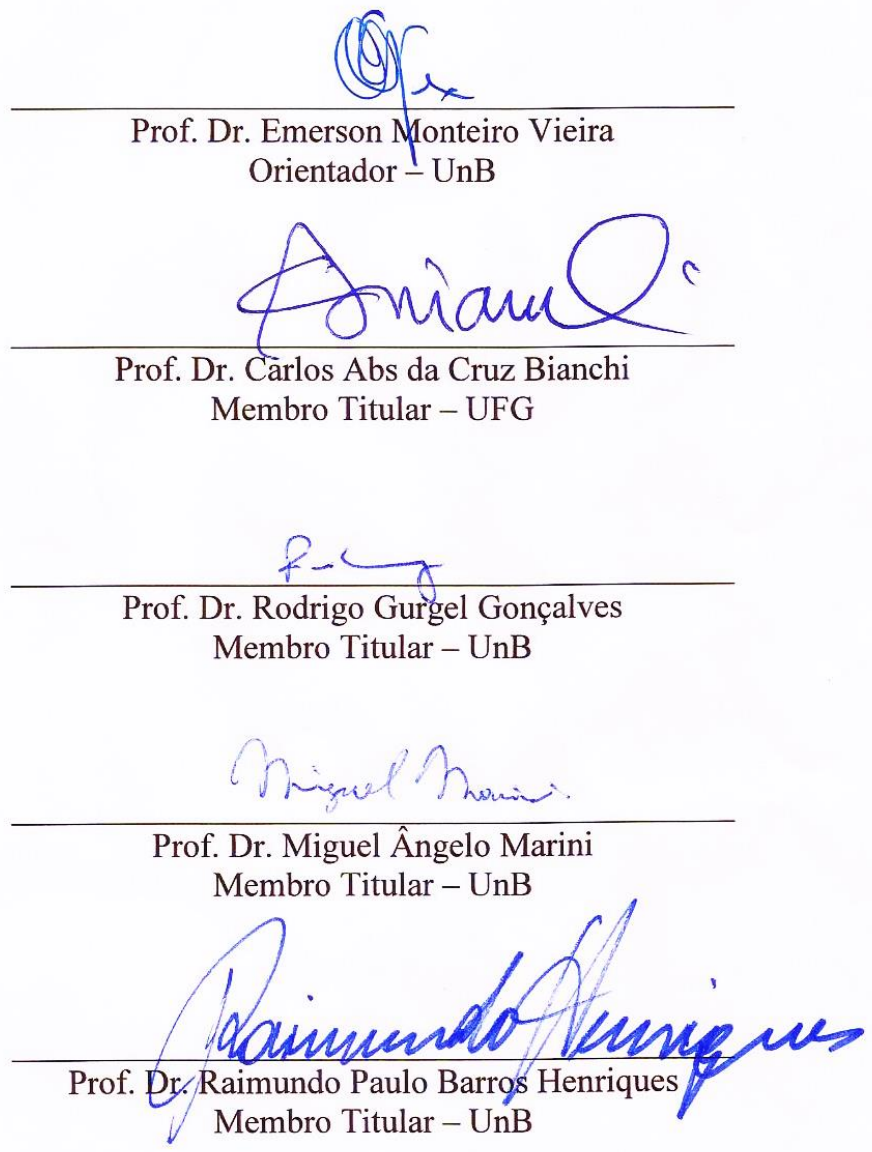

Brasília, setembro de 2015 


\section{Sumário}

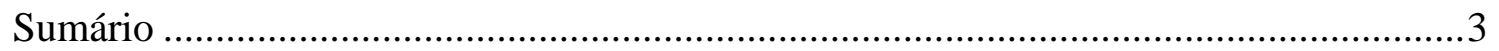

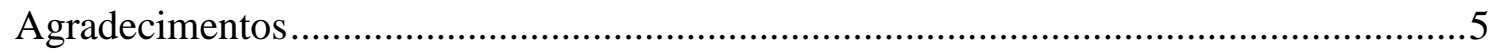

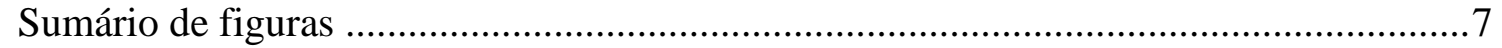

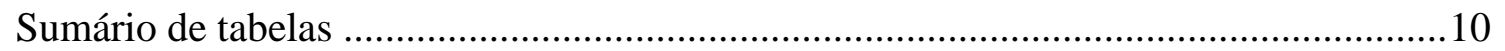

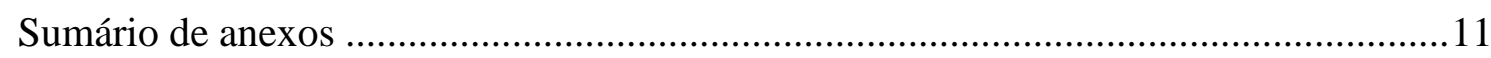

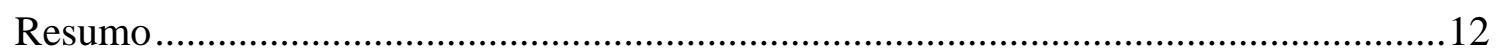

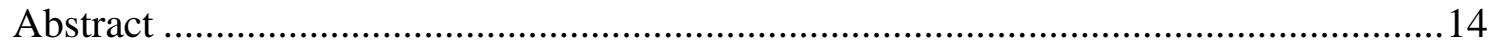

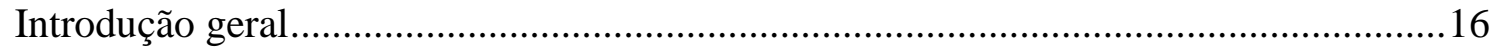

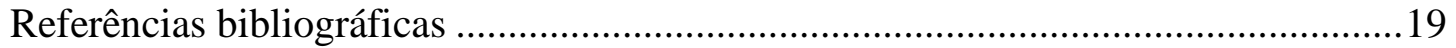

Capítulo 1 - Padrão de atividade diária e comportamento reprodutivo do roedor caviídeo

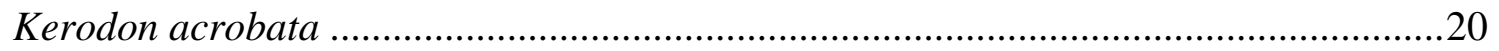

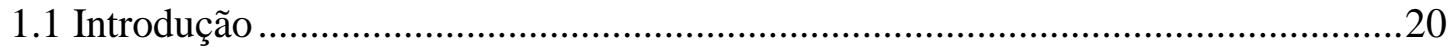

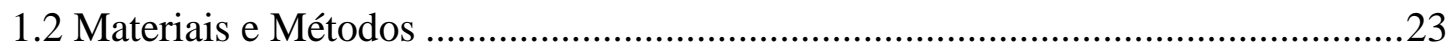

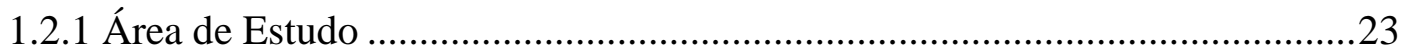

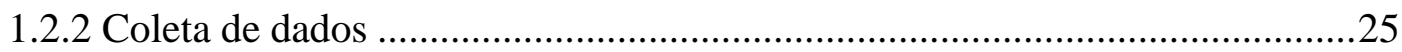

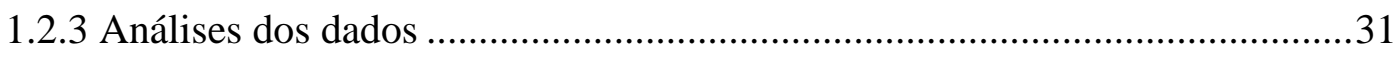

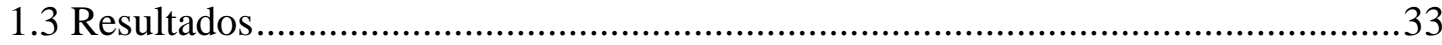

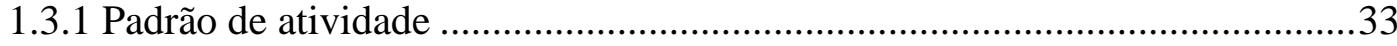

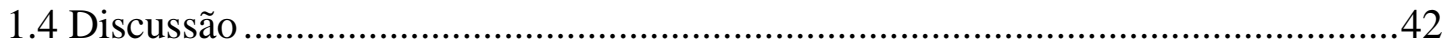

Capítulo 2 - Densidade populacional e área de vida de Kerodon acrobata ....................50

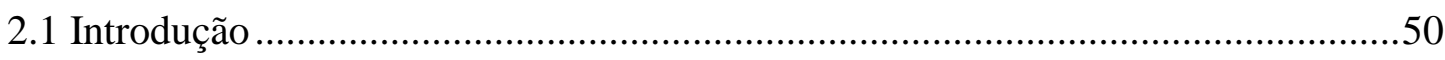

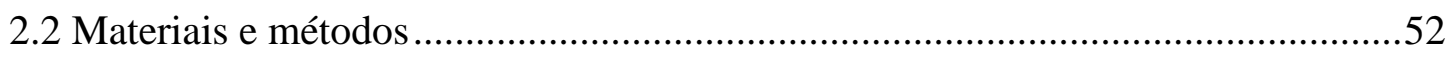

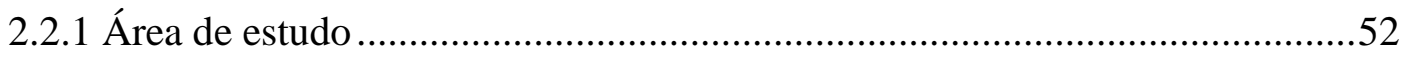

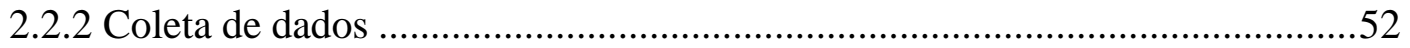

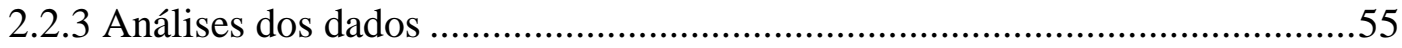

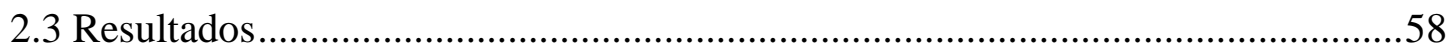

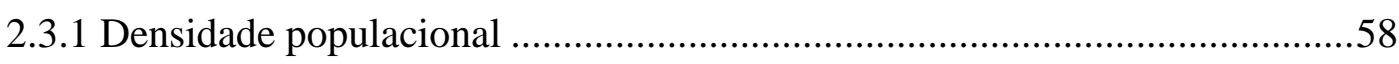

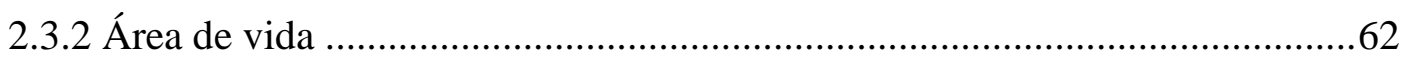

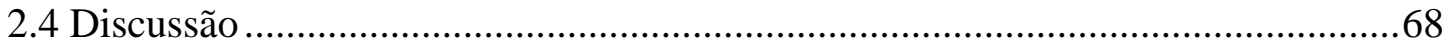

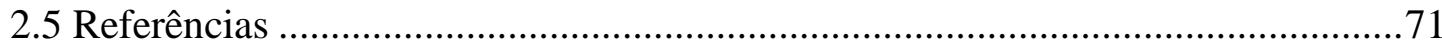

Capítulo 3 - Dieta e amplitude do nicho alimentar de Kerodon acrobata .....................83 


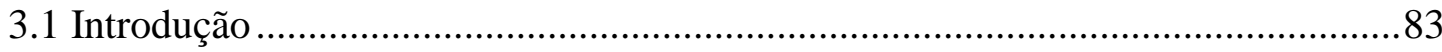

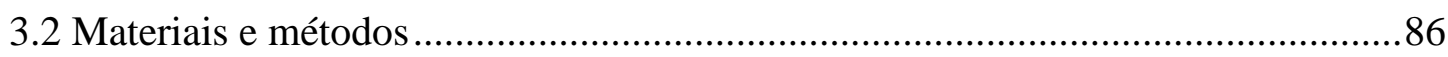

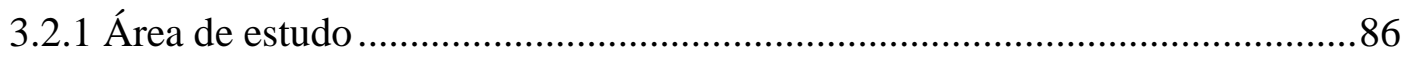

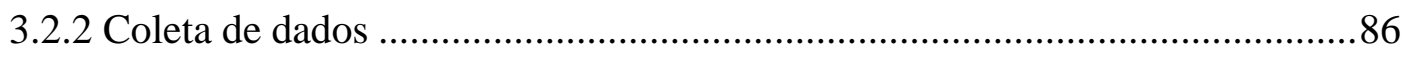

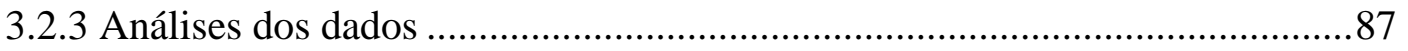

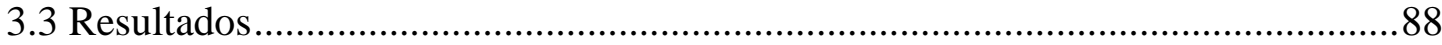

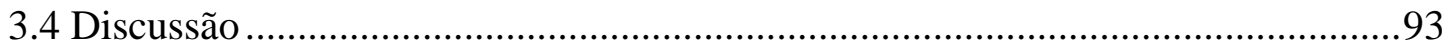

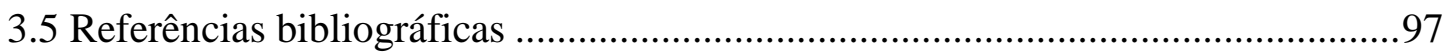

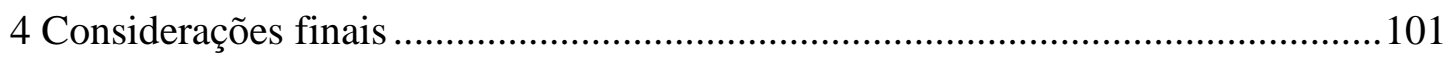




\section{Agradecimentos}

Agradeço a todos aqueles que colaboraram direta ou indiretamente à realização deste estudo.

Especialmente, ao meu orientador Prof. Dr. Emerson M. Vieira, pela orientação, conversas, apoio e paciência ao longo do curso e também, agradeço à equipe do Laboratório de Ecologia de Vertebrados pelo apoio.

Ao CNPq, pelo financiamento de grande parte do projeto, a partir da bolsa de doutorado e taxa de bancada. Ao Decanato de Pesquisa e Pós-Graduação da Universidade de Brasília e também, ao Programa de Pós-Graduação em Ecologia da Universidade de Brasília, incluindo seus professores e funcionários, pelo apoio acadêmico, laboratorial, logístico, e financeiro para a execução do projeto e no financiamento às participações em eventos científicos. À FAP-DF, pelo apoio na participação em eventos científicos, para a divulgação dos resultados desse estudo. À organização não-governamental, Idea Wild, pelo financiamento dos rádiotransmissores e ao Richard Blanchard e toda a equipe da Wildlife Materials, pelo apoio técnico do equipamento.

Ao Prof. Dr. Jader Marinho-Filho e todo o pessoal da Coleção de Mamíferos, pelo empréstimo de equipamentos, suporte nas campanhas de coletas de dados e tombamento dos exemplares coletados. À Profa. Dra. Ivone Rezende Diniz pela cessão de materiais de campo e laboratoriais. Agradeço especialmente, ao ICMBio pela autorização da pesquisa.

Agradeço os proprietários, funcionários e às famílias das fazendas Água doce, Tamanduá e Recreio, em Monte Alegre de Goiás, onde está localizada a área de estudo, em especial ao falecido Carlos Koch, que além de permitir a pesquisa em sua propriedade, sempre me recebeu muito bem e cedeu um valioso espaço para minha barraca de camping. Também agradeço aos proprietários e familiares das fazendas Asa Branca, São Domingos e do Sr. Aldir, em Aurora do Tocantins (TO); e das Fazendas Triunfo e Santa Luzia, em Ponte Alta do Bom Jesus (TO); e às equipes da SEMARH-GO e do Parque Estadual de Terra Ronca (GO), pelas autorizações e apoio. Ao funcionários e proprietários do Super Rio Branco e Supermercado Bom Preço, de Monte Alegre de Goiás, pelas diversas doações de iscas para as armadilhas fotográficas direcionadas para o registro de predadores.

Aos meus amigos e companheiros de curso, principalmente àqueles que me ajudaram explicando ou conversando sobre análises e outros temas aqui abordados e aos que puderam 
me acompanhar nas coletas de dados em campo, pois sem vocês este trabalho seria impossível: Anderson Paz, Aryanne Amaral, Bárbara Zimbres, Daniela Behs, Fernando Carvalho, Frederico Takahashi, Gabriel Oliveira, Ighor Zappes, Ingrid Mattos, Jair Faria, Juliana Bragança, Juliana Plasmo, Juliana Ribeiro, Leonardo Gomes, Leonardo Machado, Maria Rosa Zanatta, Marina Motta, Nárjara Grossmann, Pedro Podestá, Raymundo Sá-Neto, Ricardo Mattos, Rossano Ramos, Samuel Astete e Thiago Filadelfo.

Aos membros da banca examinadora do projeto de qualificação, Prof. Dr. Flávio Rodrigues, Prof. Dr. Ricardo Machado e Dr. André Mendonça; e da banca examinadora da defesa de tese, Prof. Dr. Carlos Bianchi, Prof. Dr. Rodrigo Gurgel Gonçalves, Prof. Dr. Miguel Marini, Prof. Dr. Raimundo Henriques.

Por fim, e em especial, agradeço à minha família. À minha amada esposa, amiga e “estagiária”, Profa. Dra. Clarisse Rocha, por todo o apoio em campo, na UnB e principalmente, em casa. Sem você, nada disso seria possível! À minha mãe, Leila e à minha saudosa avó, Creuza por todo o amor e apoio que vocês me deram durante todo esse processo. Ao meu pai, Fernando, que sempre me incentivou e apoiou muito. À minha filha, Carolina, por todo o amor e compreensão pelos momentos longe. À minha avó Daisy e à Luzia, por todo o carinho e incentivo.

Peço desculpas àqueles que por ventura eu tenha esquecido de mencionar aqui, mas tenham a certeza de que o maior agradecimento é tê-los, todos, comigo em meu coração. 


\section{Sumário de figuras}

Figura 1 - Delimitação da área de estudo (linha amarela), localizada à direita da Serra da Prata e da GO-112, onde ocorrem os três fragmentos de mata seca amostrados, associados a afloramentos calcários, cercados por pasto, no nordeste do estado de Goiás, no Brasil central (Barra de escala: 1500 m. Fonte: Google Earth).

Figura 2 - Fragmento de mata seca associada a afloramento calcário, rodeado por pasto, em Monte Alegre de Goiás, GO. .25

Figura 3 - Indivíduo de Kerodon acrobata, mocó, registrado em Monte Alegre de Goiás, Goiás.

Figura 4 - Distribuição das armadilhas fotográficas nas estações de captura em latrinas na mata decídua, nos fragmentos 2 e 3, da área de estudo nos anos de 2012 e 2013 em Monte Alegre de Goiás, GO (Barra de escala: 224 m. Fonte: Google Earth).

Figura 5 - Distribuição das armadilhas fotográficas nas estações de captura, nos fragmentos 2 e 3 da área de estudo, destinadas a registrar potenciais predadores carnívoros, nos anos de 2012 e 2013 em Monte Alegre de Goiás, GO (Barra de escala: 414 m. Fonte: Google Earth). 28 Figura 6 - Armadilha de espera elaborada de tarrafa de pesca, utilizada para capturar indivíduos de Kerodon acrobata em Monte Alegre de Goiás, GO.

Figura 7 - Proporção do padrão de atividade registrado para Kerodon acrobata por armadilhas fotográficas, em relação aos três períodos diários, dividido entre as estações seca e chuvosa, de julho a outubro de 2012 e de fevereiro a novembro de 2013, em Monte Alegre de Goiás, GO.

Figura 8 - Padrão de atividade dos indivíduos de $K$. acrobata monitorados por armadilhas fotográficas em latrinas durante as estações seca (linha sólida) e chuvosa (linha pontilhada) em Monte Alegre de Goiás - GO de julho de 2012 a novembro de 2013. 36

Figura 9 - Padrão de atividade dos indivíduos de $K$. acrobata monitorados por armadilhas fotográficas em latrinas (linha sólida) e fora delas (linha pontilhada) em Monte Alegre de Goiás - GO, de julho de 2012 a novembro de 2013. 36

Figura 10 - Comparação entre os padrões de atividade de $K$. acrobata (linha sólida) em latrinas e C. thous (linha pontilhada), registrados por armadilhas fotográficas em Monte Alegre de Goiás - GO, entre julho de 2012 e novembro de 2013. 
Figura 11 - Comparação entre os padrões de atividade de $K$. acrobata (linha sólida) e C. thous (linha pontilhada) registrados por armadilhas fotográficas instaladas fora de latrinas em Monte Alegre de Goiás - GO, entre julho de 2012 e abril de 2013.

Figura 12 - Comparação entre os padrões de atividade de K. acrobata (linha sólida) em latrinas e L. pardalis (linha pontilhada), registrados por armadilhas fotográficas em Monte Alegre de Goiás - GO, entre julho de 2012 e novembro de 2013. 38

Figura 13 - Comparação entre os padrões de atividade de K. acrobata (linha sólida) em latrinas e dos predadores (linha pontilhada) registrados por armadilhas fotográficas em Monte Alegre de Goiás - GO, entre julho de 2012 e novembro de 2013.

Figura 14 - Quantidade de capturas de fêmeas adultas $(n=15)$ nas estações seca e chuvosa em relação às suas condições reprodutivas, de novembro de 2011 a julho de 2013 em Monte Alegre de Goiás - GO.

Figura 15 - Distribuição das oito transecções percorridas em quatro fragmentos de mata seca, para detectar os indivíduos de $K$. acrobata durante as amostragens por distância, realizadas de novembro de 2011 a outubro de 2012, em Monte Alegre de Goiás - GO. Os balões vermelhos indicam o início (INI), ou o fim de cada transecção e as linhas brancas, o caminho percorrido.

Figura 16 - Indivíduo de Kerodon acrobata marcado com brincos e rádio-colar.

Figura 17 - Probabilidade de detecção em relação à distância perpendicular dos indivíduos de Kerodon acrobata registrados durante as amostragens por distância realizadas na estação chuvosa, em Monte Alegre de Goiás - GO, em 2011 e 2012.

Figura 18 - Probabilidade de detecção, em relação à distância perpendicular, dos indivíduos de Kerodon acrobata registrados durante as amostragens por distância realizadas durante a estação seca em Monte Alegre de Goiás - GO, em 2012.

Figura 19 - Médias e respectivos intervalos de confiança do número de indivíduos de Kerodon acrobata observados nas estações seca e chuvosa, nas matas decídua (MD) e semidecídua (MS), durante as amostragens por distância realizadas em Monte Alegre de Goiás - GO, de novembro de 2011 a outubro de 2012.

Figura 20 - Médias e intervalos de confiança das áreas de vida estimadas por Kernel-fixo 95\%, para os indivíduos de Kerodon acrobata monitorados de fevereiro a dezembro de 2013 (n=11), em Monte Alegre de Goiás - GO, Brasil. 
Figura 21 - Médias e intervalos de confiança das áreas de vida estimadas por Kernel-fixo 95\% para os indivíduos de Kerodon acrobata monitorados $(n=11)$ em três diferentes estações, de fevereiro a dezembro de 2013, em Monte Alegre de Goiás - GO, Brasil. 65 Figura 22 - Áreas de vida estimadas por Kernel-fixo 95\% para machos (azul) e fêmeas (vermelho) de K. acrobata monitorados em 2013 em Monte Alegre de Goiás - GO. .77 Figura 23 - Áreas de vida estimadas por Kernel-fixo 95\% para fêmeas (cada indivíduo, uma cor diferente) de K. acrobata monitoradas em 2013 em Monte Alegre de Goiás - GO. 77 Figura 24 - Áreas de vida estimadas por Kernel-fixo 95\% para fêmeas adultas (roxo) e jovens (verde) de K. acrobata monitoradas em 2013 em Monte Alegre de Goiás - GO. 78 Figura 25 - Áreas de vida estimadas por Kernel-fixo 95\% para machos (cada indivíduo, uma cor diferente) de K. acrobata monitorados em 2013 em Monte Alegre de Goiás. .78 Figura 26 - Áreas de vida estimadas por Kernel-fixo 95\% para machos adultos (roxo) e jovens (verde) de K. acrobata monitorados em 2013 em Monte Alegre de Goiás. 79 Figura 27 - Áreas de vida estimadas por Kernel-fixo 95\% para adultos (roxo) e jovens (verde) de K. acrobata monitorados em 2013 em Monte Alegre de Goiás - GO. .79 Figura 28 - Áreas de vida estimadas por Kernel-fixo 50 e 95\% dos indivíduos de Kerodon acrobata monitorados em 2013 no município de Monte Alegre de Goiás - GO: (a) 1, (b) 2, (c) 3, (d) 4, (e) 5, (f) 6, (g) 7, (h) 8, (i) 9, (j) 10 e (k) 11, para a primeira estação chuvosa (verde), a seca (vermelho) e a segunda estação chuvosa (azul), quando houver. Sinal (+): estimativa do centro da área de vida. 82 Figura 29- Porcentagem de itens alimentares consumidos por Kerodon acrobata nas estações seca e chuvosa, de novembro de 2011 a novembro de 2013, no município de Monte Alegre de Goiás, Goiás, Brasil. NIDE: itens não-identificados coletados a partir da serrapilheira. 90 Figura 30 - Indivíduo de Kerodon acrobata alimentando-se de flor de Handroanthus serratifolius encontrada sobre a serrapilheira, em Monte Alegre de Goiás, GO. 91 Figura 31 - Indivíduo de Kerodon acrobata alimentando-se de fruto caído de Mangifera indica em Monte Alegre de Goiás, GO. 91 


\section{Sumário de tabelas}

Tabela 1 - Estimativa de sobreposição, com intervalo de confiança (95\%), da atividade de Kerodon acrobata, amostrada por três diferentes métodos, entre julho de 2012 e novembro de 2013, em Monte Alegre de Goiás - GO 39

Tabela 2 - Estimativa de sobreposição, com intervalo de confiança (95\%), da atividade de $K$. acrobata, amostrada em latrinas e câmeras para predadores, em relação à atividade dos predadores registrados entre julho de 2012 e novembro de 2013, em Monte Alegre de Goiás.

Tabela 3 - Estimativas da abundância (N) e densidade (D) de indivíduos de Kerodon acrobata, obtidas por meio do programa DISTANCE, para as amostragens de distância realizadas de novembro de 2011 a outubro de 2012 em Monte Alegre de Goiás - GO, Brasil. Ajuste: distância truncada, em metros; $\mathrm{N}^{\circ}$ obs.: número de eventos de observação de indivíduos; AIC: Critério de Informação de Akaike; ESW: largura efetiva da faixa amostrada, em metros; CV: coeficiente de variação; GOF Chi-p: valor de p para teste de aderência. 60

Tabela 4 - Relação dos indivíduos de Kerodon acrobata, com sexo e estágio de desenvolvimento dos indivíduos, período de amostragem, número de dias amostrados, quantidade de registros (N) por área de vida estimada por Kernel 95\% para a primeira estação chuvosa (fevereiro a março), estação seca (abril a setembro), segunda estação chuvosa (outubro a dezembro) e total, durante o ano de 2013, em Monte Alegre de Goiás, Brasil.....

Tabela 5 - Sobreposição média das áreas de vidas (AV) dos indivíduos de Kerodon acrobata monitorados de fevereiro a dezembro de 2013, em Monte Alegre de Goiás - GO, Brasil. ..... 66 Tabela 6 - Sobreposição média, por estação, das áreas de vidas (AV) dos indivíduos de Kerodon acrobata monitorados de fevereiro a dezembro de 2013, em Monte Alegre de Goiás, Brasil.67 Tabela 7 - Classe e descrição dos itens vegetais consumidos por Kerodon acrobata observados durante as campanhas de coleta de dados em área de Floresta Seca em Monte Alegre de Goiás - GO, no Cerrado do Brasil central, de novembro de 2011 a novembro de 2013.

Tabela 8 - Lista de espécies vegetais observadas sendo consumidas por Kerodon acrobata, por estação, em Monte Alegre de Goiás - GO, de novembro de 2011 a novembro de 2013 e que puderam ser classificadas em algum nível taxonômico. 92 


\section{Sumário de anexos}

Anexo 1 - Descrição dos modelos testados e valor de p, para verificar padrões de autocorrelação temporal no número de mocós observados em Monte Alegre de Goiás, de novembro de 2011 a outubro de 2012, por meio da comparação da qualidade do ajuste dos modelos que consideram a campanha de coleta como variáveis aleatórias. .75 Anexo 2 - Descrição dos modelos testados e valor de p, para verificar se as variáveis estação e cobertura são significativas para a variação no número de mocós registrados em Monte Alegre de Goiás, de novembro de 2011 a outubro de 2012. .75 Anexo 3- Descrição dos modelos testados e valor de p, utilizados para comparar o modelo inicial (GLS) com o modelo que considera o indivíduo como fator aleatório (LME), para verificar se há variação nas estimativas do tamanho das áreas de vida (AV) em cada uma das três estações amostradas, em Monte Alegre de Goiás, de fevereiro a dezembro de 2013 ....... 75 Anexo 4- Valor médio estimado para o número de indivíduos de Kerodon acrobata, erro padrão e valores de z e p encontrados para o modelo selecionado (nmocos $\sim$ estacao * cobertura)... 76 Anexo 5 - Descrição dos modelos testados e valor de p, para verificar se as variáveis estação e número de pontos influenciam no tamanho das áreas de vida (AV) de mocós estimadas de fevereiro a dezembro de 2013, em Monte Alegre de Goiás. .76 


\section{Resumo}

Kerodon acrobata, o mocó do cerrado, é um roedor herbívoro, especialista em ambientes rupestres e endêmico do Cerrado brasileiro. Devido à sua distribuição restrita, limitada ao nordeste de Goiás e sudeste de Tocantins, à fragmentação das populações, às pressões sobre seu habitat e a outras ameaças, como a caça intensiva, é considerada pelo governo brasileiro, uma espécie ameaçada, incluída na categoria vulnerável. A falta de conhecimento sobre essa espécie, levou a União Internacional para Conservação da Natureza (IUCN) a classificá-la na categoria dados insuficientes (DD). A obtenção de dados referentes à história natural, uso do tempo e do espaço e dieta de uma espécie é essencial para garantir a conservação da mesma. Este estudo teve como objetivos: determinar o padrão de atividade de Kerodon acrobata, observando se esses mocós evitam os horários de atividades de predadores; investigar se existe um período reprodutivo definido; investigar possíveis variações na densidade da espécie, entre as estações do ano e entre ambientes florestais distintos; e o seu comportamento alimentar. A área de estudo era constituída por fragmentos de mata seca associada a afloramentos calcários em Goiás, no Brasil central. Para investigar o padrão de atividade de $K$. acrobata realizei buscas de latrinas ativas e armadilhas fotográficas foram instaladas para registrar as atividades destes animais. Também utilizei armadilhas fotográficas com a finalidade de registrar predadores carnívoros com potencial para predar K. acrobata. Os dados comportamentais e observações foram coletados ad libitum. Realizei capturas dos indivíduos com armadilhas que capturam os animais com vida, utilizando folhas e frutos como iscas. Complementarmente, utilizei armadilhas de espera, constituídas por tarrafas, utilizando folhas, frutos, ou urina humana como isca. Os mocós apresentaram um padrão de atividade catemeral, com atividades distribuídas em todos os períodos do dia e com três picos de atividade. Fêmeas com características reprodutivas foram capturadas somente durante a estação seca. O número de mocós registrados variou entre a mata decídua e a mata semidecídua, mas não variou entre as estações. A quantidade total de mocós observados na mata decídua foi maior do que na semidecídua. Porém, a mata semidecídua apresentou maior abundância de mocós na estação seca, provavelmente devido à maior densidade de recursos vegetais e oferta de folhas frescas nesse ambiente durante esse período, enquanto que na decídua foi maior durante a estação chuvosa. As áreas de vida estimadas não diferiram entre sexo, estações e entre jovens e adultos. Também não houve uma correlação significativa entre a massa corporal e as áreas de 
vida estimadas. A sobreposição média de áreas de vida entre os sexos foi maior do que entre fêmeas e entre machos. Indivíduos jovens apresentaram sobreposição dos seus territórios maior do que adultos. Os resultados indicaram que $K$. acrobata não apresentou uma tendência sazonal em seu comportamento reprodutivo. A espécie também não apresentou evidência de sazonalidade na defesa de recursos ou de território. O sistema de acasalamento que provavelmente mais se adequa aos dados obtidos de $K$. acrobata é a poliginia. Os indivíduos de $K$. acrobata alimentaram-se principalmente de folhas, mas também consumiram flores e frutos, ainda nas plantas ou caídos na serrapilheira, além de brotos de ramos e cascas de plantas. A amplitude de nicho não diferiu entre estação chuvosa e seca, com os mesmos recursos sendo explorados nas duas estações, mas encontrei diferença sazonal na frequência dos itens consumidos. A dieta dos mocós foi influenciada pela queda das folhas e flores durante a seca e os animais passaram a concentrar as suas atividades de forrageio na serrapilheira, mudando sua estratégia de exploração dos recursos. Detectei também, que $K$. acrobata apresenta dieta generalista em relação ao consumo de folhas, com ao menos, 16 famílias nativas consumidas. Esses resultados concordam com a ideia de que mudanças ambientais podem ser responsáveis por alterações na abundância e densidade de roedores, ao afetar a disponibilidade de recursos alimentares. A amplitude do nicho alimentar do mocó do Cerrado pode ser um fator que possibilite sua persistência em ambientes alterados. Por outro lado, dependendo da intensidade das alterações antrópicas, a estreita relação dessa espécie com ambientes rochosos e também, com os fragmentos florestais estudados, pode tornar esses animais vulneráveis às ações que ameaçam a integridade desses ambientes. Os resultados encontrados nesse estudo podem ser importantes aliados na elaboração de estratégias de conservação para o mocó do Cerrado. 


\section{Abstract}

Kerodon acrobata, the acrobatic cavy, is an herbivorous rodent, specialist in rocky environments and an endemic species from the Cerrado, a neotropical savannah. Because of its limited distribution, restricted to the northeast of Goiás and southeast of Tocantins, the fragmentation of its populations, and the pressures on its habitat and other threats, such as intensive hunting, this rodent is considered an endangered species, included in the vulnerable $\mathrm{Vu}$ ) category by the Brazilian government. The lack of knowledge on this species led the International Union for Conservation of Nature (IUCN) to classify it in the deficient data (DD) category. Obtaining data on the natural history, use of time and space, and on the diet of a species is essential to ensure the its conservation. This study aimed to: determine the activity pattern of $K$. acrobata, noting if these cavies avoid the activity budget of predators; investigate whether there is a defined breeding season; investigate possible variations in density of the species, between seasons and between different forest environments; and its feeding behavior. The study area consisted of dry forest fragments associated with limestone outcrops in Goiás State, in central Brazil. To investigate the activity pattern of $K$. acrobata, I searched for active latrines where camera traps were installed to record the activities of these animals. I also used camera traps in order to register carnivorous predators with potential to prey upon K. acrobata. The behavioral data and observations were collected ad libitum. I captured individuals using live traps, with leaves and fruits as bait. The acrobatic cavies showed a cathemeral activity pattern, with activities distributed throughout the day, and with three peaks of activity. Females with reproductive traits were captured only during the dry season. The number of cavies observed ranged between deciduous and semi-deciduous forests, but did not vary between seasons. The total amount of cavies observed in deciduous forest was higher than in semideciduous forest. However, the semi-deciduous forest showed greater abundance of acrobatic cavies in the dry season, probably due to the higher densities of plant resources and fresh leaves supply at this environment during that period, while at deciduous forest the abundance was higher during the rainy season. Estimated sizes of home ranges did not differ between sexes, seasons nor between juveniles and adults. There was also no significant correlation between body mass and the estimated sizes of home ranges. The average home range overlap between sexes was higher than among females and males. Juveniles showed higher home range overlap than adults. The results indicated that Kerodon acrobata did not show a seasonal trend in its 
reproductive behavior. The species also showed no evidence of seasonal defense of resources or territory. The mating system that probably best fits the data obtained from $K$. acrobata is the polygyny. Kerodon acrobata individuals fed mainly on leaves, but also consumed flowers and fruits, directly from plants, or even that fallen in the litter, as well as shoots of branches and plant barks. Niche breadth did not differ between wet and dry seasons, with the same resources being exploited in both seasons, but I found a seasonal difference in the frequency of items consumed. Falling leaves and flowers influenced the diet of acrobatic cavies during the dry season, when the animals began to focus their foraging activities in litter, changing the resource exploitation strategy. I also observed that $K$. acrobata has a generalist diet in relation to leaf consumption, with at least 16 native families consumed. These results agree with the idea that environmental changes may be responsible for changes in the abundance and density of rodents, by affecting the availability of food resources. The food niche breadth of the acrobatic cavy may be a factor that allows its persistence in disturbed habitats. On the other hand, depending on the intensity of the anthropogenic changes, the close relationship of this species with rocky environments and also with the forest fragments studied could make these animals vulnerable to actions that threaten the integrity of these environments. The results found in this study may be important allies in the development of conservation strategies for the acrobatic cavy. 


\section{Introdução geral}

Os roedores da família Caviidae ocorrem em diversos hábitats, desde ambientes tropicais úmidos de várzea até campos rupestres secos em altitudes de até $4.000 \mathrm{~m}$ (Nowak, 1999). Habitam áreas abertas de campos, estepes, bordas de florestas, pântanos e montanhas rochosas. Este grupo de herbívoros possui a dieta constituída por itens como folhas, frutos, etc. A reprodução pode ocorrer durante todo o ano, se as condições climáticas forem favoráveis e o ciclo de vida é relativamente longo se comparado a outros roedores (Nowak, 1999).

O gênero Kerodon F. Cuvier, 1825 pertence à família Caviidae e atualmente inclui duas espécies de mocós que são endêmicas do Brasil: K. rupestris (Wied, 1820) e K. acrobata Moojen, Locks \& Langguth, 1997 (Oliveira \& Bonvicino, 2006; Bonvicino et al., 2008). Os mocós possuem tamanho grande (331 a $385 \mathrm{~mm}$ ) e massa corporal entre 750 e 1080g, pelagem densa e macia, não possuem cauda e seus membros são adaptados a ambientes rochosos, com três dedos nas patas posteriores, tubérculos plantares bastante desenvolvidos, garras robustas e curtas (Bonvicino et al., 2008). Também emitem vocalização de alarme característica, utilizam locas em rochas como abrigo e para nidificar e defecam em latrinas, geralmente, em locais elevados (Oliveira \& Bonvicino, 2006).

Kerodon acrobata, ou mocó acrobata, é um roedor de distribuição restrita, endêmico do bioma Cerrado, que foi descrito há apenas 18 anos e os dados disponíveis na literatura apontavam, até recentemente, que a espécie ocorreria somente no estado de Goiás (Moojen et al., 1997; Oliveira \& Bonvicino, 2006; Bonvicino et al., 2008; Langguth \& Reis, 2008; Bezerra et al., 2010) e possivelmente, Tocantins (Woods \& Kilpatrick, 2005). Essa espécie pode ser diferenciada de K. Rupestris por caracteres morfológicos, cranianos e pelo cariótipo (Zappes et al., 2014). é associada a afloramentos rochosos, como os de calcário, em ambientes de floresta seca e cerrado sensu stricto (Moojen et al., 1997; Oliveira \& Bonvicino, 2006; Bonvicino et al., 2008; Langguth \& Reis, 2008; Bezerra et al., 2010). Indivíduos foram coletados nos municípios de Campos Belos, Guarani de Goiás, Nova Roma e São Domingos (Moojen et al., 1997; Bezerra et al., 2010). Durante anos, o registro deste roedor no estado de Tocantins, no município de Dianópolis, foi questionado (Moojen et al., 1997) e não foram encontrados espécimes, nem relatos sobre este mocó em expedições de campo realizadas neste município posteriormente (Bezerra et al., 2010). Porém, novos registros foram realizados nesse estado, no município de Aurora do Tocantins (Zappes et al., 2014). Adicionalmente, também já observei 
esses mocós habitando uma pedreira desativada, localizada em afloramento rochoso não constituído por calcário e associado a cerrado rupestre, no município de Teresina de Goiás e em afloramentos calcários associados a ambientes de mata seca no estado do Tocantins, nos municípios de Aurora do Tocantins, onde coletei dois indivíduos, Combinado, Novo Alegre, Taguatinga do Tocantins e Ponte Alta do Bom Jesus, embora nesse último, algumas características dos animais observados, como pelagem avermelhada e vocalização mais "rouca", sejam diferentes das apresentadas nas outras localidades (obs. pessoal).

Pouco se sabe sobre a ecologia e biologia de $K$. acrobata e por isso, seu estado de conservação segundo a International Union for Conservation of Nature (IUCN) é classificado na categoria "dados insuficientes" (DD), devido à sua recente descrição e por serem necessárias maiores informações sobre sua distribuição, ecologia, ameaças e status populacional (Langguth \& Reis, 2008). Porém, desde a última revisão do estado de conservação da espécie pela entidade (Langguth, \& Reis, 2008), mais informações foram levantadas sobre sua biologia, ecologia e distribuição (Bezerra et al., 2010; Zappes et al., 2014). Moojen e colaboradores (1997) consideraram que $K$. acrobata tem comportamento ativo e acrobata e observaram que a espécie utiliza fendas em rochas calcárias como ninhos e alimenta-se primariamente de folhas, mas também de cactos. Alguns aspectos comportamentais e ecológicos conhecidos sobre a espécie são semelhantes aos registrados para K. rupestris (Moojen et al., 1997; Nowak, 1999; Oliveira \& Bonvicino, 2006; Bonvicino et al., 2008; Langguth \& Reis, 2008; Bezerra et al., 2010).

Devido à sua distribuição restrita, isolamento das populações, à fragmentação e pressões sobre seu habitat e outras ameaças, como a caça intensiva, $K$. acrobata é considerada uma espécie ameaçada no Brasil, categoria vulnerável (critério B1ab(iii,v)) (MMA, 2014). Para conseguir planejar e implantar esforços para a conservação de populações de espécies raras é necessário ter conhecimentos sobre a auto-ecologia das espécies-alvo. É necessário investigar, entre outras coisas, o(s) ambiente(s) em que a espécie ocorre e sua distribuição, as interações com estes ambientes e outros organismos vivos, sua demografia e seu comportamento (Primack \& Rodrigues, 2001).

Portanto, o objetivo desse estudo é elucidar aspectos importantes da ecologia de $K$. acrobata, com o intuito de que esse conhecimento venha a auxiliar ações para a conservação da espécie. Para tanto, pesquisei uma população residente em três fragmentos de mata seca associados a afloramentos calcários em Monte Alegre de Goiás, no nordeste de Goiás. No capítulo 1, investiguei a influência da sazonalidade climática sobre o padrão de atividade diária 
e o comportamento reprodutivo. No capítulo 2 verifiquei a densidade de indivíduos em dois ambientes florestais com diferentes níveis de caducifólia entre as estações seca e chuvosa e o tamanho das áreas de vida e a porcentagem de sobreposição dessas. No capítulo 3 investiguei a dieta e a amplitude de nicho alimentar ao longo das duas estações citadas anteriormente. 


\section{Referências bibliográficas}

Bezerra, A.M.R.; Bonvicino, C.R.; Menezes, A.A.N. \& Marinho-Filho, J. 2010. Endemic climbing cavy Kerodon acrobata (Rodentia: Caviidae: Hydrochoerinae) from dry forest patches in the Cerrado domain: new data on distribution, natural history, and morphology. Zootaxa 2724: 29-36.

Bonvicino, C.R.; Oliveira, J.A. \& D’Andrea, P.S. 2008. Guia dos Roedores do Brasil, com chaves para gêneros baseadas em caracteres externos. Centro Pan-Americano de Febre Aftosa - OPAS/OMS. Rio de Janeiro, RJ. 120 p.

Langguth, A. \& Reis, M. 2008. Kerodon acrobata. In: IUCN 2010. IUCN Red List of Threatened Species. Version 2010.1. Disponível em: www.iucnredlist.org. Acessado em $01 / 01 / 2015$.

MMA - Ministério do Meio Ambiente. 2014. Portaria No 444, de 17 de dezembro de 2014. Lista Nacional Oficial de Espécies da Fauna Ameaçadas de Extinção. Diário Oficial da União, Brasília, DF, n. 245. Seção 1, p. 121-126.

Moojen, J.; Locks, M. \& Langguth, A. 1997. A new species of Kerodon Cuvier, 1825 from the State of Goiás, Brazil (Mammalia, Rodentia, Caviidae). Boletim do Museu Nacional do Rio de Janeiro, Série Zoologia 377: 1-10.

Nowak, R.M. 1999. Walker's Mammals of the World. Volume II. $6^{\mathrm{a}}$ ed. The Johns Hopkins University Press. Baltimore and London. 1.100p.

Oliveira, J.A. \& Bonvicino, C.R. 2006. Ordem Rodentia. Pp: 347-406. In: Reis, N.R.; Peracchi, A.L.; Pedro, W.A.; Lima, I.P. (Eds.) Mamíferos do Brasil. Universidade Estadual de Londrina. Londrina, PR. 437p.

Primack, R.B. \& Rodrigues, E. 2001. Biologia da Conservação. Editora Planta. Londrina, PR. $328 \mathrm{p}$.

Woods, C.A. \& Kilpatrick, C.W. 2005. Infraorder Hystricognathi. Pp. 1538-1600. In: Wilson, D.E. \& Reeder, D.M. (Eds.) Mammal Species of the World, a Taxonomic and Geographic Reference. $3^{\mathrm{a}}$ ed. John Hopkins University Press, Baltimore MD. 2.142p.

Zappes, I.A.; Portella, A.S. \& Lessa, G.M. 2014. Description of Karyotype of Kerodon acrobata, an endemic rodent in Brazilian Cerrado. Brazilian Journal of Biology 74(1): 251-256. 


\section{Capítulo 1 - Padrão de atividade diária e comportamento reprodutivo do roedor caviídeo Kerodon acrobata}

\subsection{Introdução}

Quase todo animal tem a vida dividida em dois estados comportamentais: atividade e repouso (Halle \& Stenseth, 2000a). Durante a atividade, diversas tarefas vitais são desenvolvidas, desde a exploração do ambiente até a procura por parceiros e a mais essencial é a de forrageio. Em atividade, os animais se submetem a um maior gasto energético e ao aumento no risco de mortalidade, devido a fatores como a predação. O repouso pode ser considerado a antítese da atividade, pois as condições sob a qual é realizado são opostas. A diversidade de padrões de atividade entre as espécies sugere que o "timing" para atividade e repouso é crucial para a sobrevivência dos animais (Halle \& Stenseth, 2000a). O padrão de atividades mais comum é "unimodal" (com um pico de atividade em 24 horas) e "monofásico", ocorrendo quase exclusivamente durante o dia ou à noite. Porém existem padrões bimodais, como o crepuscular, polifásicos, como o catemeral e acíclicos, quando não existe um padrão aparente, em relação ao ciclo luz/escuro (Van Schaik \& Griffiths, 1996; Halle \& Stenseth, 2000b).

A "catemeralidade" pode ser um padrão que se manifesta ao longo de todo o ano, ou sazonalmente, com alternância de atividades predominantemente diurna para noturna (ou viceversa), ou para um padrão de atividade de 24 horas (Curtis \& Rasmussen, 2002; Tattersall, 2006). Tal variação no padrão de atividade é controlada, ou ao menos, influenciada por diversos fatores ambientais, como duração do dia, luminosidade noturna, temperatura, pluviosidade, competição, predação, maré e outros, porém, provavelmente sob influência de herança evolutiva (Halle \& Stenseth, 2000a; Curtis \& Rasmussen, 2002; Tattersall, 2006). O termo “catemeral” foi cunhado por Tattersall (1987), para ser utilizado no lugar de "diel", quando a atividade animal não ocorre em uma periodicidade rcorrente nas 24 horas do dia, mas é mais ou menos igualmente distribuída dentro desse período. Van Schaik e Griffiths (1996) classificaram como catemeral, em seu estudo, as espécies de mamíferos que apresentaram de 10 a $90 \%$ dos registros de suas atividades durante o período noturno. Diversos mamíferos já foram documentados apresentando atividade catemeral (Tattersall, 2006), como ungulados (Van Schaik \& Griffiths, 1996; Gómez et al., 2005), primatas lemurídeos (Tattersall, 1987; Curtis \& Rasmussen, 2002; Donati, \& Borgognini-Tarli, 2006; Erkert \& Cramer, 2006) e do 
novo mundo (Fernandez-Duque \& Erkert, 2006), carnívoros (Van Schaik \& Griffiths, 1996) e pequenos mamíferos, incluindo roedores (Halle, 2006). As causas para a manifestação desse padrão de atividade comportamental ainda são amplamente discutidas (Tattersall, 2006).

A sazonalidade climática e consequentemente, de recursos, também pode afetar outros aspectos biológicos e ecológicos de mamíferos. Por exemplo, algumas espécies de roedores cricetídeos que habitam ambientes florestais do Cerrado, como as matas de galeria, apresentam reprodução sazonal, dependendo da variação de fatores como o fotoperíodo, a precipitação, o microclima, a composição vegetal, a disponibilidade de alimento, ou a competição (Mares \& Ernest, 1995). Enquanto que outras se reproduzem ao longo de todo o ano, também dependendo da variedade de recursos disponíveis (Mares \& Ernest, 1995). Porém, nas áreas de savana, como campo cerrado e cerrado sensu stricto, roedores equimídeos e sigmodontíneos tendem a alcançar as maiores densidades na transição chuva-seca e durante a estação seca e as menores durante a estação chuvosa (Vieira, 1997).

Os sistemas de acasalamento em mamíferos incluem monogamia, poliginia e promiscuidade, entre outros e são associados a várias formas de guarda de parceiros, como defesa de território e fêmeas (Clutton-Brock, 1989). As estratégias de acasalamento são características de uma população ou uma espécie e podem refletir uma variedade de táticas sexo-específicas, geralmente definidas pela ocorrência ou não de múltiplos acasalamentos por machos, fêmeas ou ambos (Waterman, 2007). Os quatro sistemas de acasalamento mais presentes em roedores são: o promíscuo, em que as fêmeas são territorialistas e as áreas de vida dos machos se sobrepõem; a poliginia, em que os machos defendem o acesso a um harém, ou aos recursos utilizados pelas fêmeas; a monogamia, em que um macho guarda e copula exclusivamente com uma fêmea; e a eusocialidade, em que diversas fêmeas aparentadas procriam com um ou mais machos e cuidam dos filhotes cooperativamente (Clutton-Brock, 1989; Wolff, 2007). Caso os recursos utilizados pelas fêmeas estejam agregados, consequentemente, estas também estarão e um sistema de acasalamento chamado de poliginia pode se manifestar (Clutton-Brock, 1989).

Os roedores do gênero Kerodon habitam ambientes rochosos e utilizam locas nas rochas para nidificar (Nowak, 1999). Na Caatinga, a reprodução de K. rupestris ocorre quase o ano todo, exceto no período mais seco, de abril a junho (Lacher, 1981). Em cativeiro, Roberts et al. (1984) registraram, uma média de 76 dias de gestação para a espécie (a maior dentre os Caviinae). As ninhadas variaram de um a três filhotes, que atingiram a maturidade sexual a 
partir de 133 dias de idade e essas fêmeas tiveram a primeira concepção em torno de 151 dias. Além disso, os autores observaram que esta espécie tem as gerações mais longas, uma característica de browsers (herbívoros em que a dieta é composta por $>50 \%$ de folhas e ramos) e uma menor fecundidade. Esses autores verificaram também, que o padrão de concepções foi fortemente relacionado aos pareamentos entre machos e fêmeas aplicados pelos pesquisadores, não apresentando uma tendência sazonal nos nascimentos. Porém, diferentemente das condições encontradas na natureza, o acesso à água dessas populações de cativeiro era permanente e os indivíduos foram alimentados com uma dieta balanceada, o que os levou a concluir que a reprodução em Kerodon não é sazonal, mas primariamente influenciada pela disponibilidade de recursos. A outra espécie do gênero, $K$. acrobata, foi observada abrigandose e nidificando em fendas em rochas calcárias (Moojen et al., 1997), porém não existem informações acerca de seu padrão de atividades, nem sobre sua reprodução. Durante observações preliminares, em campo, diversos indivíduos foram observados ativos durante o dia e à noite (obs. pessoal). Estudos sobre o comportamento animal proporcionam conhecimento para a elaboração de estratégias de conservação para as espécies estudadas (Alcock, 2001).

Este estudo tem como objetivos: determinar o padrão de atividade de Kerodon acrobata, verificar se ele varia entre as estações, observar se os mocós evitam os horários de atividades de predadores carnívoros e investigar se existe um período reprodutivo definido, em uma população residente em fragmentos de mata seca, associados a afloramentos calcários no Cerrado do Brasil central. As hipóteses a serem investigadas são:

1) Os indivíduos de Kerodon acrobata evitam os horários de atividade de predadores carnívoros.

2) Kerodon acrobata apresenta um padrão de atividade catemeral, distribuindo suas atividades nos diferentes períodos do ciclo luz/escuro diário.

3) Kerodon acrobata se reproduz na estação chuvosa, época de maior oferta de folhas, seu principal recurso alimentar. 


\subsection{Materiais e Métodos}

\subsection{1 Área de Estudo}

A área de estudo está inserida no município de Monte Alegre de Goiás, localizado na região do Vale do Paranã, nordeste do estado de Goiás, no Brasil central. Segundo a classificação climática de Köppen-Geiger, o município possui clima Aw (Tropical com estação seca no inverno; Cardoso et al., 2015). A precipitação média anual fica entre 1000 e 1200 mm (Cardoso et al., 2015), porém de acordo com dados do Instituto Nacional de Meteorologia (Inmet), a precipitação no município em 2011 foi de 885,33 mm, 735,8 mm em 2012 e 804,4 mm em 2013. O mês de julho é o mês mais seco (média histórica de 0,6 mm - 1972/2001) e a maioria da precipitação anual cai em janeiro (média histórica de 355 mm - 1972/2001) (Silvando et al., 2006). O mês mais quente durante o ano é setembro (média: $26,7^{\circ} \mathrm{C}$ ), e junho $\left(23,8^{\circ} \mathrm{C}\right)$ é o mês com a menor temperatura média.

A área amostrada é constituída por três fragmentos de mata seca de aproximadamente (1) 15,8 , (2) 89 e (3) 3,4 ha, próximos e associados a afloramentos calcários, localizada a leste da GO-112 e da Serra da Prata (Figura 1). Encontra-se rodeada por pastos (Figura 2) e está inserida em propriedades rurais particulares das Fazendas Água Doce, Tamanduá e Recreio (23L 0304341S, 8532406W). As florestas estacionais, ou matas secas, não possuem associação com cursos de água, mas ocorrem em solos mais ricos em nutrientes e são caracterizadas por diversos níveis de caducifólia durante a estação seca, quando atingem até menos de $50 \%$ de cobertura arbórea e na estação chuvosa, de 70 a 90\% (Nascimento et al., 2004). Durante a estação seca, as rochas são cobertas por camadas de folhas secas, que combinadas com a riqueza de calcário, suportam o crescimento florestal na estação chuvosa (Felfili et al., 2007).

O Vale do Paranã está inserido na bacia do rio Paranã, que compõe a bacia hidrográfica do rio Tocantins e possui um dos mais significativos enclaves de florestas estacionais deciduaisdo Brasil (Scariot \& Sevilha, 2005). As matas secas da região do Vale do Paranã enfrentam longas estações secas (5 a 7 meses) e podem ser divididas em florestas semidecíduas e decíduas, com a diferença de que essas últimas crescem sobre os afloramentos calcários existentes (Nascimento et al., 2004; Felfili et al., 2007). Estudos nessa região encontraram, em diferentes fragmentos, riqueza de 39 a 52 espécies arbóreas, com domínio das leguminosas e grande semelhança em composição com a Caatinga (Nascimento et al., 2004; Felfili et al., 2007). Apesar de os afloramentos calcários serem importantes para a preservação da 
biodiversidade, a exploração desse minério em algumas regiões tem provocado a erradicação das florestas estacionais decíduas que crescem sobre esses afloramentos (Silva \& Scariot, 2004). As matas secas do Brasil Central, além de pouco estudadas, também são ameaçadas pelo manejo de fogo para formação e manutenção de pastagens e áreas agrícolas e pela extração seletiva de madeira-de-lei (Silva \& Scariot, 2004; Felfili et al., 2007). Estima-se que de 1977 a 2008, perderam $66 \%$ de sua extensão e que a mata semidecídua praticamente desapareceu (Bianchi \& Haig, 2013).

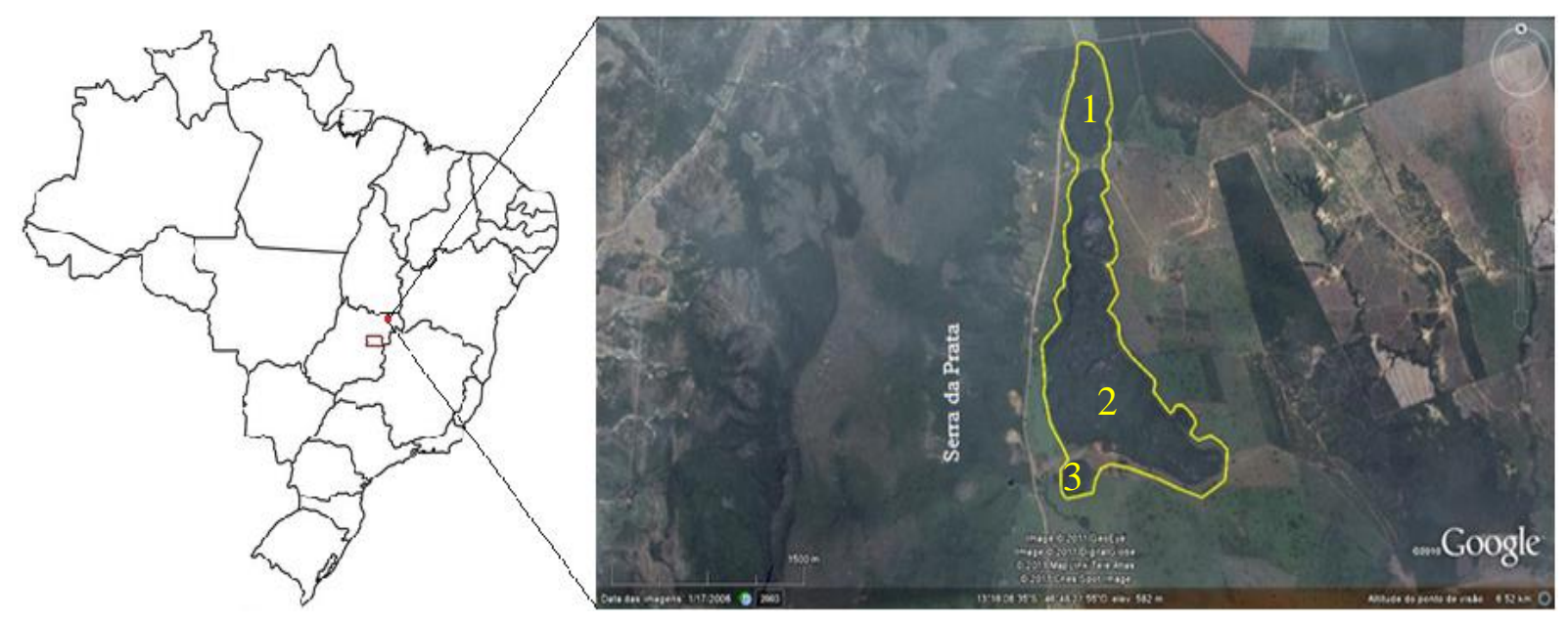

Figura 1 - Delimitação da área de estudo (linha amarela), localizada à direita da Serra da Prata e da GO-112, onde ocorrem os três fragmentos de mata seca amostrados, associados a afloramentos calcários, cercados por pasto, no nordeste do estado de Goiás, no Brasil central (Barra de escala: 1500 m. Fonte: Google Earth). 


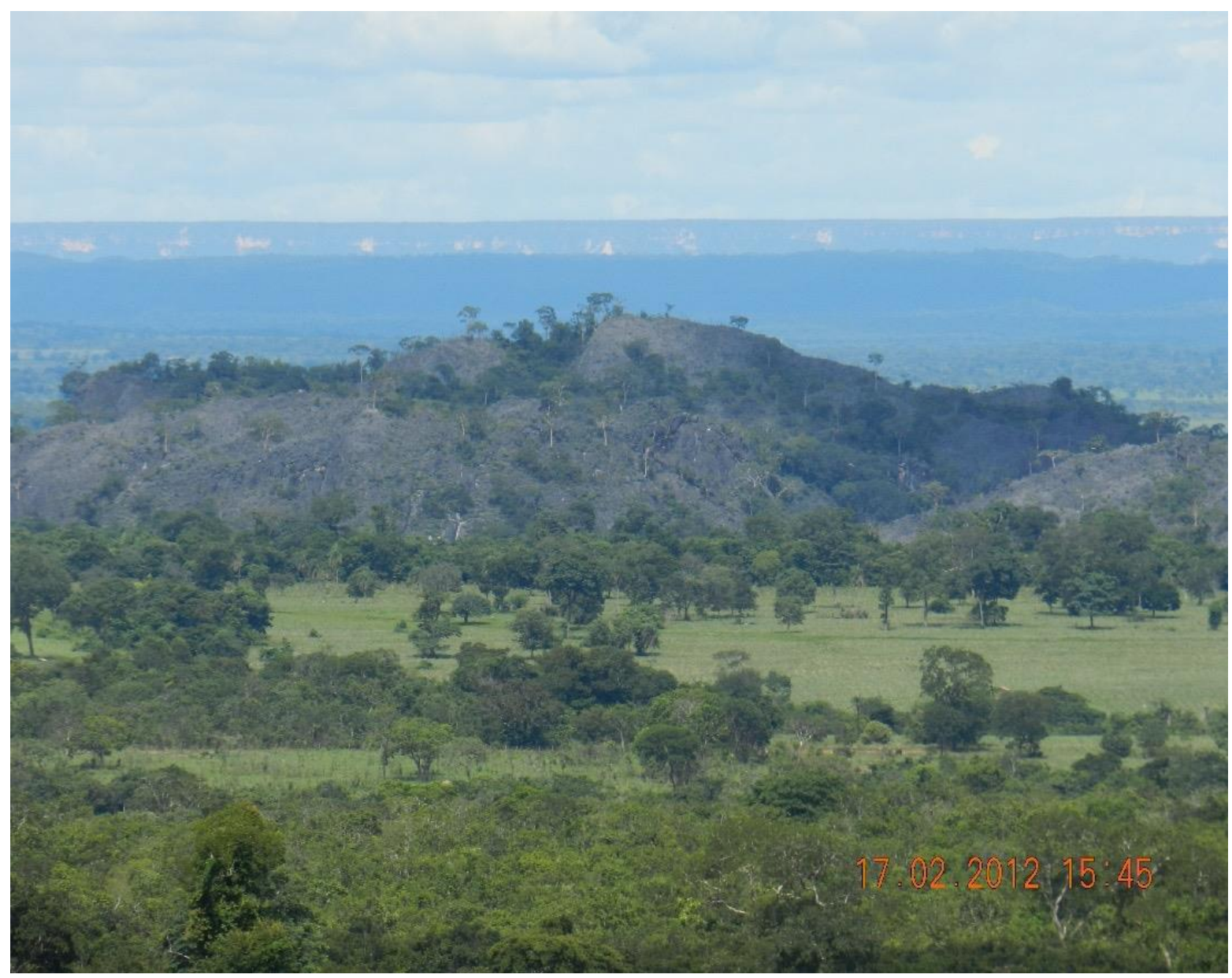

Figura 2 - Fragmento de mata seca associada a afloramento calcário, rodeado por pasto, em Monte Alegre de Goiás, GO.

\subsubsection{Coleta de dados}

\subsubsection{Padrão de Atividade}

Para investigar o padrão de atividade de Kerodon acrobata (Figura 3) realizei buscas de latrinas ativas utilizadas pela espécie na área de estudo. Após a localização das latrinas, armadilhas fotográficas (modelo Trophy Cam, Bushnell, Overland Park, KS, USA) foram instaladas e programadas para registrar as atividades apresentadas nesses locais. O uso desse tipo de equipamento para coletar dados comportamentais possui duas vantagens, segundo Van Schaik \& Griffiths (1996): podem ajudar a caracterizar os padrões de atividade com maior 
acurácia e evitam que a presença e atividade humana (e.g., do observador) modifiquem o período de atividade dos animais estudados.

Foram instaladas armadilhas fotográficas em 13 estações de captura (Figura 4), na mata decídua, durante os meses de julho a outubro de 2012 e de fevereiro a novembro de 2013. As armadilhas foram georreferenciadas com o auxílio de aparelho receptor móvel do sistema de posicionamento global (global positioning system - GPS), do modelo GPSMAP 60CSx (Garmin International, Inc., Olathe, KS, USA). Em duas dessas estações de captura, durante o ano de 2012 e em fevereiro de 2013, as armadilhas funcionaram durante 10 dias consecutivos a cada mês e foram inspecionadas a cada três dias, para verificação das baterias e dos cartões de memória. Em 2013, as máquinas permaneceram ativas mensalmente, por três dias, seguindo um rodízio nas outras estações de captura. Para evitar a inclusão de registros com dependência temporal nas análises, foram descartados todos os vídeos produzidos no mesmo ponto amostral em um intervalo de menos de uma hora (Oliveira-Santos et al., 2013). Para a caracterização do padrão de atividade de $K$. acrobata, foi considerada a classificação de Van Schaik \& Griffiths (1996). Essas armadilhas fotográficas foram programadas para realizar filmagens com duração de um minuto (capacidade máxima do equipamento), com intervalos de um segundo entre elas, para maximizar o registro dos mocós, caso as armadilhas fossem ativadas pelo vento, ou por espécies que não fossem o alvo, etc.

Também utilizei oito armadilhas fotográficas com a finalidade de registrar predadores carnívoros com potencial para predar indivíduos de $K$. acrobata (Figura 5). Estas armadilhas foram distribuídas na mata decídua do afloramento calcário e na mata semidecídua sobre solo. Devido à dificuldade em localizar rastros e caminhos de passagem (trilhas) sobre os afloramentos, estas armadilhas foram armadas com iscas de carne bovina à sua frente, para atrair predadores. Essas armadilhas permaneceram ativas para fotografar por dez dias, entre julho e outubro de 2012 e de janeiro a abril de 2013 e foram revisadas e iscadas a cada 5 dias. 


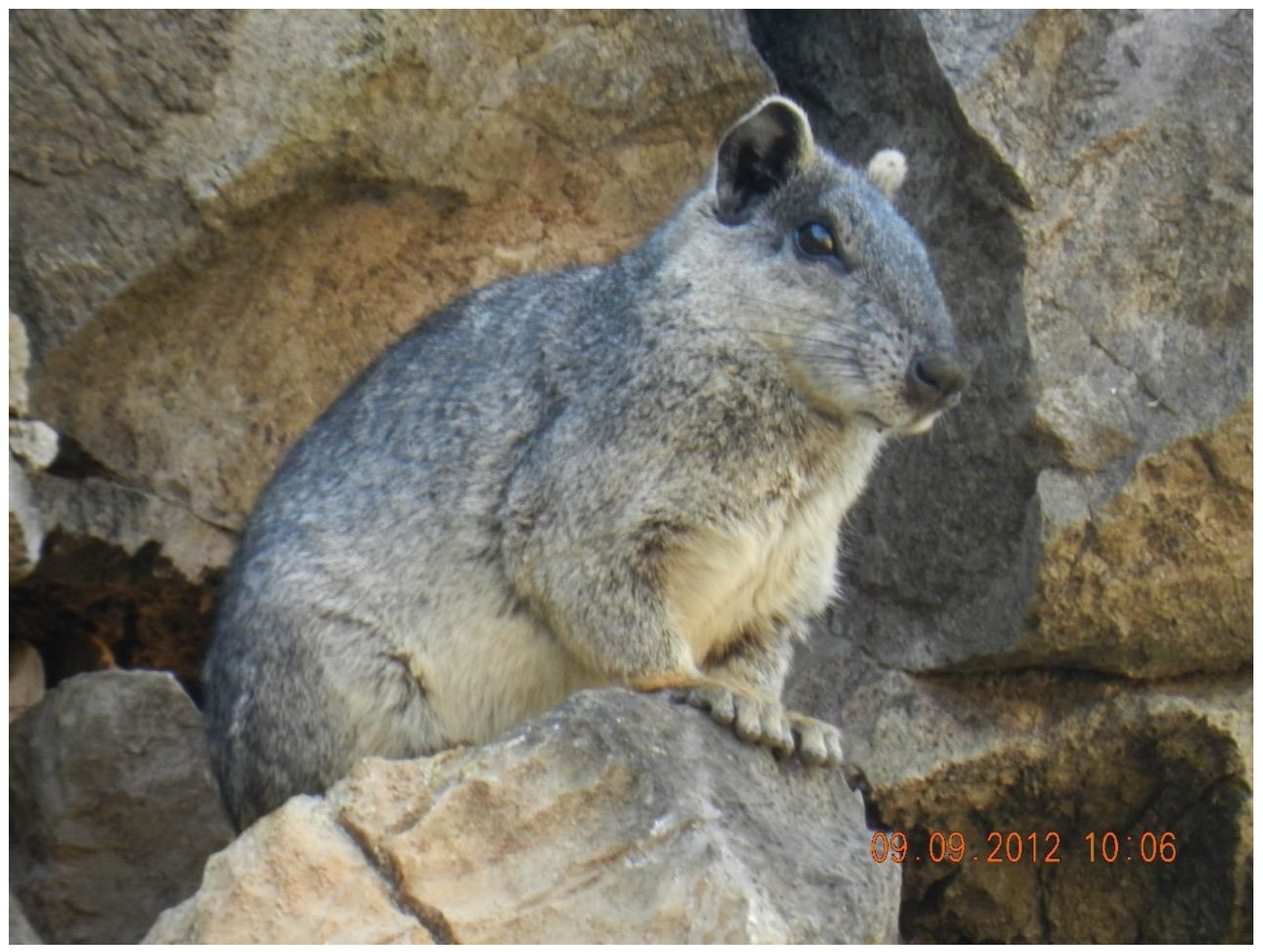

Figura 3 - Indivíduo de Kerodon acrobata, mocó, registrado em Monte Alegre de Goiás, Goiás. 


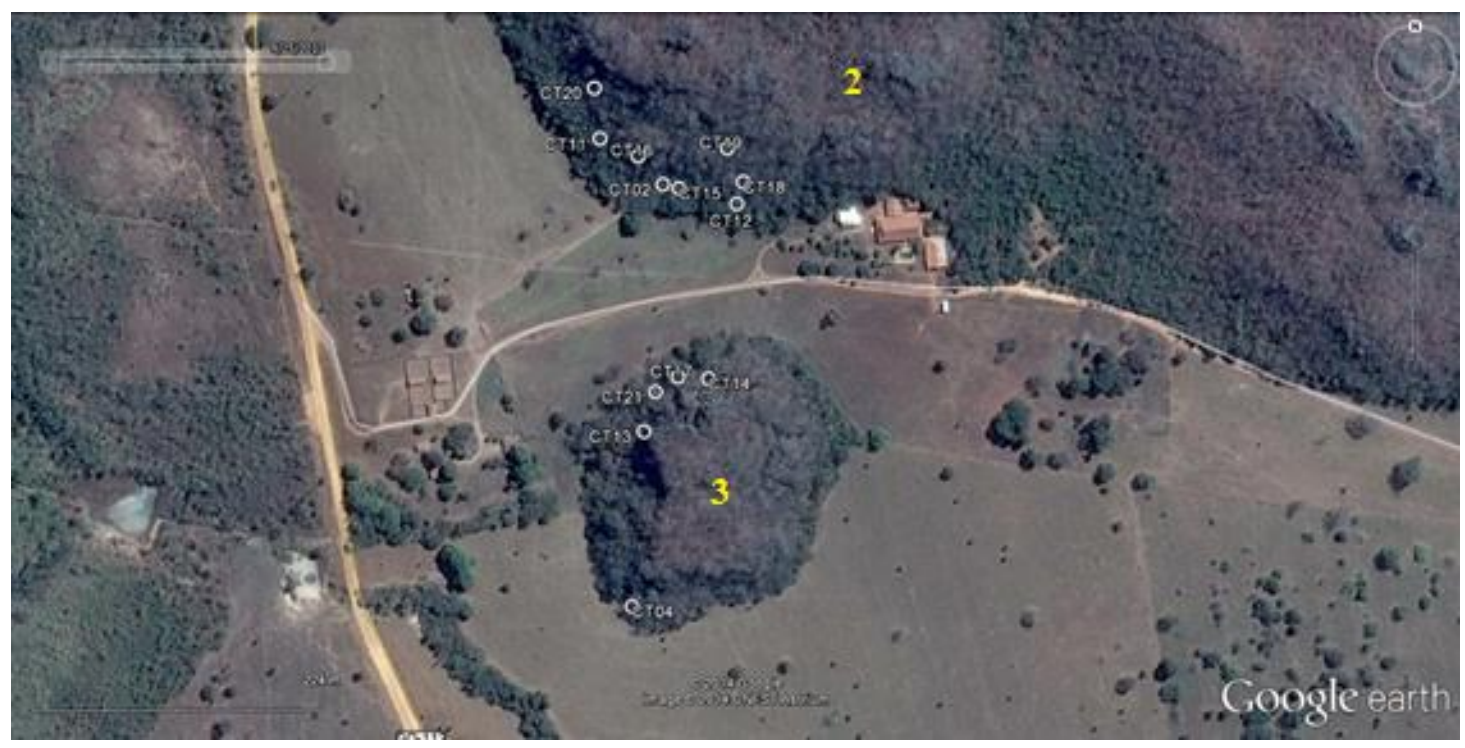

Figura 4 - Distribuição das armadilhas fotográficas nas estações de captura em latrinas na mata decídua, nos fragmentos 2 e 3, da área de estudo nos anos de 2012 e 2013 em Monte Alegre de Goiás, GO (Barra de escala: 224 m. Fonte: Google Earth).

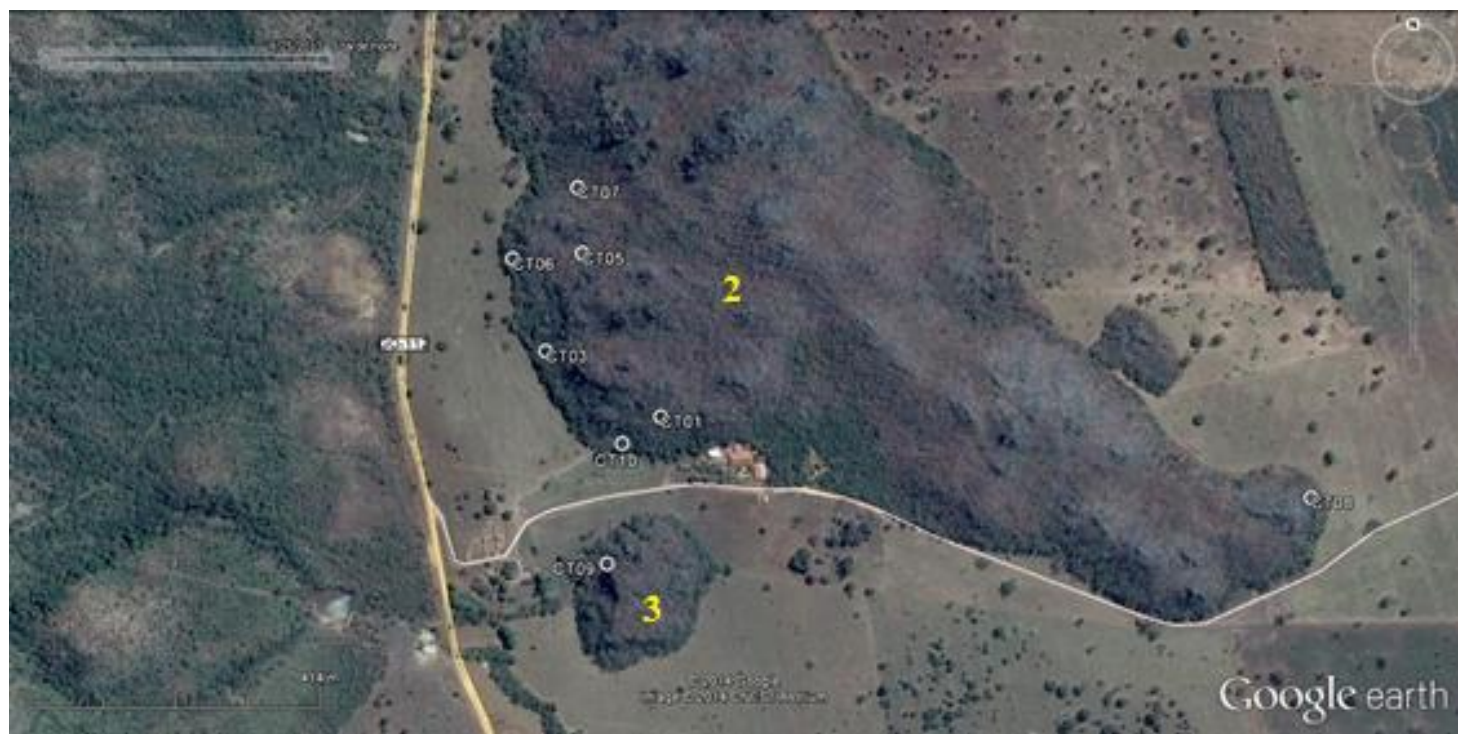

Figura 5 - Distribuição das armadilhas fotográficas nas estações de captura, nos fragmentos 2 e 3 da área de estudo, destinadas a registrar potenciais predadores carnívoros, nos anos de 2012 e 2013 em Monte Alegre de Goiás, GO (Barra de escala: 414 m. Fonte: Google Earth). 


\subsubsection{Reprodução}

Para investigar se $K$. acrobata possui um período reprodutivo sazonal, definido na estação chuvosa, os vídeos produzidos pelas armadilhas fotográficas foram examinados (ver item 1.2.2.1), assim como evidências de reprodução obtidas por meio de avaliações da condição reprodutiva das fêmeas capturadas, aliadas a observações diretas dos comportamentos exibidos pelos animais não capturados em campo. Também foram registradas as presenças de lactentes (filhotes) na área de estudo, facilmente diferenciados por causa do menor tamanho em relação a jovens e adultos. Os dados comportamentais e observações foram coletados ad libitum, de novembro de 2011 a novembro de 2013, exceto em dezembro de 2012. Cada observação desses eventos e registros teve a data, estação e sua frequência contabilizada (Lacher, 1981; Asher et al., 2008).

Os seguintes padrões de comportamento (adaptados de Asher et al., 2008) relacionados à reprodução foram selecionados para as análises: 1) sexual e cuidado parental, e 2) agonístico e marcação de território. O padrão para comportamento sexual observado foram as tentativas de cópula e o cuidado parental foi a amamentação. Os comportamentos agonísticos registrados foram: brigas, perseguições durante corridas e afugentamento de indivíduos. As marcações de território observadas foram realizadas com urina, em substratos, ou em indivíduos e também, esfregando a região da glândula perineal em substratos variados.

As capturas dos indivíduos foram realizadas com armadilhas que capturam os animais com vida (autorização ICMBio ${ }^{\circ}$ 20239-3), sendo estas, gaiolas com uma ou duas portas (armadilha de passagem), com a utilização de iscas para atrair os indivíduos. Cinquenta armadilhas foram instaladas linearmente a cada $10 \mathrm{~m}$ (fragmento 1) e permaneceram ativas durante dez noites por mês entre novembro de 2011 e outubro de 2012. Foram utilizadas 20 gaiolas de duas portas medindo $70 \times 40 \times 34,5 \mathrm{~cm}$ e $30 \mathrm{com}$ apenas uma entrada, seis delas medindo $35 \times 17 \times 17 \mathrm{~cm}$ e as outras $24 \mathrm{com} 45 \times 18,5 \times 16 \mathrm{~cm}$. Entre janeiro e julho de 2013, foram utilizadas apenas 10 das armadilhas maiores, que permaneceram ativas de 10 a 15 noites. As armadilhas foram inspecionadas duas vezes por dia, durante as primeiras horas do dia e no meio da tarde e iscadas diariamente, caso fosse necessário. Complementarmente, foram utilizadas armadilhas de espera, constituídas por rede (tarrafa) suspensa e ceva (Figura 6). As tarrafas mediam $2 \mathrm{~m}$ altura por 1,5 $\mathrm{m}$ de diâmetro na abertura ou 1,60 $\mathrm{m}$ de altura por $1,80 \mathrm{~m}$ de abertura, ambas com malhas de dois centímetros. A parte superior do cone das tarrafas foi amarrada com corda, cuja ponta ficou atada a troncos, após ser passada em uma roldana presa 
a galhos de árvores a aproximadamente $4 \mathrm{~m}$ do solo. Iscas foram dispostas sob as tarrafas e um observador se posicionou próximo às cordas, principalmente durante os horários de pico de atividade dos mocós. Quando algum indivíduo se posicionava sob a tarrafa, a corda era liberada e a rede caía sobre ele. Como $K$. acrobata alimenta-se primariamente de folhas, utilizei como iscas, para armadilhas e tarrafas, folhas de hortaliças (i.e. alface, couve, espinafre, repolho e rúcula) encontradas nos mercados locais, frutos de manga (Mangifera $\mathrm{sp}$. ), ou urina humana (essa última, utilizada somente abaixo das redes).

Dentre os animais capturados, somente as fêmeas foram consideradas para avaliar o período reprodutivo da espécie. As fêmeas capturadas foram consideradas reprodutivas quando se apresentaram grávidas (por apalpação de abdômen) ou lactantes (quando apresentaram secreção de leite pelas mamas). Fêmeas jovens, filhotes e adultas pós-lactantes (com mamas evidentes, porém sem secreção de leite) não foram consideradas em período reprodutivo. Os machos capturados não foram considerados para as análises. Os jovens foram classificados como indivíduos de massa corporal de até $1 \mathrm{Kg}$ e cujas características corporais reprodutivas não estavam aparentes. Os animais capturados foram marcados com brincos numerados (National Band \& Tag Co., Newport, KY, USA) para coelhos (modelo 1841) e pequenos mamíferos (modelo 1005-1). Para facilitar a identificação dos indivíduos em campo, utilizei anilhas coloridas, fixadas com os brincos (modelo 1842 - National Band \& Tag Co., Newport, KY, USA). Adicionalmente, os mocós capturados foram pesados com balança digital (Marine Sports, Brasil), com capacidade de $25 \mathrm{Kg}$ e precisão de $0,01 \mathrm{Kg}$ e medidas morfométricas também foram registradas (tamanho do corpo, orelha direita e pata direita). 


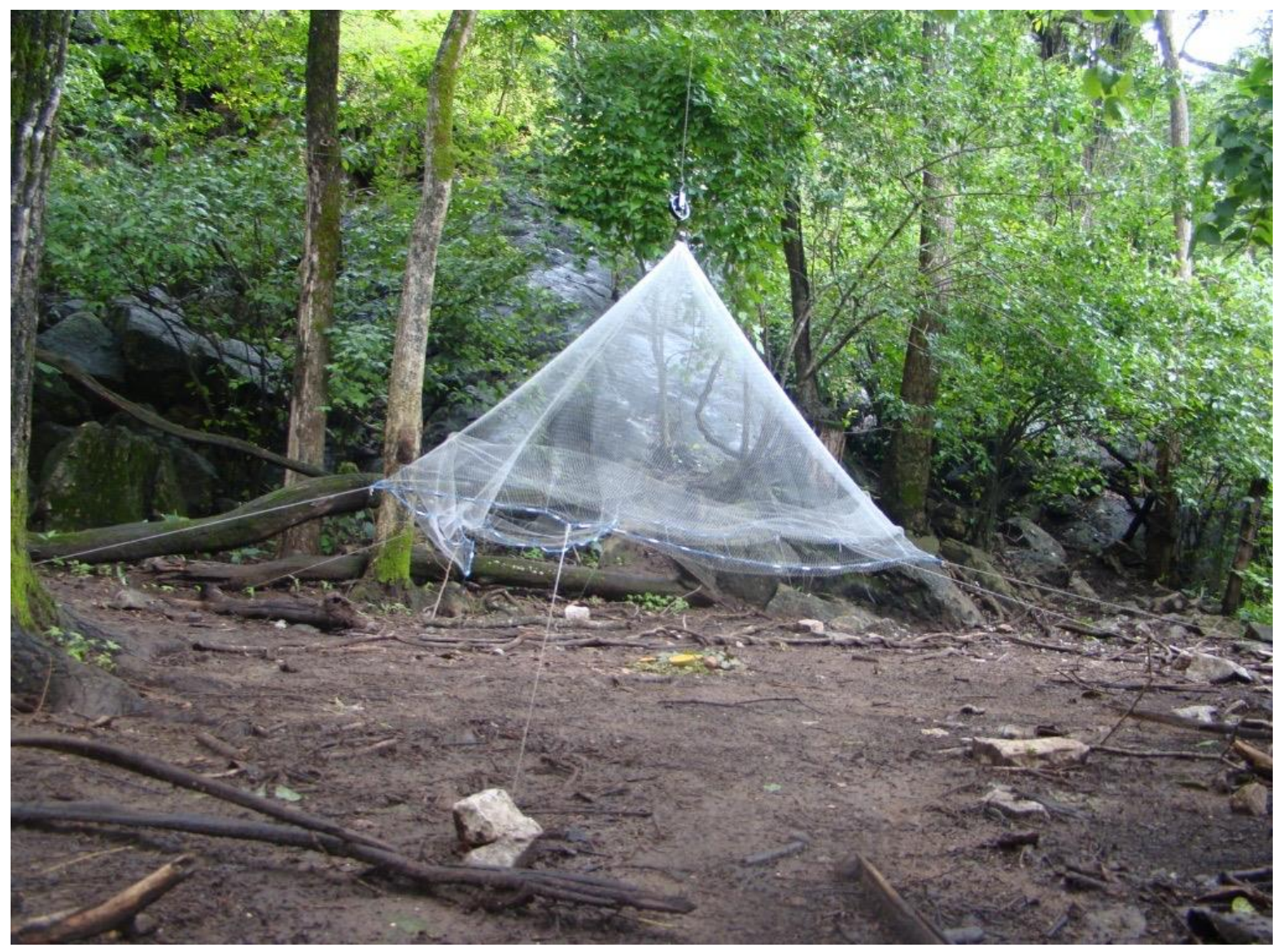

Figura 6 - Armadilha de espera elaborada de tarrafa de pesca, utilizada para capturar indivíduos de Kerodon acrobata em Monte Alegre de Goiás, GO.

\subsubsection{Análises dos dados}

\subsubsection{Padrão de atividade}

Para caracterizar o padrão de atividade de $K$. acrobata e verificar se esse padrão difere entre as estações e se os indivíduos evitam os horários de pico de atividade dos predadores carnívoros, foi empregado o método de Ridout e Linkie (2009), no qual o padrão de atividade é estimado pela densidade kernel, método não paramétrico para estimar curvas de densidades, onde cada observação é ponderada pela distância, em relação a um valor central, servindo de base para medir a sobreposição de atividade entre grupos de dados. Para estimar os valores de sobreposição temporal de atividade, o horário de cada registro foi considerado como uma 
amostra aleatória de uma distribuição contínua, estimando a probabilidade de se observar os indivíduos em qualquer período do dia. Os valores de sobreposição foram calculados para a distribuição Von Mises, com parâmetro de concentração Kernel, k = 3, parâmetro de suavização (smoothing) $\mathrm{c}=1$, pelo estimador $\Delta 1$, apropriado para pequenas amostras e bootstrap de 1000 replicações (Foster et al., 2013; Ridout \& Linkie, 2009). O índice gerado varia de 0 (sem sobreposição) a 1 (sobreposição completa). Filmes e fotografias de indivíduos de uma mesma espécie, que não puderam ser identificados individualmente e que foram obtidos por uma mesma câmera, dentro do intervalo de uma hora, foram considerados como um mesmo registro. Todas as análises e gráficos foram gerados no programa R 3.1.1 (R Core Team, 2014), utilizando os pacotes “boot” (Canty \& Ripley, 2014) e "circular" (Lund \& Agostinelli, 2013).

Para verificar se $K$. acrobata é uma espécie catemeral, eu considerei a classificação de Van Schaik e Griffiths (1996), em que espécies com <10\% dos registros das atividades durante a fase escura são diurnas; as com $>90 \%$ de registros nessa fase são noturnas; e as que apresentam entre 10 e $90 \%$ da atividade à noite são catemerais. Para testar se o desvio das observações, em relação aos valores marginais de 10 ou $90 \%$ foram significativos, realizei o teste binomial (bicaudal, com $\mathrm{p}<0,05$ ) com a probabilidade definida em $\mathrm{p}=0,1$ ou $\mathrm{p}=0,9$, dependendo da proximidade do valor de porcentagem nos registros realizados, em relação à porcentagem de definição de noturno. Para verificar se atividade dos mocós é, ou não crepuscular, comparei a atividade crepuscular observada com a esperada $(2 / 24$ horas $=8 \%)$, utilizando o teste binomial com $\mathrm{p}=0,08$. Esses testes foram realizados no programa $\mathrm{R} 3.1 .1$ ( $\mathrm{R}$ Core Team, 2014), utilizando os pacotes básicos. Os horários do nascer e pôr-do-sol foram obtidos diretamente do aparelho GPSMAP 60CSx e foi considerada a duração de uma hora para cada período crepuscular. O início do crepúsculo matutino foi determinado em uma hora antes do nascer do sol e o crepúsculo vespertino em uma hora após o poente. 


\subsubsection{Reprodução}

Para verificar se existe diferença entre as estações seca e chuvosa, na distribuição das frequências de observações (1) de eventos reprodutivos e (2) de comportamento territorial, foi utilizado o teste t de Student (Crawley, 2007). As frequências dos comportamentos reprodutivos e territoriais registradas em uma mesma campanha foram agrupadas para as análises. Foram considerados eventos reprodutivos: comportamentos sexuais, cuidado parental, evidências de características reprodutivas em fêmeas capturadas e a observação de lactentes. Foram considerados comportamento territorialistas: os comportamentos agonísticos e de marcação. Dada a aparente fidelidade territorial da espécie, principalmente entre as fêmeas, foi possível distinguir em cada campanha, os locais e consequentemente, os grupos em que os indivíduos foram observados apresentando os comportamentos registrados. Apenas o primeiro registro dos comportamentos investigados foi utilizado para cada indivíduo (ou grupo), por campanha. $\mathrm{O}$ conjunto de dados analisado teve como base as observações realizadas em cada campanha e foi classificado por estação (seca ou chuvosa). Os testes de premissas e as análises foram realizados com o auxílio do programa R 3.1.1 (Crawley, 2007; R Core Team, 2014).

\subsection{Resultados}

\subsubsection{Padrão de atividade}

Do total de 538 registros de mocós em atividade (filmes e fotos), 107 (20\%) ocorreram durante à noite, sendo 24 na estação chuvosa (outubro a março, das 18:45-04:29) e 83 na seca (abril a setembro, das 19:40 às 05:29). De acordo com o teste binomial, a proporção observada de comportamento noturno diferiu $(\mathrm{p}=0,05)$ do limite inferior estabelecido para definir o padrão de atividade noturno (10\%). Os mocós foram registrados $70 \%$ das vezes durante o dia $\left(n^{\circ}\right.$ registros $\left.=378\right)$, sendo 140 na estação chuvosa (05:30-17:44) e 238 na seca (06:30-18:39). Nos períodos crepusculares ocorreram $10 \%$ de registros que não diferiram do esperado para esses períodos $(\mathrm{n}=53)$, dentro da definição do padrão de atividade catemeral $(\mathrm{p}<0,05)$. Nestes períodos, foram 26 registros nas chuvas (04:30-05:29 e 17:45-18:44) e 27 na seca (05:30-06:29 e 18:40-19:39). Dos 190 registros realizados durante a estação chuvosa, $74 \%$ do período de atividade foi observado durante o dia, enquanto que à noite foram 12\%, contra 14\% nos horários 
crepusculares. Na estação seca, dentre os 348 registros, $68 \%$ da atividade foi observada durante o dia, $24 \%$ à noite e $8 \%$ em períodos crepusculares (Figura 7). Os mocós apresentaram um padrão de atividade catemeral, com atividades distribuídas em todos os períodos do dia e três picos de atividade, um em cada período crepuscular e outro próximo ao meio-dia.

Dentre as 14 latrinas monitoradas, verifiquei que uma constituía-se em abrigo (CT04, Figura 4), além de servir de latrina e um grupo de até cinco animais chegou a utilizá-lo simultaneamente, para descanso. Esta latrina não foi incluída nas análises de padrão de comportamento. Foram realizadas 515 filmagens de mocós em atividade. A atividade diária dos mocós, em latrinas, apresentou sobreposição de 0,83 (intervalo de confiança de 95\%, 0,71-0,88) entre as estações seca e chuvosa, indicando uma alta similaridade na atividade da espécie entre as estações, porém com uma maior atividade noturna durante a estação seca (Figura 8). O padrão de atividade de $K$. acrobata em latrinas apresentou três picos, dois em horários crepusculares e um próximo ao meio-dia (Figura 9).

As armadilhas fotográficas direcionadas aos potenciais predadores carnívoros também registraram mocós em atividade $(n=23)$, concentrada principalmente durante o dia (Figura 9), enquanto que os predadores apresentaram um padrão de atividade predominantemente noturno. Entre os diferentes locais para a amostragem do padrão de atividade de K. acrobata, os que tiveram o maior valor estimado de sobreposição foram os que tiveram as armadilhas fotográficas instaladas para registrar predadores e em latrinas (Tabela 1). Os predadores registrados foram: Cerdocyon thous ( $\mathrm{n}=73$ registros), três indivíduos de Leopardus pardalis $(\mathrm{n}=16)$ e uma Panthera onca fêmea $(\mathrm{n}=3)$. Cerdocyon thous apresentou atividade predominantemente noturna, com seu horário de atividade iniciando após o entardecer e encerrando-se pouco após o raiar do dia (Figura 10 e Figura 11). Leopardus pardalis apresentou atividade predominantemente noturna, porém com alguns registros durante o dia, com três picos próximos aos apresentados por $K$. acrobata (Figura 12) e por isso, foi o predador com a maior estimativa de sobreposição de atividade em relação a $K$. acrobata (Tabela 2). Na Figura 13 são apresentados os padrões de atividade para estes dois predadores em conjunto (C. thous e $L$. pardalis). Panthera onca foi registrada em atividade apenas durante a noite. 


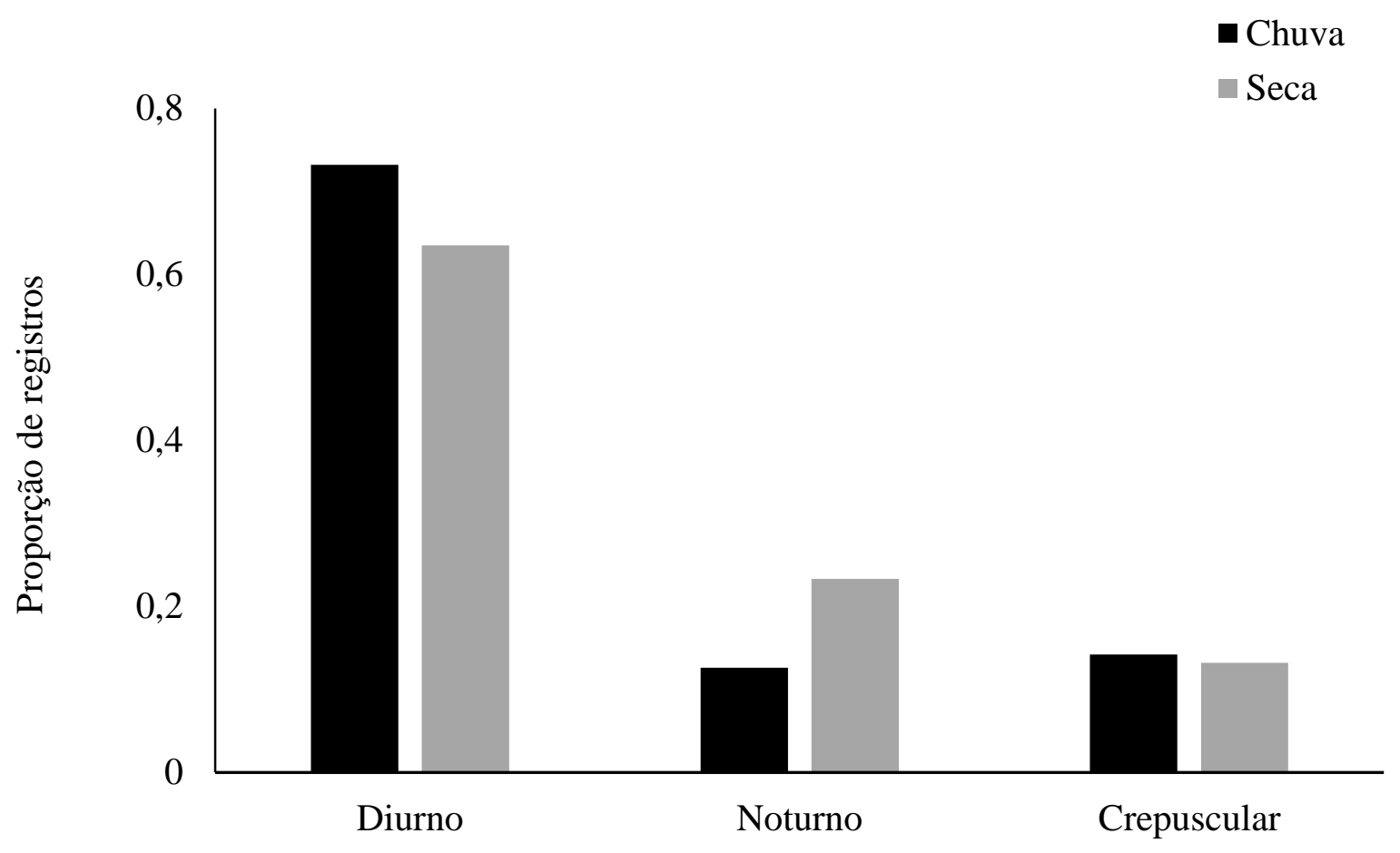

Período

Figura 7 - Proporção do padrão de atividade registrado para Kerodon acrobata por armadilhas fotográficas, em relação aos três períodos diários, dividido entre as estações seca e chuvosa, de julho a outubro de 2012 e de fevereiro a novembro de 2013, em Monte Alegre de Goiás, GO. 


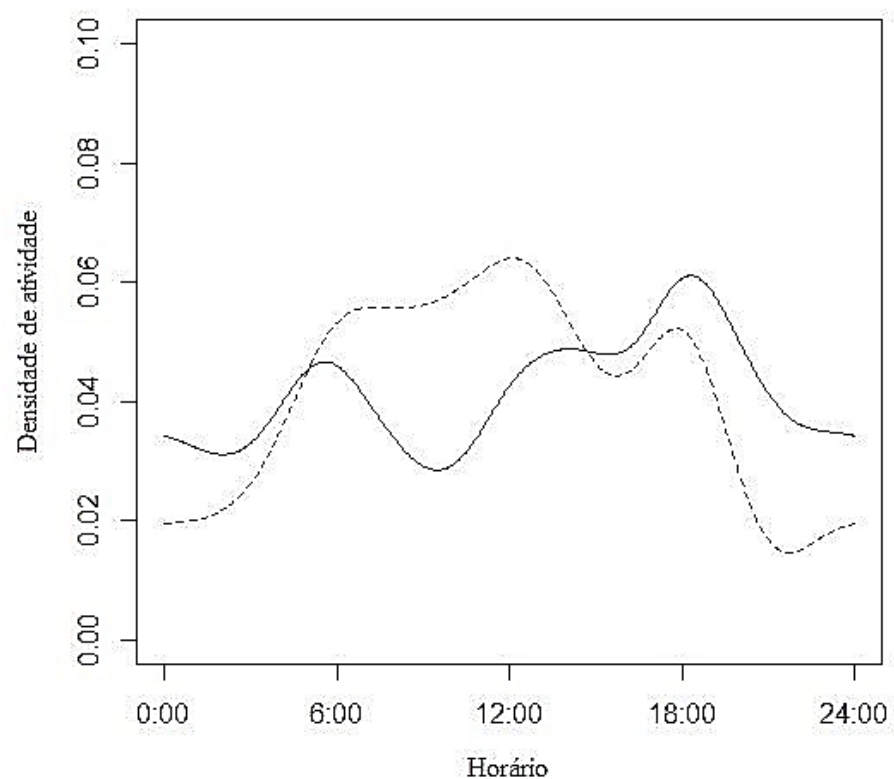

Figura 8 - Padrão de atividade dos indivíduos de K. acrobata monitorados por armadilhas fotográficas em latrinas durante as estações seca (linha sólida) e chuvosa (linha pontilhada) em Monte Alegre de Goiás - GO de julho de 2012 a novembro de 2013.

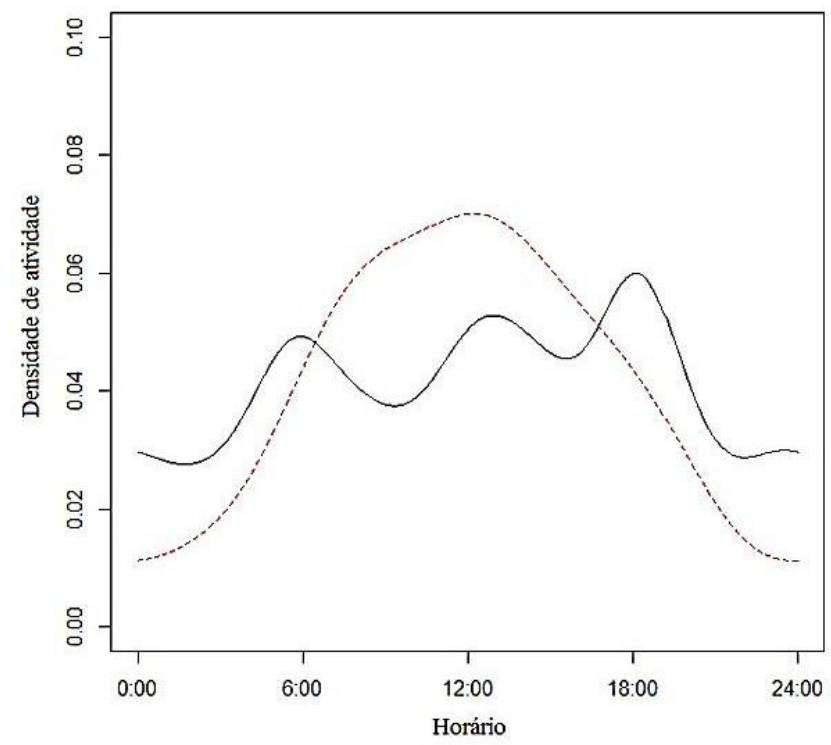

Figura 9 - Padrão de atividade dos indivíduos de $K$. acrobata monitorados por armadilhas fotográficas em latrinas (linha sólida) e fora delas (linha pontilhada) em Monte Alegre de Goiás - GO, de julho de 2012 a novembro de 2013. 


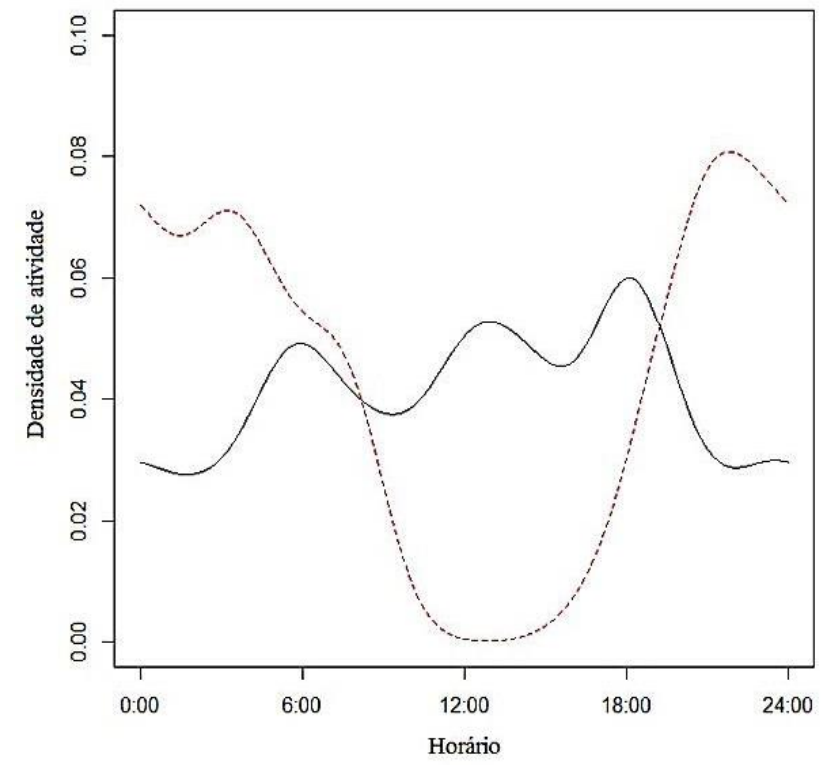

Figura 10 - Comparação entre os padrões de atividade de $K$. acrobata (linha sólida) em latrinas e C. thous (linha pontilhada), registrados por armadilhas fotográficas em Monte Alegre de Goiás - GO, entre julho de 2012 e novembro de 2013.

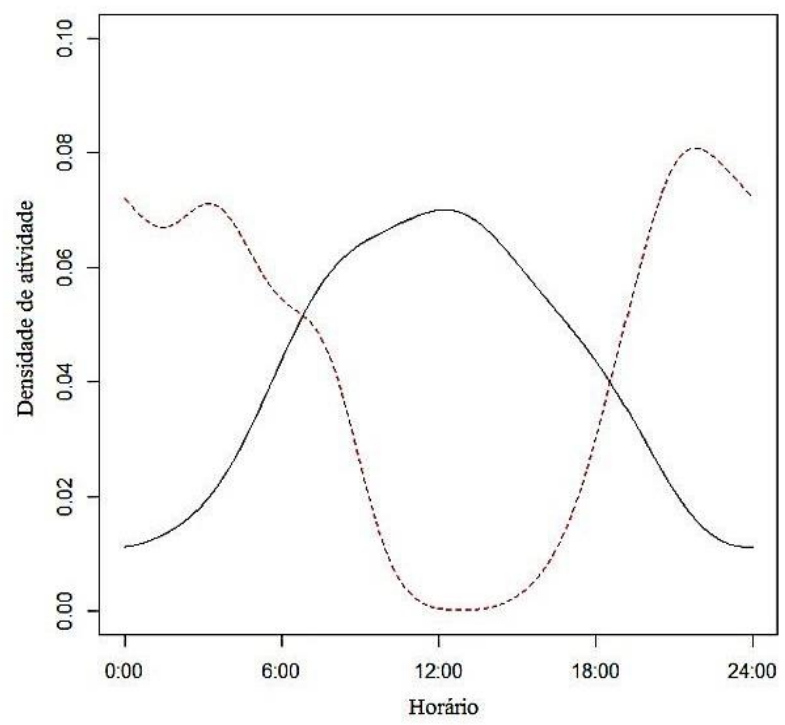

Figura 11 - Comparação entre os padrões de atividade de K. acrobata (linha sólida) e C. thous (linha pontilhada) registrados por armadilhas fotográficas instaladas fora de latrinas em Monte Alegre de Goiás - GO, entre julho de 2012 e abril de 2013. 


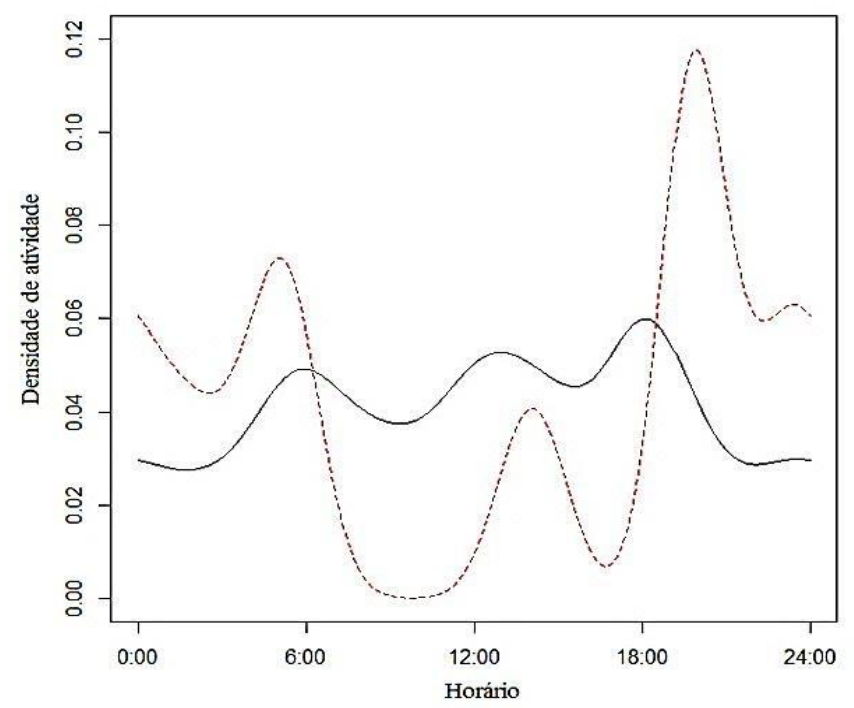

Figura 12 - Comparação entre os padrões de atividade de $K$. acrobata (linha sólida) em latrinas e L. pardalis (linha pontilhada), registrados por armadilhas fotográficas em Monte Alegre de Goiás - GO, entre julho de 2012 e novembro de 2013.

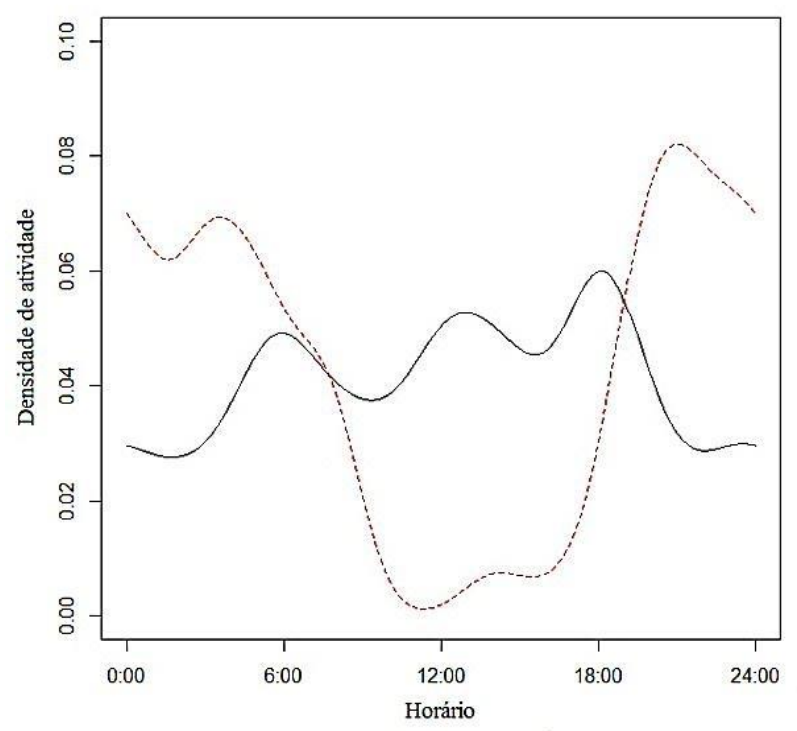

Figura 13 - Comparação entre os padrões de atividade de K. acrobata (linha sólida) em latrinas e dos predadores (linha pontilhada) registrados por armadilhas fotográficas em Monte Alegre de Goiás - GO, entre julho de 2012 e novembro de 2013. 
Tabela 1 - Estimativa de sobreposição, com intervalo de confiança (95\%), da atividade de Kerodon acrobata, amostrada por três diferentes métodos, entre julho de 2012 e novembro de 2013, em Monte Alegre de Goiás - GO.

\begin{tabular}{cccc}
\hline & Abrigo & Latrinas & Câmeras para predadores \\
\hline Abrigo & $\mathrm{x}$ & $0,69(0,62-0,75)$ & $0,78(0,60-0,89)$ \\
Latrinas & & $\mathrm{x}$ & $0,81(0,60-0,87)$ \\
Câmeras para predadores & & & $\mathrm{X}$ \\
\hline
\end{tabular}

Tabela 2 - Estimativa de sobreposição, com intervalo de confiança (95\%), da atividade de $K$. acrobata, amostrada em latrinas e câmeras para predadores, em relação à atividade dos predadores registrados entre julho de 2012 e novembro de 2013, em Monte Alegre de Goiás.

\begin{tabular}{cccc}
\hline Kerodon acrobata & Leopardus pardalis & Cerdocyon thous & Ambos predadores \\
\hline Latrinas & $0,63(0,43-0,69)$ & $0,60(0,50-0,66)$ & $0,61(0,52-0,67)$ \\
Câmeras predadores & $0,46(0,20-0,55)$ & $0,46(0,24-0,53)$ & $0,46(0,26-0,52)$ \\
\hline
\end{tabular}




\subsubsection{Reprodução}

Foram realizadas ao todo, 67 capturas de 41 indivíduos. Em gaiolas, obtive 49 capturas de 26 indivíduos. Para esse método, o esforço total foi de 6.515 armadilhas/noite, resultando em sucesso de $0,75 \%$. Nas armadilhas de espera foram realizadas 16 capturas de 13 indivíduos. Uma fêmea jovem foi capturada em um laço instalado na entrada de uma toca, em novembro de 2011. Outra fêmea, adulta, foi capturada com dardo tranquilizante, após ser encontrada andando em galhos de árvores, na altura da copa da mata semidecídua, em março de 2013.

No total, foram realizadas 15 capturas de 13 fêmeas adultas. Dessas, apenas duas capturas ocorreram na estação chuvosa e as fêmeas não apresentavam características reprodutivas. Durante a seca, ocorreram 13 capturas de 11 fêmeas adultas. Entre estas, sete apresentavam características reprodutivas (Figura 14). Fêmeas com características reprodutivas (grávidas e lactantes) foram capturadas somente durante a estação seca (abril a setembro), exceto em agosto. As lactantes foram observadas amamentando nas duas estações, exceto de fevereiro a abril e em dezembro, enquanto que lactentes não foram observados apenas no mês de abril. Eventos de cópulas não foram observados em campo. Porém tentativas de cópulas foram observadas $(n=9)$ em ambas as estações, de janeiro a março, em maio, julho e agosto. Não foi observada diferença nos registros de comportamentos sexuais entre as estações $(\mathrm{t}=$ 1,4392; g.1. $=22 ; \mathrm{p}=0,1642)$.

Foram registrados 121 eventos de perseguição, 76 durante a estação seca e 45 na chuvosa. Somente uma briga foi observada, durante a estação seca, no mês de junho. Machos foram confirmados perseguindo outros machos em $21 \%(n=26)$ dos registros, sendo 18 eventos observados na seca e oito durante as chuvas. Fêmeas realizaram perseguições em 17 oportunidades, sendo oito atrás de outras fêmeas, e em três eventos foi possível observar a presença de prole da perseguidora. Foram cinco perseguições observadas na estação chuvosa e 12 na seca. Em 78 oportunidades não foi possível registrar o sexo dos indivíduos envolvidos nas perseguições.

Foram observados 55 eventos de marcação. As marcações de urina observadas espalhadas em grande quantidade, pelos diferentes substratos (rocha, troncos, folhiço, etc.), fora de latrinas, foram observadas principalmente durante a seca, mas também durante o início (outubro) e fim (março) da estação chuvosa, porém esses indícios não foram incluídos nas análises. Machos foram observados urinando em fêmeas durante a estação chuvosa $(n=4)$, de janeiro a março e em uma ocasião durante a estação seca. Eles também foram observados 
urinando e andando, aparentemente de forma a marcar território, durante a seca $(n=5)$ e ao final da estação chuvosa, em março $(n=1)$. Fêmeas foram observadas urinando em machos ( $n$ = 5) durante as estações seca (maio e setembro) e chuvosa (outubro). Apenas uma fêmea foi observada urinando em outra fêmea (jovem), em novembro. Machos foram observados esfregando a região da glândula perineal por rochas e troncos $(n=31)$, principalmente durante a seca (abril a setembro), mas também durante as chuvas $(n=6)$. Uma fêmea foi observada realizando comportamento semelhante em julho, durante a seca. Machos foram observados esfregando o pênis exposto $(n=6)$, sobre rochas e troncos, durante a seca e durante as chuvas $(n=4)$. Não foi encontrada diferença nos registros de comportamentos territorialistas entre as estações ( $\mathrm{t}=-1,909 ; \mathrm{g} .1 .=22 ; \mathrm{p}=0,069)$.

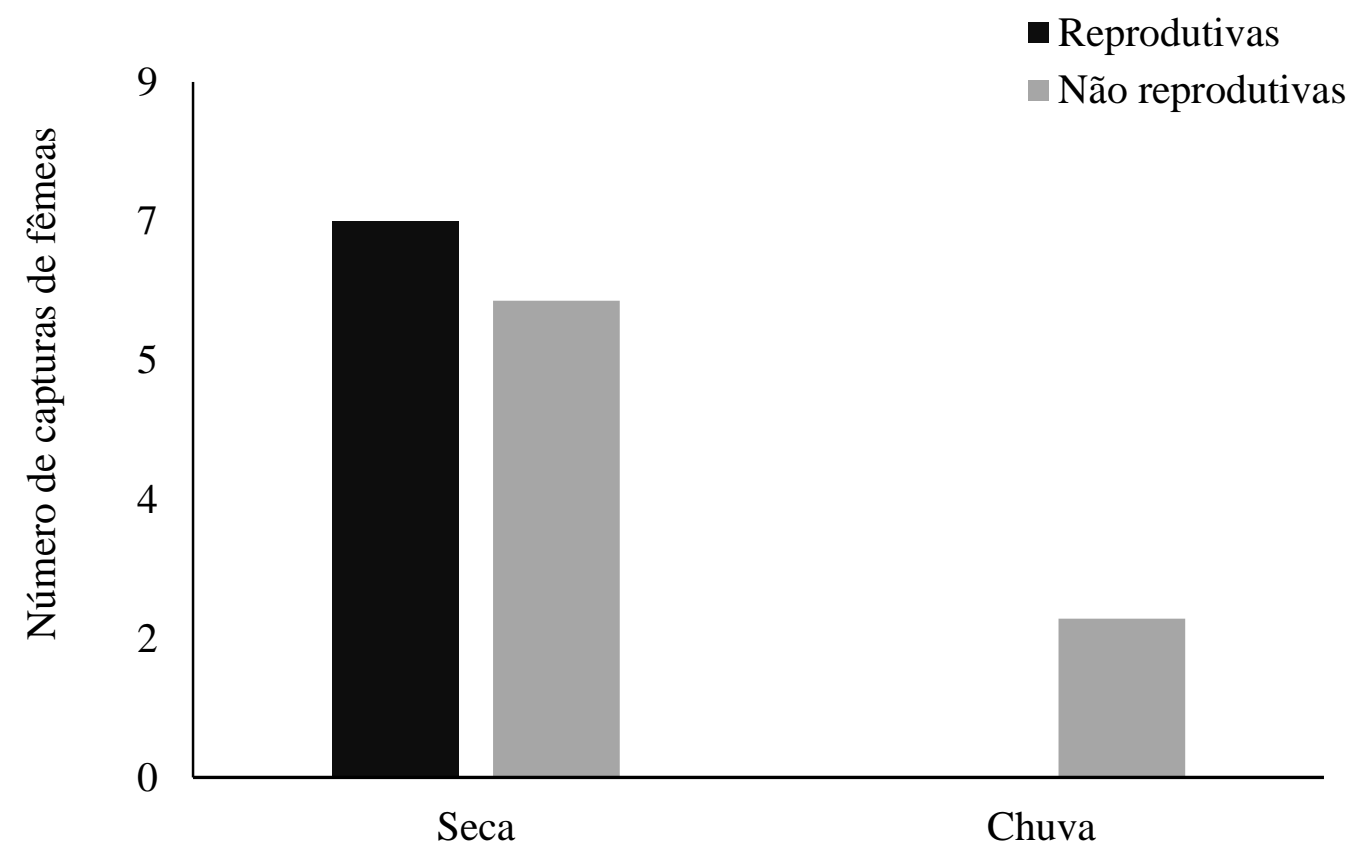

Figura 14 - Quantidade de capturas de fêmeas adultas $(n=15)$ nas estações seca e chuvosa em relação às suas condições reprodutivas, de novembro de 2011 a julho de 2013 em Monte Alegre de Goiás - GO. 


\subsection{Discussão}

A maior parte das atividades dos mocós, ao longo do ano, foram registradas durante o dia $(67 \%)$, porém também foram registradas atividades durante os períodos crepusculares e noturno. Entretanto, é esperado que o nível de atividade de animais catemerais geralmente difira em relação às condições de luminosidade (Halle \& Stenseth, 2000) e estas variam ao longo do ano. Com isso, os registros das atividades noturna e crepuscular variaram em importância entre as estações, sendo a noturna maior do que a crepuscular durante a seca e menor durante a estação chuvosa. Portanto, Kerodon acrobata apresentou um padrão de atividade catemeral ao longo do ano e também, ao considerarem-se as duas estações separadamente.

Apesar de a espécie possuir dois picos de atividade, um ao alvorecer e outro ao anoitecer, também se apresentou em atividade durante todo o dia, inclusive com outro pico próximo ao meio-dia, diferente do encontrado para K. rupestris por Sousa e Menezes (2006). Esta diferença pode não encontrar resposta no clima da região de ocorrência de K. acrobata, já que as temperaturas médias das máximas do norte de Goiás são muito semelhantes às verificadas na Caatinga, variando de $32^{\circ}$ a $36^{\circ} \mathrm{C}$ (Nimer, 1972), contando ainda, com a grande semelhança na composição florística entre esses biomas (Nascimento et al., 2004; Felfili et al., 2007). Portanto, o padrão de atividade desse roedor parece ser regulado pela atividade de seus predadores, pois alguns de seus predadores carnívoros potenciais se mostraram mais ativos durante a noite. Entretanto, gaviões e serpentes, como cascavéis e jiboias, que também apresentam atividade noturna (França \& Braz, 2013), podem ser observados ativos e até forrageando durante o dia. Mesmo caçadores clandestinos foram flagrados em ação durante o dia (obs. pess.). Embora predadores, como a jaguatirica, possam visitar intencionalmente e permanecer por mais tempo, próximos aos abrigos ativos de suas presas (Emsens et al., 2013), no presente estudo nenhum predador foi registrado nas latrinas ativas amostradas.

O padrão de atividade diário de roedores pode ser influenciado pelo grupo taxonômico ao qual estão inseridos e é mais semelhante entre as espécies de uma mesma família, subfamília ou tribo (Roll et al., 2006). Sendo assim, os taxa intimamente relacionados tendem a ser ativos na mesma parte do dia (efeito filogenético). Entretanto, os padrões de atividade podem variar até mesmo dentro de uma espécie, seja entre estações, ou em relação ao sexo, idade ou estágio reprodutivo do animal (Halle \& Stenseth, 2000a). Em um estudo em cativeiro sobre o ritmo circadiano da atividade motora do roedor caviídeo Kerodon rupestris, Sousa e Menezes (2006) observaram uma sincronia desse ritmo, sob um ciclo de 12 horas de luz/escuro. Os animais 
observados apresentaram atividade durante as fases clara e escura, porém com picos nas transições entre as fases e com alterações na distribuição da atividade, sob diferentes intensidades de luz. Apesar de sugerirem que essa espécie não possui um nicho temporal específico, os autores afirmam que a espécie é predominantemente crepuscular. O risco de predação e a alta variação de temperatura da Caatinga foram apontados como os fatores causadores dessa flexibilidade na distribuição da atividade motora ao longo das 24 horas do dia, enquanto que os dados do presente estudo indicam que o padrão de atividade dos mocós acrobatas é influenciado pelo dos predadores.

As ninhadas de $K$. acrobata observadas na área de estudo possuíam um a dois filhotes, sendo um o mais comum. Os resultados indicam que o mocó acorbata não apresentou uma tendência sazonal em seu padrão reprodutivo, assim como já reportado para $K$. rupestris (Roberts et al., 1984). Apesar de fêmeas com características reprodutivas terem sido capturadas apenas durante a estação seca, na estação chuvosa apenas duas fêmeas foram capturadas. Embora as condições na área de estudo sejam menos amenas do que em ambientes controlados de cativeiro e a estação chuvosa apresente maior fartura de folhas nas matas decídua e semidecídua, na estação seca as matas produzem maior quantidade de flores e frutos e isso deve contribuir para manter as condições nutricionais favoráveis para a reprodução do mocó acrobata ao longo do ano. Porém, parece haver uma sincronia nos nascimentos, pois diversas fêmeas procriaram no mesmo período. A espécie também não apresentou evidência de sazonalidade na defesa de recursos, ou território, realizando perseguições e marcações ao longo de todo o ano e tal comportamento observado em relação às fêmeas pode não indicar, necessariamente, um período reprodutivo. Os machos defenderam o acesso às fêmeas, comportamento manifestado ao seguirem-nas, marcá-las com urina e não tolerando outros machos adultos nas proximidades. Porém, também realizaram marcações de território, com urina e esfregando a região da glândula perineal em rochas e troncos de árvores vivas e mortas. Lacher (1981) observou apenas indivíduos de cativeiro e não em campo, realizando marcações esfregando a região perineal e somente por três vezes em 20 meses. O mesmo autor sugeriu que a comunicação olfativa poderia não ser tão importante em $K$. rupestris quanto em Galea. Porém, é possível que esse comportamento de marcação em Kerodon se manifeste apenas em $K$. acrobata, ou em locais com maiores densidades de indivíduos. As marcações de urina observadas espalhadas pelos substratos, fora de latrinas, não foram incluídas nas análises, pois existe a possibilidade de que 
também sejam produzidas durante as chuvas, mesmo que em menor quantidade, mas sejam dissolvidas pela água e não tenha sido possível observá-las.

O sistema de acasalamento que provavelmente mais se adequa a Kerodon acrobata é a poliginia, onde os machos podem defender as pequenas áreas núcleo e de vida das fêmeas e não aparentam ser necessários na criação dos filhotes (Clutton-Brock, 1989; Wolff, 2007), porém contribuem com comportamento de vigilância contra predadores, emitindo sinais vocais de alerta. Um sistema de acasalamento poligínico parece ser o caso de alguns roedores caviídeos, como Cavia aperea e K. rupestris (Asher et al., 2008; Nowak, 1999). Na poliginia, cada macho acasala com um mesmo grupo de fêmeas em sucessivas estações reprodutivas e para conseguir isso, podem defender as fêmeas receptivas, ou um território (Clutton-Brock, 1989). Além disso, fêmeas distribuídas agregadamente no espaço tendem a entrar no cio em sincronia (Ims, 1990), caracterizando uma estação reprodutiva. Em um estudo com C. aperea (Caviidae), foram verificados grupos formados por casais e pequenos haréns, constituídos por um macho e duas fêmeas (Asher et al., 2004). Este estudo indicou que os machos não defendiam as fronteiras de seus territórios contra outros machos, porém, marcavam suas fêmeas por meio de glândulas anais e perseguiam outros machos que se aproximavam dessas fêmeas. Esta estratégia reprodutiva é conhecida como poliginia com defesa, ou guarda das fêmeas (Clutton-Brock, 1989). Kerodon rupestris foi observado apresentando poliginia de defesa de recursos, formando haréns, com os machos defendendo ativamente e mantendo fidelidade às pilhas de rochas que habitavam e onde as fêmeas buscavam abrigo, porém registros de eventos de marcação de território foram escassos (Lacher, 1981; Nowak, 1999). A proporção sexual em que esta espécie ocorre em ambientes naturais, três machos para 15 fêmeas, também favorece este tipo de sistema de acasalamento, em que machos defendem o recurso, em torno do qual as fêmeas se agregam (Lacher, 1981). Aparentemente, a proporção de fêmeas para machos também é maior para K. acrobata na área amostrada nesse estudo. Os caviídeos em geral, possuem ciclo de vida relativamente longo, com período de gestação relativamente curto para a subordem Hystricomorpha e a sua reprodução pode ocorrer durante todo o ano, se as condições climáticas forem favoráveis (Nowak, 1999). Os filhotes nascem bem desenvolvidos e atingem a maturidade sexual cedo (Nowak, 1999). Apesar de os roedores compreenderem aproximadamente, $43 \%$ das espécies de mamíferos, superando todas as outras ordens, tanto em abundância de indivíduos quanto no número de gêneros e espécies, ainda é enorme a quantidade 
de espécies sobre as quais faltam informações básicas e descritivas a respeito de comportamentos sociais (Lacey \& Solomon, 2003). 


\subsection{Referências bibliográficas}

Alcock, J. 2001. Animal Behaviour - An Evolutionary Approach. $7^{\text {a }}$ Ed. Sinauer Associates Inc., Sunderland, Massachusets.494p.

Alcock, J. 2010. Comportamento Animal - Uma abordagem evolutiva. $9^{\text {a }}$ Ed. Editora Artmed. Porto Alegre. 606p.

Asher, M.; Oliveira, E.S. \& Sachser, N. 2004. Social system and spatial organization of wild guinea pigs (Cavia aperea) in a natural population. Journal of Mammalogy 85(4): 788796.

Asher, M.; Lippmann, T.; Epplen, J.T.; Kraus, C.; Trillmich, F. \& Sachser, N. 2008. Large males dominate: ecology, social organization, and mating system of wild cavies, the ancestors of the guinea pig. Behavioral Ecology and Sociobiology 62(9): 1509-1521.

Bianchi, C.A. \& Haig, S.M. 2013. Deforestation trends of tropical dry forests in Central Brazil. Biotropica 45(3): 395-400.

Canty, A. \& Ripley, B. 2014. boot: Bootstrap functions. R-package Version 1.3-13. Comprehensive R Archive Network. http://cran.r-project.org/web/packages/boot.

Cardoso, M.R.D.; Marcuzzo, F.F.N. \& Barros, J.R. 2015. Classificação climática de KöppenGeiger para o estado de Goiás e o Distrito Federal. Acta Geográfica 8(16): 40-55.

Clutton-Brock, T.H. 1989. Mammalian mating systems. Proceedings of the Royal Society of London, Series B 236(1285): 339-372.

Crawley, M.J. 2007. The R Book. John Wiley \& Sons Ltd. West Sussex, Inglaterra. 942p.

Curtis, D.J. \& Rasmussen, M.A. 2002. Cathemerality in lemurs. Evolutionary Anthropology 11(S1): 83-86.

Donati, G. \& Borgognini-Tarli, S.M. 2006. Influence of abiotic factors on cathemeral activity: the case of Eulemur fulvus collaris in the Littoral Forest of Madagascar. Folia Primatologica 77(1-2): 104-122.

Emsens, W.J.; Hirsch, B.T.; Kays, R. \& Jansen, P.A. 2014. Prey refuges as predator hotspots: ocelot (Leopardus pardalis) attraction to agouti (Dasyprocta punctata) dens. Acta Theriologica 59(2): 257-262.

Erkert, H.G. \& Cramer, B. 2006. Chronobiological background to cathemerality: circadian rhythms in Eulemur fulvus albifrons (Prosimii) and Aotus azarai boliviensis (Anthropoidea). Folia Primatologica 77(1-2): 87-103. 
Felfili, J.M.; Nascimento, A.R.T.; Fagg, C.W. \& Meirelles, E.M. 2007. Floristic composition and community structure of a seasonally deciduous forest on limestone outcrops in Central Brazil. Revista Brasileira de Botânica 30(4): 611-621.

Fernandez-Duque, E. \& Erkert, H.G. 2006. Cathemerality and lunar periodicity of activity rhythms in owl monkeys of the Argentinian Chaco. Folia Primatologica 77(1-2): 123-138.

Foster, V.C.; Sarmento, P.; Sollmann, R.; Tôrres, N.; Jácomo, A.T.A.; Negrões, N.; Fonseca, C. \& Silveira, L. 2013. Jaguar and puma activity patterns and predator-prey interactions in four Brazilian biomes. Biotropica 45(3): 373-379.

França, F.G.R. \& Braz, V.S. 2013. Diversity, activity patterns, and habitat use of the snake fauna of Chapada dos Veadeiros National Park in Central Brazil. Biota Neotropica 13(1): 74-85.

Gómez, H.; Wallace, R.B.; Ayala, G. \& Tejada, R. 2005. Dry season activity periods of some Amazonian mammals. Studies on Neotropical Fauna and Environment 40(2): 91-95.

Halle, S. \& Stenseth, N.C. 2000a. Introduction. Pp 3-17. In: Halle, S. \& Stenseth, N.C. (Eds.) Activity Patterns in Small Mammals - an Ecological Approach. Ecological Studies Vol. 141. Springer-Verlag, Heidelberg. 332p.

Halle, S. \& Stenseth, N.C. 2000b. Theoretical considerations - Introduction. Pp 21-47. In: Halle, S. \& Stenseth, N.C. (Eds.) Activity Patterns in Small Mammals - an Ecological Approach. Ecological Studies Vol. 141. Springer-Verlag, Heidelberg. 332p.

Halle, S. 2006. Polyphasic activity patterns in small mammals. Folia Primatologica 77(1-2): $15-26$.

Ims, R.A. 1990. The ecology and evolution of reproductive synchrony. Trends in Ecology and Evolution 5(5): 135-140.

Lacey, E.A. \& Solomon, N.G. 2003. Social biology of Rodents: trends, challenges, and future directions. Journal of Mammalogy 84(4): 1135-1140.

Lacher Jr, T.E. 1981. The comparative social behavior or Kerodon rupestris and Galea spixii and the evolution of behavior in the Caviidae. Bulletin of Carnegie Museum of Natural History 17: 1-71.

Lund, U. \& Agostinelli, C. 2013. Circular: Circular statistics. R-package Version 0.4-7. Comprehensive R Archive Network. http://cran.r-project.org/web/packages/circular

Mares, M.A. \& Ernest, K.A. 1995. Population and community ecology of small mammals in a gallery forest of central Brazil. Journal of Mammalogy 76(3): 750-768. 
Moojen, J.; Locks, M. \& Langguth, A. 1997. A new species of Kerodon Cuvier, 1825 from the State of Goiás, Brazil (Mammalia, Rodentia, Caviidae). Boletim do Museu Nacional do Rio de Janeiro, Série Zoologia 377: 1-10.

Nascimento, A.R.T; Felfili, J.M. \& Meirelles, E.M. 2004. Florística e estrutura da comunidade arbórea de um remanescente de Floresta Estacional Decidual de encosta, Monte Alegre, GO, Brasil. Acta Botanica Brasilica 18(3): 659-669.

Nimer, E. 1972. Climatologia da Região Centro-Oeste do Brasil - Introdução à climatologia dinâmica. Revista Brasileira de Geografia 34(4): 3-30.

Nowak, R.M. 1999. Walker's Mammals of the World. Volume II.6 ${ }^{\text {a }}$ ed. The Johns Hopkins University Press. Baltimore e Londres. 1.100p.

Oliveira-Santos, L.G.R.; Zucco, C.A.; Agostinelli, C. 2013. Using conditional circular kernel density functions to test hypotheses on animal circadian activity. Animal Behaviour 85(1): 269-280.

R Core Team. 2014. R: A Language and Environment for Statistical Computing. R Foundation for Statistical Computing. Vienna, Áustria. http://www.R-project.org

Ridout, M.S. \& Linkie, M. 2009. Estimating overlap of daily activity patterns from camera trap data. Journal of Agricultural, Biological, and Environmental Statistics 14(3): 322-337.

Roberts, M.; Maliniak, E. \& Deal, M. 1984. The reproductive biology of the rock cavy, Kerodon rupestris, in captivity: a study of reproductive adaptation in a trophic specialist. Mammalia 48(2): 253-265.

Roll, U; Dayan, T \& Kronfeld-Schor, N. 2006. On the role of phylogeny in determining activity patterns of rodents. Evolutionary Ecology 20(5): 479-490.

Scariot, A. \& Sevilha, A.C. 2005. Biodiversidade, estrutura e conservação de florestas estacionais deciduais no Cerrado. Pp. 121-140. In: Scariot, A.; Sousa-Silva, J. C. \& Felfili, J. M. (Orgs.) Cerrado: ecologia, biodiversidade e conservação. MMA, Brasília. 439p.

Silva, L.A. \& Scariot, A. 2004. Comunidade arbórea de uma floresta estacional decídua sobre afloramento calcário na Bacia do rio Paranã. Revista Árvore 28(1): 61-67.

Silvando, C.S.; Santana, N.M.P. \& Pelegrini, J.C. 2006. Caracterização climática do estado de Goiás. Secretaria de Indústria e Comércio, Superintendência de Geologia e Mineração, Goiânia. 133p. 
Sousa, R.A. \& Menezes, A.A.L. 2006. Circadian rhythm of motor activity of the Brazilian rock cavy (Kerodon rupestris) under artificial photoperiod. Biological Rhythm Research 37(5): 443-450.

Tattersall, I. 1987. Cathemeral activity in primates: a definition. Folia Primatologica 49(3-4): 200-202.

Tattersall, I. 2006. The concept of cathemerality: history and definition. Folia Primatologica 77(1-2): 7-14.

Van Schaik, C.P. \& Griffiths, M. 1996. Activity periods of Indonesian rain forest mammals. Biotropica 28(1): 105-112.

Vieira, M.V. 1997. Dynamics of a rodent assemblage in a Cerrado of Southeast Brazil. Revista Brasileira de Biologia 57(1): 99-107.

Waterman, J. 2007. Male mating strategies in rodents. Pp. 27-41. In: Wolff, J.O. \& Sherman, P.W. (Eds.) Rodent societies: an ecological \& evolutionary perspective. The University of Chicago Press, Chicago. 610p.

Wolff, J.O. 2007. Social biology of rodents. Integrative Zoology 2(4): 193-204. 


\section{Capítulo 2 - Densidade populacional e área de vida de Kerodon acrobata}

\subsection{Introdução}

A densidade populacional de uma espécie é considerada um parâmetro flexível, que reflete a estabilidade e o estado de conservação de um ecossistema, enquanto que a área de vida é supostamente, uma propriedade intrínseca às espécies (Makarieva et al., 2005). Área de vida (home range) é o espaço, geralmente ao redor de um abrigo, a qual um animal percorre em busca de comida e somente a parte defendida de outros de sua espécie pode ser considerada território (Burt, 1943). A densidade de uma espécie pode ser afetada por mudanças ambientais que limitem os recursos essenciais a ela (Brown, 1984). Eventos climáticos, como a precipitação, afetam a disponibilidade de recursos alimentares, podendo ocasionar flutuações populacionais sazonais (Ribeiro et al., 2011), enquanto que fenômenos, como a sucessão ecológica, podem afetar positiva ou negativamente, a abundância de roedores a longo prazo (Deitloff et al., 2010). Entretanto, a massa corporal é considerada um fator mais importante na predição da variação na densidade populacional em mamíferos terrestres do que fatores climáticos, geográficos e metodológicos (Silva et al., 2001).

Estudos sobre roedores e marsupiais têm demonstrado que, no Cerrado, o tamanho populacional e a demografia de algumas espécies podem variar entre as estações seca e chuvosa (Vieira, 1997; Ribeiro \& Marinho-Filho, 2005; Ribeiro et al., 2011). Em um estudo no Cerrado boliviano, os roedores de ambientes florestais e de savana apresentaram variações anuais na abundância das espécies, com padrões temporais diferentes entre esses ambientes. Nas florestas, os tamanhos populacionais flutuaram entre os anos, enquanto que nas savanas houve declínio, a cada ano, nos tamanhos das populações locais, sem ligação aparente com chuvas, enchentes ou regime de fogo, resultando na extinção de Cavia aperea, um caviídeo residente (Emmons, 2009).

Roedores herbívoros podem apresentar áreas de vida mais amplas e com maior sobreposição em razão de baixas densidades de alimento, em contraste às altas densidades dos recursos alimentares (South, 1999). Entretanto, a maior densidade de recursos vegetais faz com que, geralmente, herbívoros tenham menores áreas de vida do que, por exemplo, carnívoros com massa corporal semelhante, cujos recursos alimentares são distribuídos mais esparsamente (Kelt \& Van Vuren, 2001). 
A distribuição espacial de recursos no ambiente, como alimento e elementos que forneçam proteção contra predadores (e.g., cobertura vegetal, locas em rochas), pode determinar a distribuição de fêmeas e consequentemente, dos machos (Birney et al., 1976; Ostfeld, 1985; Clutton-Brock, 1989). Fêmeas, principalmente no cio, representam um recurso importante para roedores machos (Ostfeld, 1985). Em diversas espécies animais, os machos podem se tornar agressivos com outros machos durante o período reprodutivo, defendendo territórios e alterando a taxa de sobreposição destes, para monopolizar as fêmeas. Porém o custo energético dessa defesa é alto, de modo que fora da estação reprodutiva pode haver uma convivência de relativa harmonia, em espaços não defendidos da área de vida (Alcock, 2010). Além disso, alguns animais são biologicamente programados para ocupar áreas de vida exclusivas, onde normalmente, intrusos não são tolerados (Makarieva et al., 2005). Os roedores do gênero Kerodon utilizam locas em rochas para abrigo e nidificação (Nowak, 1999), K. rupestris defende as pilhas de rochas que habita (Lacher Jr, 1981) e K. acrobata foi observado habitando fendas em afloramentos calcários (Moojen et al., 1997) associados a matas secas, na região do Vale do Paranã. Essas florestas enfrentam longas estações secas (5 a 7 meses) e podem ser divididas em florestas semidecíduas e decíduas, sendo que essas últimas crescem sobre os afloramentos calcários existentes na região e sua cobertura vegetal perde a maior parte das folhas durante a estação seca (Nascimento et al., 2004; Felfili et al., 2007).

No presente estudo investiguei variações na densidade e área de vida do mocó acrobata (K. acrobata) em fragmentos de mata seca no Brasil central. Especificamente, devido à variação sazonal na produção de recursos vegetais em ambientes de mata seca, pretendi avaliar se ocorre flutuação no tamanho populacional entre as estações seca e chuvosa e entre os dois ambientes florestais presentes na área de estudo. Investiguei a área de vida dos indivíduos de K. acrobata e avaliei possíveis diferenças no tamanho e na sobreposição média dessas áreas, associadas ao sexo, estágios de desenvolvimento (jovem e adulto) e às estações do ano (seca e chuvosa). Em relação às questões investigadas, as seguintes previsões são propostas:

1) A densidade de indivíduos é maior durante a estação seca, época de menor disponibilidade de recursos alimentares nas matas secas.

2) Mais indivíduos serão encontrados na floresta semidecídua durante a estação seca, devido à maior oferta de alimento nesse ambiente, em relação à floresta decídua, durante essa estação. 
3) A média das áreas de vida dos machos de K. acrobata é maior do que a das fêmeas, para abranger maior quantidade de parceiras.

4) Durante a estação seca, os indivíduos de $K$. acrobata aumentam sua área de vida, para conseguirem alimento, em virtude da menor oferta de recursos, em relação à estação chuvosa (i.e. folhas nas plantas).

\subsection{Materiais e métodos}

\subsection{1 Área de estudo}

Idem item 1.2.1.

\subsubsection{Coleta de dados}

\subsubsection{Densidade populacional}

Para estimar a densidade de Kerodon acrobata na área amostrada, utilizei a metodologia de amostragem por distância, em que transecções lineares são percorridas e os indivíduos observados são contabilizados (Buckland et al., 1993; Buckland et al., 2001; Desbiez \& Tomas, 2003). Devido à natureza rugosa da área de estudo, determinada pelos afloramentos calcários habitados pelos indivíduos de $K$. acrobata, a amostragem por distância foi conduzida em transecções lineares "por partes" (piecewise), adaptadas de Anderson et al. (1979). Para detectar os indivíduos de $K$. acrobata, percorri em velocidade constante, oito transecções lineares localizadas nas bordas de afloramentos calcários, presentes em três fragmentos de mata seca (Figura 15). Percorri cada uma das transecções uma vez por mês, de novembro de 2011 a outubro de 2012, registrando a distância percorrida ao final de cada trajeto, com o auxílio de um aparelho receptor móvel do sistema de posicionamento global (Global Positioning System - GPS), do modelo GPSMAP 60CSx (Garmin International, Inc., Olathe, KS, USA). O método de amostragem por distância requer a mensuração da distância perpendicular dos indivíduos observados em relação à transecção percorrida. Para isso, registrei (1) a distância entre os mocós observados e o observador (distância radial) e (2) o ângulo formado entre a direção dos animais e a transecção percorrida. A distância radial foi estimada com o auxílio de um medidor de distâncias a laser (DLE 150 Professional - Bosch) e o ângulo foi estimado com o auxílio do 
limbo de uma bússola. A distância perpendicular foi calculada pelo programa DISTANCE 6.0 Release 2 (Thomas et al., 2009), por meio da fórmula:

$$
\mathbf{x}=\mathbf{r} * \operatorname{seno} \theta
$$

onde, "X" é a distância perpendicular, "r" é a distância radial e " $\theta$ " é o ângulo entre o animal e a transecção percorrida.

A quantidade de indivíduos observados foi confirmada por meio de um binóculo $10 \mathrm{x}$ 50 mm (modelo Action - Nikon Inc., El Segundo, CA, USA). Também foi registrado o tipo de vegetação em que os animais se encontravam (mata decídua, ou semidecídua).

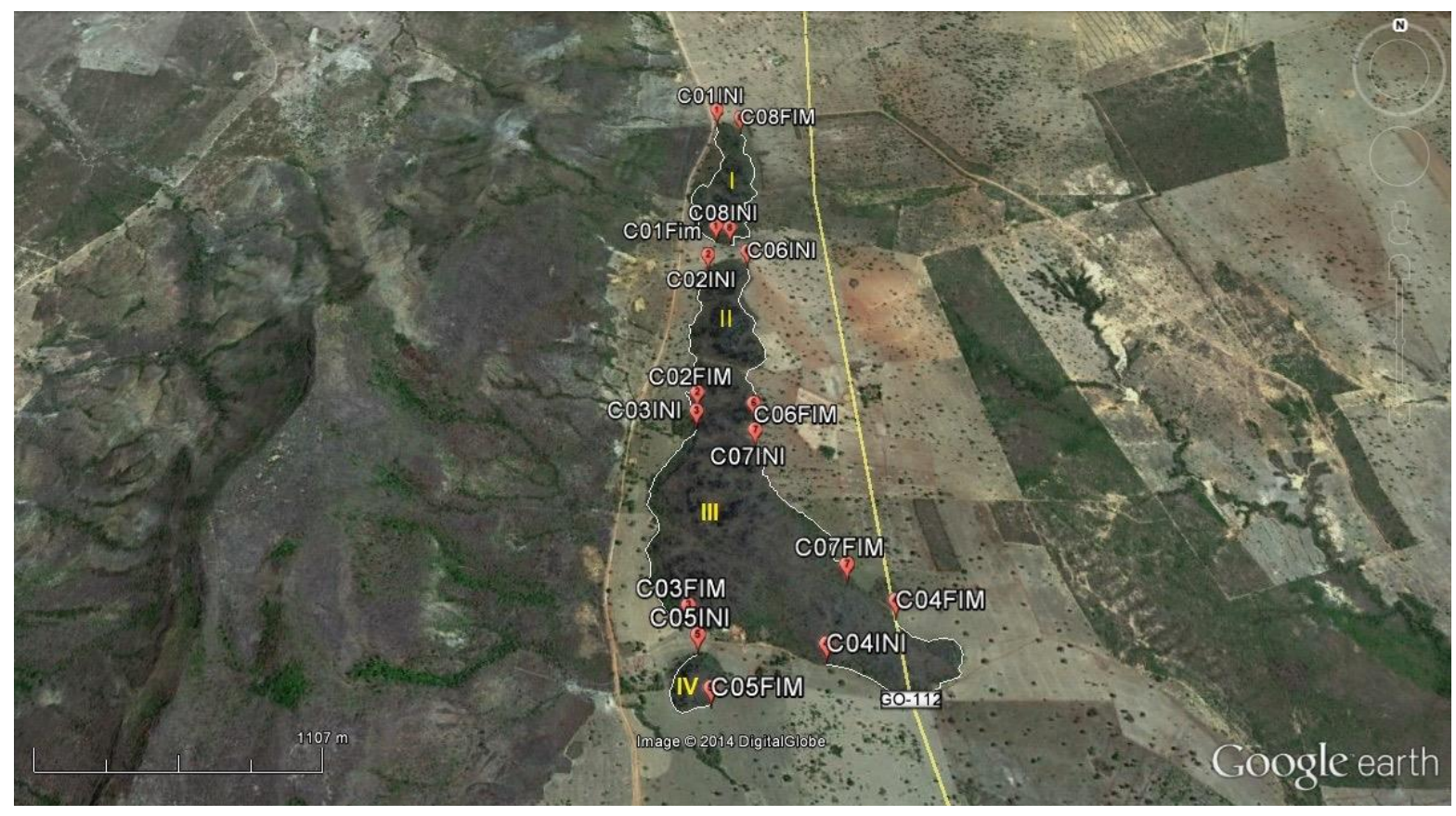

Figura 15 - Distribuição das oito transecções percorridas em quatro fragmentos de mata seca, para detectar os indivíduos de $K$. acrobata durante as amostragens por distância, realizadas de novembro de 2011 a outubro de 2012, em Monte Alegre de Goiás - GO. Os balões vermelhos indicam o início (INI), ou o fim de cada transecção e as linhas brancas, o caminho percorrido. 


\subsubsection{2 Área de vida}

Estimei a área de vida dos indivíduos de $K$. acrobata capturados de fevereiro a dezembro de 2013 por meio de rádio telemetria (White \& Garrot, 1990; Moraes Jr \& Chiarello 2005). Para instalar os transmissores, capturei os indivíduos de acordo com a metodologia descrita no item 1.2.2 (Capítulo 1). Cada indivíduo capturado recebeu um colar equipado com rádio transmissor VHF, modelo SOM-2380 (Wildlife Materials Inc., Murphysboro, IL, USA), com frequências variando entre 148.181 e $148.520 \mathrm{MHz}$ e entre 174.304 e $174.990 \mathrm{MHz}$ (Figura 16). O conjunto de cada colar pesava em média 20,5g (18 a 21,8g), menos de $5 \%$ da massa corporal dos indivíduos marcados.

Como ainda não eram conhecidas informações sobre a área de vida, ou velocidade máxima da espécie, para aplicar medidas para evitar autocorrelação espacial durante a amostragem (Rooney et al., 1998), busquei estimar a localização dos animais monitorados a cada três horas, durante o dia e ao menos uma vez à noite. As localizações foram estimadas por triangulações realizadas por uma estação móvel, a partir de dois pontos georreferenciados, verificando-se a direção (bearing) do sinal dos transmissores em relação ao norte, com o auxílio de uma bússola. Para captar os sinais emitidos pelos transmissores foram utilizados dois receptores VHF do modelo TR-4 (Telonics, Mesa, AZ, USA), um com capacidade para captar frequências entre 148 e $152 \mathrm{MHz}$ e outro de 173 a $177 \mathrm{MHz}$ e uma antena direcional rígida de dois elementos. 


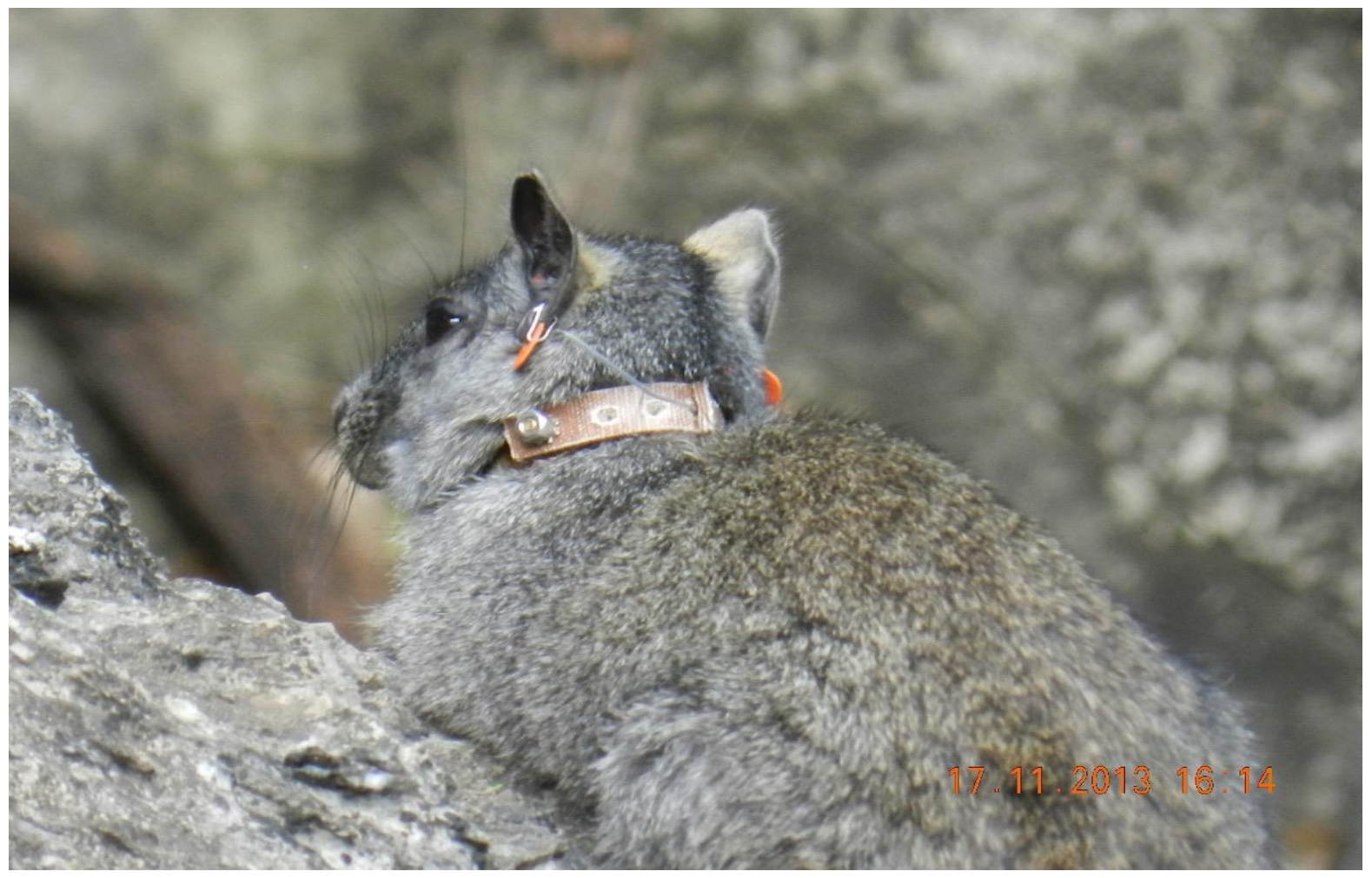

Figura 16 - Indivíduo de Kerodon acrobata marcado com brincos e rádio-colar.

\subsubsection{Análises dos dados}

\subsubsection{Densidade populacional}

A densidade de indivíduos foi estimada com o auxílio do programa DISTANCE. Os resultados relativos à densidade também foram agrupados de acordo com a estação em que foram coletados, para avaliar se haveria diferença na densidade de indivíduos de $K$. acrobata entre as estações seca e chuvosa. Para tanto, os intervalos de confiança resultantes dessas estimativas foram analisados para verificar se existe sobreposição entre eles.

Para verificar se a cobertura florestal e a estação são fatores que influenciam a abundância de mocós (variável resposta) na área de estudo, utilizei o método de seleção de Modelos Lineares Generalizados Mistos - GLMM (Zuur et al., 2009), com distribuição de Poisson, indicada para dados de contagem (Crawley, 2007). Nesse modelo completo considerei como variáveis independentes a estação do ano (seca e chuvosa) e tipo de cobertura da vegetação (mata decídua (MD) e mata semidecídua (MS)). Como as coletas foram repetidas 
mensalmente em cada transecção, foi necessário utilizar o local da transecção (censo) como variável aleatória. Posteriormente, a variável campanha de coleta (campanha) foi testada também como variável aleatória, para verificar se havia correlação (temporal) entre as campanhas. Para escolher o melhor modelo completo estes foram comparados por meio do teste de razão de verossimilhança, LRT (Zuur et al., 2009). O modelo completo com as variáveis "censo" e "campanha" foi considerado o melhor modelo (Anexo 1). Modelo completo:

\section{$N^{0}$ de mocós $\sim$ cobertura * estação + (1|censo/campanha $)$, family = poisson $)$}

Realizei a seleção de modelos a partir da remoção sequencial das variáveis independentes, em função dos resultados dos testes de razão de verossimilhança, comparando os modelos que possuíam com os que não possuíam cada uma das variáveis (Zuur et al., 2009). O modelo final foi obtido quando estavam presentes no modelo apenas as variáveis significativas. Em cada passo, retirei a variável com maior valor de p (Anexo 2). O modelo final foi validado pela avaliação visual de gráficos de resíduos normalizados para conferir a normalidade, a homocedasticidade e a ausência de padrões, seguindo protocolo apresentado por Zuur et al. (2009). Para realizar estas análises foram utilizados os pacotes "Ime4" (Bates et al., 2014) e "Imtest" (Hothorn et al., 2014) do programa R 3.1.1 (Venables et al., 2005; R Core Team, 2014).

\subsubsection{2 Área de vida}

Os bearings coletados foram inseridos no programa LOAS Versão 4.0.3.8 (Ecological Software Solutions, Sacramento, CA, USA), para gerar as estimativas das localizações dos animais monitorados, que por sua vez, foram utilizadas para estimar as áreas de vida e as suas sobreposições. As áreas de vida de $K$. acrobata foram estimadas somente com os dados coletados a partir do terceiro dia em que cada indivíduo estava equipado com uma coleira, para que se acostumassem ao equipamento (White \& Garrot, 1990). Estimei as áreas de vida pelo estimador Kernel-fixo, com 95\% dos pontos, utilizando o programa Ranges8 v2.16 (Kenward et al., 2008). 
Para verificar se os tamanhos das áreas de vida estimadas foram influenciados pela quantidade de localizações utilizadas nas estimativas, foi utilizado o coeficiente de correlação de Spearman no programa R 3.1.1 (R Core Team, 2014). Como a quantidade de localizações não influenciou as estimativas totais de área de vida, não foi necessário incluir esta variável nas análises $\left(\mathrm{r}_{\mathrm{s}}=-0,12, \mathrm{p}=0,73\right)$. O mesmo ocorreu entre o tamanho das áreas de vida e o número de dias amostrados $\left(r_{s}=-0,14, p=0,69\right)$. Assim, para verificar se existe diferença no tamanho total das áreas de vida entre os sexos e entre os estágios de desenvolvimento (jovem e adulto), foram realizados Testes $t$.

Para verificar se existe diferença entre o tamanho estimado para as áreas de vida entre a estação seca e as duas chuvosas amostradas, realizei a seleção de modelos pelo método dos Mínimos Quadrados Generalizados (GLS). Para tanto, utilizei o pacote "nlme” (Pinheiro et al., 2015) do programa R 3.1.1 (R Core Team, 2014). No modelo completo estão presentes as variáveis “estação" e "npontos" (número de localizações) utilizadas para estimar o tamanho das áreas de vida:

\section{gls (área de vida estacao * npontos)}

Como as áreas de vida foram estimadas mais de uma vez para cada indivíduo (em três diferentes estações: chuvosa 1 - fevereiro a março; seca - abril a setembro; chuvosa 2 - outubro a dezembro), considerei os indivíduos como fatores aleatórios em um modelo linear de efeito misto (LME). Por meio do teste de razão de verossimilhança (LRT), verifiquei que o fator indivíduo não influenciou na qualidade do modelo, indicando que não foi necessário considerar esse fator aleatoriamente (Anexo 3). A seleção e validação dos modelos foram realizadas seguindo o protocolo de Zuur et al. (2009), conforme descrito anteriormente para GLMM.

A sobreposição das áreas de vida dos machos foi estimada com auxílio do programa Ranges8. Para estimar a sobreposição das áreas de vida entre os sexos e entre indivíduos do mesmo sexo, foi calculada a proporção (\%) da área sobreposta em relação à área de uso de cada animal monitorado. 


\subsection{Resultados}

\subsubsection{Densidade populacional}

Realizei 96 amostragens em 76,2 Km percorridos, com 535 registros de K. acrobata em 352 eventos de observações. Durante a estação chuvosa realizei 214 registros de mocós em 154 observações, distribuídas em 48 amostragens, em um total de 38,4 Km percorridos. O modelo que melhor se ajustou às observações durante a estação chuvosa foi a função de detecção Hazard-rate simples. Por meio do teste de aderência (goodness-of-fit-GOF) e inspeção visual, observei a necessidade de truncar a análise dessa estação, excluindo os registros das observações realizadas dentro dos primeiros cinco metros de distância perpendicular em relação ao observador (Tabela 3). Esse truncamento permitiu um melhor ajuste das observações à função de detecção (Figura 17). O modelo que melhor se ajustou às observações da estação seca também foi o da função de detecção Hazard-rate simples. Por meio do teste de aderência e inspeção visual, observei a necessidade de truncar a análise, excluindo os registros das observações incluídas nos primeiros 10 metros de distância perpendicular ao observador (Tabela 3). O truncamento permitiu um melhor ajuste dos registros à função de detecção (Figura 18). Após o truncamento, foram consideradas 144 observações (Tabela 3), com uma largura efetiva da faixa amostrada de 16,5 m. A probabilidade de detecção (p) foi de 0,42 e a taxa de encontro (ER) foi de 0,004 (Coeficiente de Variação - CV) = 18,5\%; intervalo de confiança (IC) $95 \%=0,003$ a 0,005$)$.

Os mocós foram registrados a uma distância de até $39,4 \mathrm{~m}$ do observador durante a estação chuvosa. A densidade foi estimada em 1,5 indivíduos/ha (CV = 19,85\%; IC 95\% = 1,0 a 2,3) e a abundância foi estimada em 332 indivíduos (CV = 19,85\%; IC 95\% = 224 a 492). O tamanho médio dos grupos de mocós durante essa estação foi estimado em 1,4 indivíduos (erro padrão (SE) $\pm 0,06)$.

Na estação seca registrei 321 mocós em 198 eventos de observação, em 48 amostragens, onde percorri 37,7 Km. Após o truncamento, foram consideradas 135 observações (Tabela 3) em uma largura efetiva da faixa amostrada de $10,1 \mathrm{~m}$. A probabilidade de detecção foi de 0,35 e a taxa de encontro foi igual à da estação chuvosa $(E R=0,004 ; C V=20,7 \%$; $\mathrm{IC} 95 \%=0,002$ a 0,005 ). Os mocós foram observados a uma distância de até $28,8 \mathrm{~m}$ do trajeto percorrido durante a estação seca. A densidade foi estimada em 2,8 indivíduos/ha (CV = 23,62\%; IC 95\% $=1,8$ a 4,5) e a abundância foi de 609 indivíduos $(\mathrm{CV}=23,62 \%$; IC 95\% = 383 a 968). O 
tamanho médio dos grupos de mocós durante a estação seca foi estimado em 1,6 indivíduos (SE $= \pm 0,09)$.

O número de mocós registrados variou entre a mata decídua e a mata semidecídua $(\mathrm{p}<$ 0,001), sendo maior na mata decídua (Figura 19, Anexo 4). Estes registros não variaram entre as estações seca e chuvosa $(\mathrm{p}=0,150)$. Entretanto, foi verificada uma diferença entre os registros na MD e MS nas diferentes estações $(p=0,003)$, sendo que foram observados mais indivíduos na MS durante a seca do que na chuva e na MD foram registrados mais indivíduos durante a chuva do que na seca (Figura 19, Anexo 4). 
Tabela 3 - Estimativas da abundância (N) e densidade (D) de indivíduos de Kerodon acrobata, obtidas por meio do programa DISTANCE, para as amostragens de distância realizadas de novembro de 2011 a outubro de 2012 em Monte Alegre de Goiás - GO, Brasil. Ajuste: distância truncada, em metros; $\mathrm{N}^{\circ}$ obs.: número de eventos de observação de indivíduos; AIC: Critério de Informação de Akaike; ESW: largura efetiva da faixa amostrada, em metros; CV: coeficiente de variação; GOF Chi-p: valor de p para teste de aderência.

\begin{tabular}{|c|c|c|c|c|c|c|c|c|c|c|}
\hline Estação & $\begin{array}{c}\text { Função de } \\
\text { detecção }\end{array}$ & $\begin{array}{c}\text { Ajuste } \\
\text { (m) }\end{array}$ & $\mathbf{N}^{\circ}$ obs. & $\mathbf{N}$ & AIC & $\begin{array}{c}\text { ESW } \\
(\mathbf{m})\end{array}$ & $\begin{array}{c}\text { ESW } \\
\text { CV }(\%)\end{array}$ & $\underset{\text { (ind./ha) }}{D}$ & $\begin{array}{c}\text { D } \\
\text { CV }(\%)\end{array}$ & $\begin{array}{l}\text { GOF } \\
\text { Chi-p }\end{array}$ \\
\hline Chuvosa & $\begin{array}{c}\text { Hazard-rate } \\
\text { simples }\end{array}$ & - & 154 & 246 & $1.035,4$ & 23,5 & 19,7 & 1,1 & 18,5 & $<0,001$ \\
\hline Chuvosa* & $\begin{array}{c}\text { Hazard-rate } \\
\text { simples }\end{array}$ & $0-5$ & 144 & 332 & 900,95 & 16,5 & 6,3 & 1,5 & 19,8 & 0,4998 \\
\hline Seca & $\begin{array}{c}\text { Hazard-rate } \\
\text { simples }\end{array}$ & - & 198 & 394 & $1.288,5$ & 22,9 & 3,2 & 1,8 & 20,2 & $<0,001$ \\
\hline Seca* & $\begin{array}{c}\text { Hazard-rate } \\
\text { simples }\end{array}$ & $0-10$ & 135 & 609 & 734,5 & 10,1 & 10,4 & 2,8 & 23,6 & 0,3157 \\
\hline
\end{tabular}

Legenda: * Estimativa considerada. 


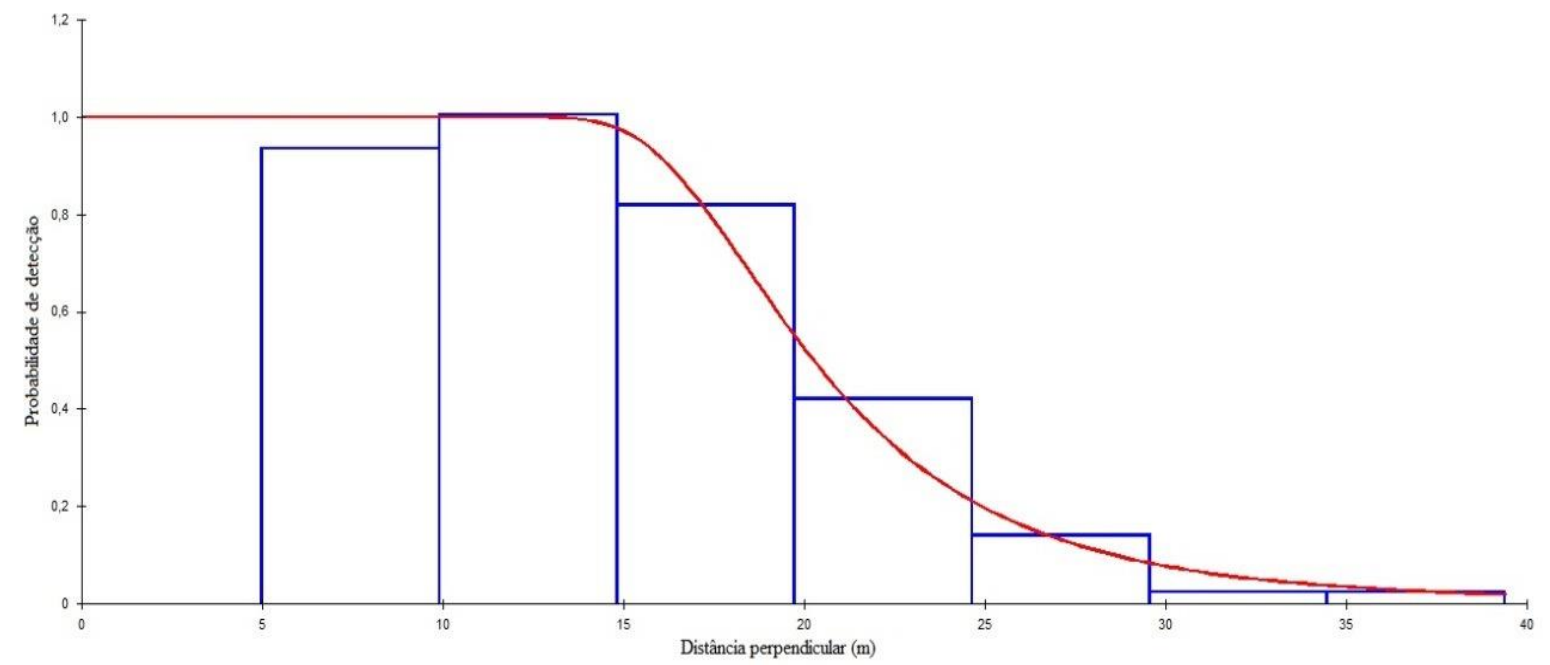

Figura 17 - Probabilidade de detecção em relação à distância perpendicular dos indivíduos de Kerodon acrobata registrados durante as amostragens por distância realizadas na estação chuvosa, em Monte Alegre de Goiás - GO, em 2011 e 2012.

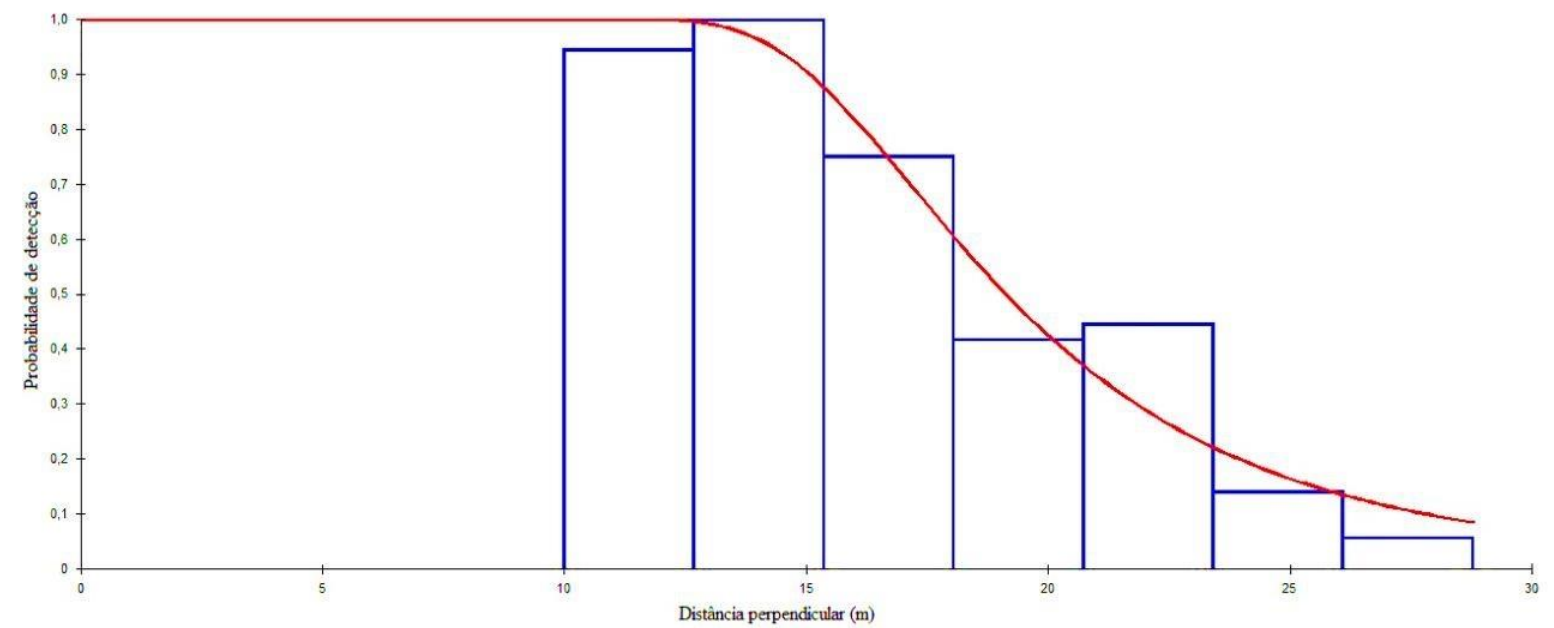

Figura 18 - Probabilidade de detecção, em relação à distância perpendicular, dos indivíduos de Kerodon acrobata registrados durante as amostragens por distância realizadas durante a estação seca em Monte Alegre de Goiás - GO, em 2012. 


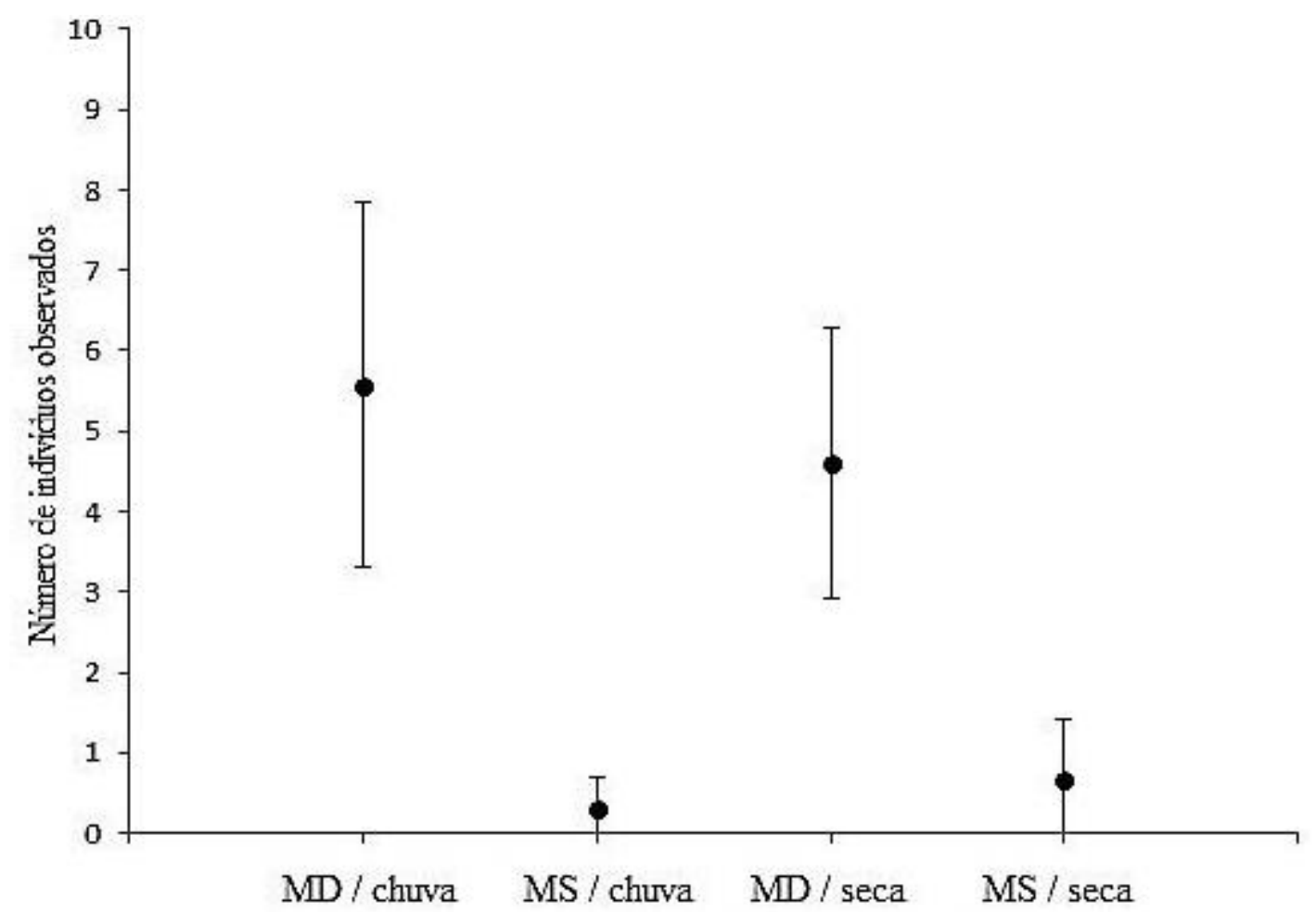

Figura 19 - Médias e respectivos intervalos de confiança do número de indivíduos de Kerodon acrobata observados nas estações seca e chuvosa, nas matas decídua (MD) e semidecídua (MS), durante as amostragens por distância realizadas em Monte Alegre de Goiás - GO, de novembro de 2011 a outubro de 2012.

\subsection{2 Área de vida}

Foram estimadas as áreas de vida de 11 indivíduos monitorados por rádio telemetria (Tabela 4). Os indivíduos monitorados apresentaram áreas de vida estimadas entre 0,09 a 0,67 ha e média de 0,2 ha (Figura 20).

As áreas de vida estimadas para os machos $(n=4)$ variaram de 0,11 a 0,67 ha e apresentaram em média 0,3 ha. As fêmeas $(n=7)$ apresentaram áreas de vida entre 0,09 e 0,34 ha e a média $(0,15$ ha) não diferiu da dos machos $(\mathrm{t}=-1,410 ; \mathrm{g} .1 .=9 ; \mathrm{p}=0,10)$. As estimativas para as áreas de vida dos adultos $(\mathrm{n}=6)$ ficaram entre 0,09 e 0,67 ha, com média de 0,24 ha. Os jovens $(n=5)$ apresentaram áreas de vida entre 0,14 e 0,23 ha e média de 0,16 ha, que não 
diferiu dos adultos $(\mathrm{t}=0,451 ; \mathrm{g} .1 .=9 ; \mathrm{p}=0,67)$. $\mathrm{O}$ tamanho estimado para as áreas de vida não diferiu $(\mathrm{p}=0,929)$ entre as três estações amostradas (Figura 21, Anexo 5). Não houve também uma correlação significativa entre a massa dos animais e as respectivas áreas de vida estimadas $(\mathrm{S}=226,03 ; \mathrm{p}=0,936)$.

A sobreposição média das áreas de vida entre os sexos foi maior (36\%, Apêndice Figura 22) do que entre fêmeas (26\%, Apêndices - Figura 23 e Figura 24) e entre machos (24\%, Apêndices - Figura 25, Figura 26, e Tabela 5). Indivíduos jovens apresentaram sobreposição média dos seus territórios maior $(43 \%)$ do que ao considerar somente entre adultos $(21 \%$, Apêndice - Figura 27) e também, entre esses dois estágios de desenvolvimento (31\%).

A sobreposição média das áreas de vida estimadas dos indivíduos capturados em um mesmo afloramento foi de $31 \%$. Ao considerar somente os indivíduos capturados em uma mesma estação de captura (Grupo 1), essa média aumenta para 44\%. Dentro do Grupo 1, a média de sobreposição entre sexos foi estimada em $48 \%$, valor maior que o estimado entre indivíduos do sexo feminino (39\%) e também, considerando-se somente fêmeas adultas (17\%).

Considerando-se as estações seca e chuvosa, a sobreposição média das áreas de vida dos indivíduos monitorados foi maior durante a seca (32\%) e menor durante a segunda estação chuvosa amostrada (23\%) (Tabela 6, Apêndice - Figura 28). A sobreposição média das áreas de vida estimadas foi maior entre os sexos, durante a seca (37\%), do que entre machos (28\%) e entre fêmeas (25\%). Observando-se apenas os indivíduos capturados em uma mesma estação de captura (Grupo 1), a sobreposição média também foi maior durante a seca (44\%) e entre os sexos ( $49 \%$ na seca e $44 \%$ na segunda estação chuvosa). 
Tabela 4 - Relação dos indivíduos de Kerodon acrobata, com sexo e estágio de desenvolvimento dos indivíduos, período de amostragem, número de dias amostrados, quantidade de registros (N) por área de vida estimada por Kernel 95\% para a primeira estação chuvosa (fevereiro a março), estação seca (abril a setembro), segunda estação chuvosa (outubro a dezembro) e total, durante o ano de 2013, em Monte Alegre de Goiás, Brasil.

\begin{tabular}{|c|c|c|c|c|c|c|c|c|c|c|}
\hline \multirow{2}{*}{$\begin{array}{c}\text { Indivíduo } \\
\text { (frequência) }\end{array}$} & \multirow{2}{*}{ Sexo } & \multirow{2}{*}{$\begin{array}{c}\text { Estágio } \\
\text { desenvolv. }\end{array}$} & \multirow{2}{*}{$\begin{array}{c}\text { Massa } \\
(\mathbf{K g})\end{array}$} & \multirow{2}{*}{ Amostragem } & \multirow{2}{*}{ Dias } & \multicolumn{2}{|c|}{$\mathbf{N}$} & \multicolumn{3}{|c|}{ Área (ha) } \\
\hline & & & & & & Seca & Chuvosa & Seca & Chuvosa & Total \\
\hline $1-174.304$ & $\mathrm{~F}$ & $\mathrm{~J}$ & 0,74 & $15 / 02$ a $30 / 05 / 2013$ & 66 & 136 & 148 & 0,03 & 0,17 & 0,14 \\
\hline $2-174.990$ & M & $\mathrm{J}$ & 0,66 & $24 / 02$ a $11 / 12 / 2013$ & 119 & 340 & $109(45)$ & 0,11 & $0,14(0,04)$ & 0,16 \\
\hline $3-174.636$ & $\mathrm{~F}$ & A & 1,26 & $26 / 03$ a $11 / 12 / 2013$ & 101 & 341 & $22(46)$ & 0,09 & $0,09(0,02)$ & 0,09 \\
\hline $4-174.714$ & $\mathrm{M}$ & A & 0,92 & $28 / 03$ a $11 / 12 / 2013$ & 99 & 338 & $14(48)$ & 0,70 & $0,08(0,14)$ & 0,67 \\
\hline $5-174.545$ & $\mathrm{~F}$ & A & 1,27 & $15 / 04$ a $11 / 12 / 2013$ & 86 & 298 & (47) & 0,13 & $(0,03)$ & 0,12 \\
\hline $6-174.616$ & $\mathrm{~F}$ & $\mathrm{~J}$ & 0,63 & $16 / 05$ a $11 / 12 / 2013$ & 69 & 228 & (48) & 0,10 & $(0,60)$ & 0,10 \\
\hline $7-148.460$ & $\mathrm{~F}$ & A & 0,91 & $16 / 05$ a $11 / 12 / 2013$ & 69 & 228 & (44) & 0,12 & $(0,07)$ & 0,12 \\
\hline $8-148.420$ & $\mathrm{~F}$ & $\mathrm{~J}$ & 0,67 & $16 / 05$ a $11 / 12 / 2013$ & 69 & 230 & (44) & 0,16 & $(0,07)$ & 0,15 \\
\hline $9-148.520$ & M & $\mathrm{J}$ & 0,67 & $27 / 05$ a $11 / 12 / 2013$ & 63 & 207 & (46) & 0,24 & $(0,13)$ & 0,23 \\
\hline $10-148.260$ & M & A & 1,06 & $08 / 07$ a $11 / 12 / 2013$ & 44 & 129 & (48) & 0,11 & $(0,08)$ & 0,11 \\
\hline $11-148.181$ & $\mathrm{~F}$ & A & 1,22 & $15 / 07$ a $11 / 12 / 2013$ & 37 & 99 & (48) & 0,03 & 0,17 & 0,14 \\
\hline
\end{tabular}




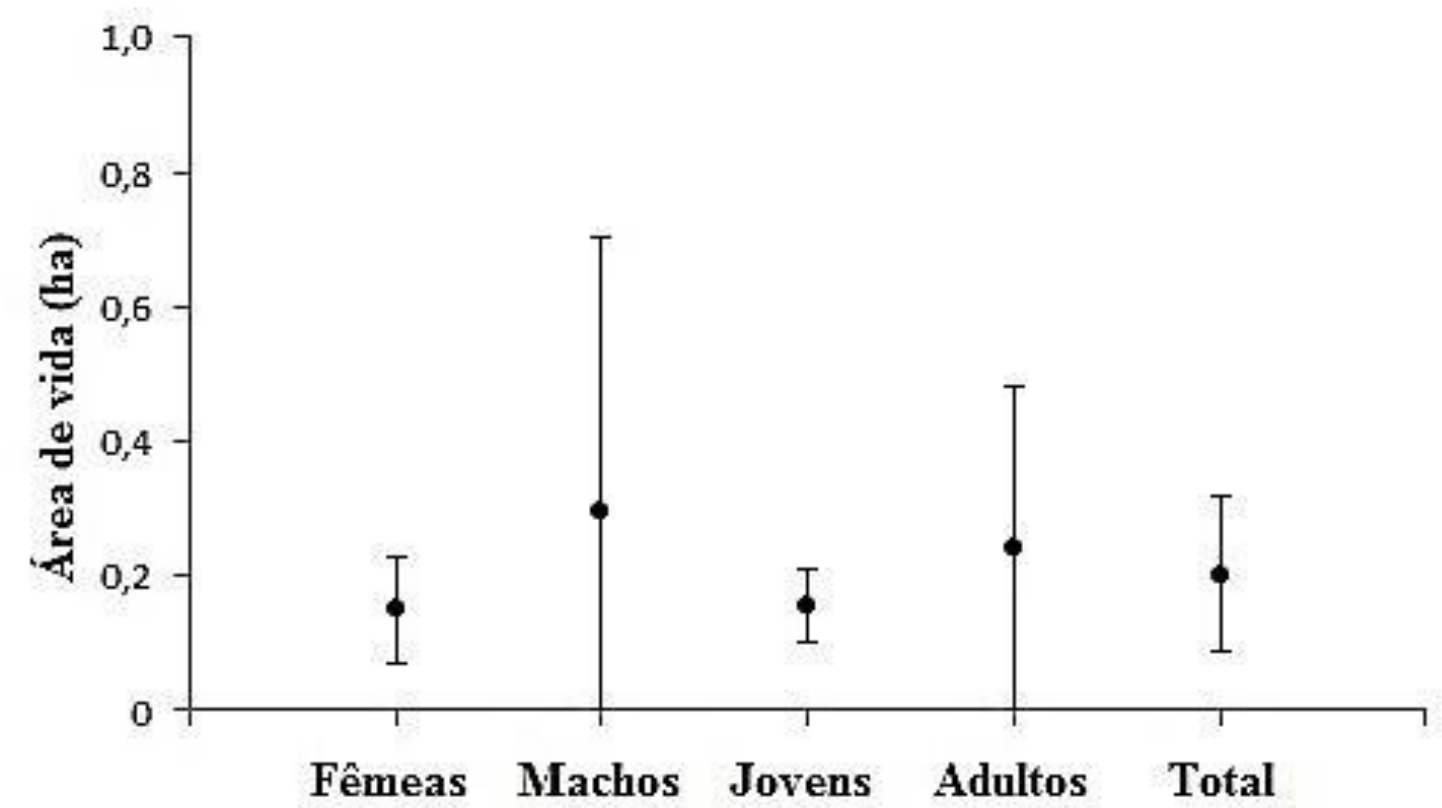

Figura 20 - Médias e intervalos de confiança das áreas de vida estimadas por Kernel-fixo 95\%, para os indivíduos de Kerodon acrobata monitorados de fevereiro a dezembro de 2013 (n=11), em Monte Alegre de Goiás - GO, Brasil.

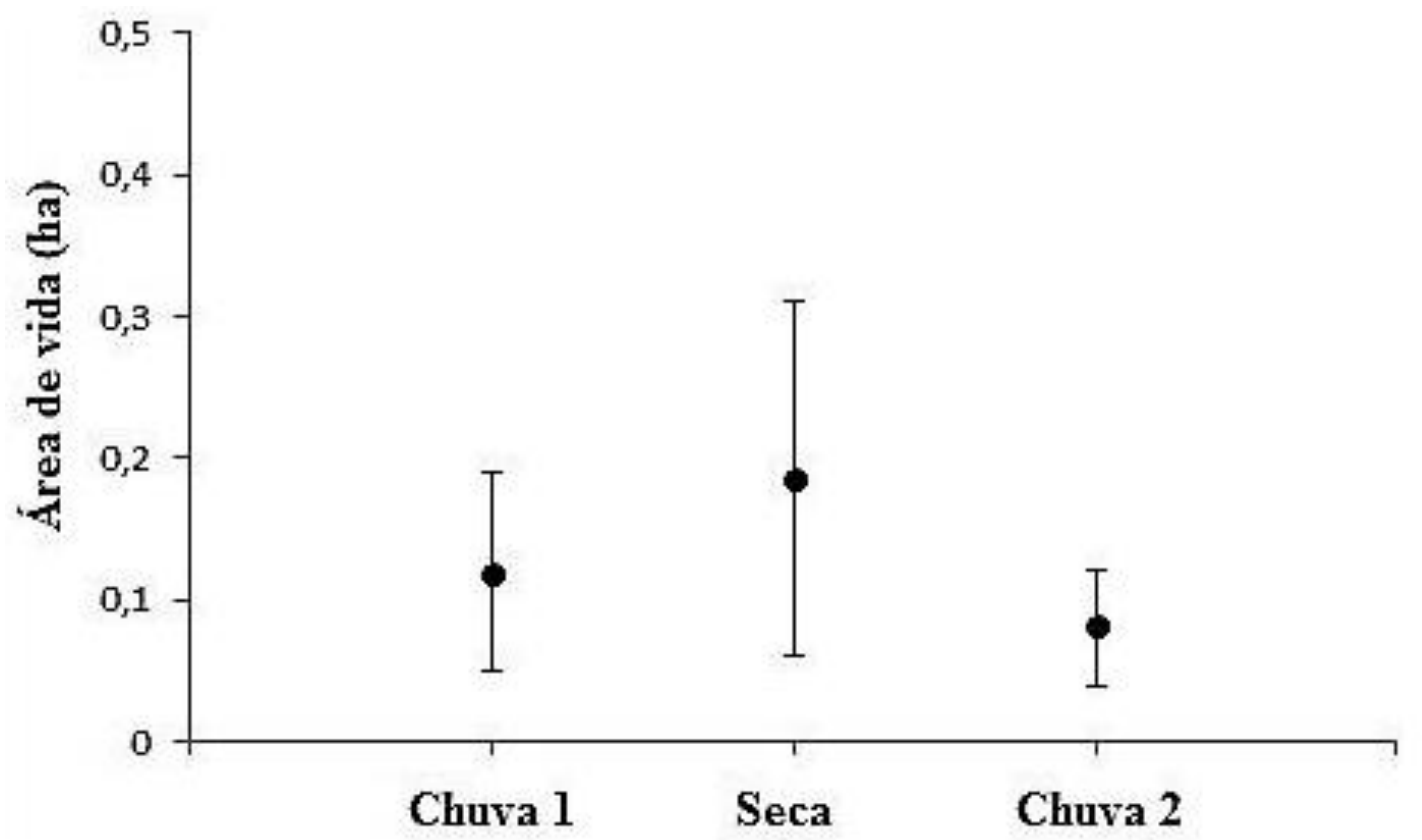

Figura 21 - Médias e intervalos de confiança das áreas de vida estimadas por Kernel-fixo 95\% para os indivíduos de Kerodon acrobata monitorados $(\mathrm{n}=11)$ em três diferentes estações, de fevereiro a dezembro de 2013, em Monte Alegre de Goiás - GO, Brasil. 
Tabela 5 - Sobreposição média das áreas de vidas (AV) dos indivíduos de Kerodon acrobata monitorados de fevereiro a dezembro de 2013, em Monte Alegre de Goiás GO, Brasil.

\begin{tabular}{lcc}
\hline \multicolumn{1}{c}{ Conjunto } & Sobreposição média AV (\%) & N de indivíduos \\
\hline Geral & 31 & 10 \\
M x M & 24 & 4 \\
F x F & 26 & 6 \\
Entre sexos & 36 & 10 \\
A x A & 21 & 5 \\
J x J & 43 & 5 \\
Entre estágios de desenvolvimento & 31 & 10 \\
\hline Grupo 1 & 44 & 5 \\
F x F (Grupo 1) & 39 & 5 \\
F + A (Grupo 1) & 17 & 3 \\
M x M (Grupo 1) & 38 & 8 \\
Entre sexos (Grupo 1) & 48 & 8 \\
Entre estágios de desenvolvimento & & \\
(Grupo1) & 46 & \\
& & \\
\hline
\end{tabular}

Conjunto: grupo de indivíduos utilizados para as estimativas $(\mathrm{M}$ - machos; $\mathrm{F}$ - fêmeas; A - adultos; J - jovens; Grupo1 - indivíduos capturados em uma mesma estação de captura). $\mathrm{N}$ de indivíduos: número de indivíduos utilizados para estimar a sobreposição média. 
Tabela 6 - Sobreposição média, por estação, das áreas de vidas (AV) dos indivíduos de Kerodon acrobata monitorados de fevereiro a dezembro de 2013, em Monte Alegre de Goiás, Brasil.

\begin{tabular}{|c|c|c|}
\hline Estação / Conjunto & $\begin{array}{c}\text { Sobreposição média } \\
\text { AV (\%) }\end{array}$ & $\mathbf{N}$ de indivíduos \\
\hline Chuval & 29 & 3 \\
\hline Seca & 32 & 10 \\
\hline Chuva2 & 23 & 9 \\
\hline Seca - M x M & 28 & 4 \\
\hline Seca - F x F & 25 & 6 \\
\hline Seca - entre sexos & 37 & 10 \\
\hline Seca - Grupo1 & 44 & 8 \\
\hline Seca - F x F Grupo1 & 38 & 5 \\
\hline Seca - entre sexos Grupo1 & 49 & 8 \\
\hline Chuva2 - M x M & 16 & 4 \\
\hline Chuva2 - F x F & 16 & 5 \\
\hline Chuva2 - entre sexos & 29 & 9 \\
\hline Chuva2 - Grupo1 & 37 & 7 \\
\hline Chuva2 - M x M Grupo1 & 31 & 3 \\
\hline Chuva2 - F x F Grupo1 & 26 & 4 \\
\hline Chuva2 - entre sexos Grupo1 & 44 & 7 \\
\hline
\end{tabular}

Legenda: Estação / Conjunto: estação em que a sobreposição média foi calculada (chuvosa, ou seca) e conjunto de dados utilizados para as estimativas ( $\mathrm{M}$ - machos; F - fêmeas; Grupo1 - indivíduos capturados em uma mesma estação de captura). $\mathrm{N}$ de indivíduos: número de indivíduos utilizados para estimar a sobreposição média. 


\subsection{Discussão}

Os mocós apresentaram, na estação seca, maiores estimativas de abundância e de densidade, tamanho de grupo, e sobreposição média de áreas de vida. A estimativa das áreas de vida foi maior na estação seca, assim como a de abundância na mata semidecídua, em relação à decídua nesse período, porém não houve diferença significativa nesses casos. Entretanto, considerando-se somente as estimativas de abundância em cada formação florestal, a mata semidecídua apresentou maior abundância de mocós na estação seca e a decídua na estação chuvosa. Esses resultados concordam com a ideia de que mudanças ambientais, como as causadas pela sazonalidade climática, podem ser responsáveis por alterações na abundância e densidade de roedores, ao afetar a disponibilidade de recursos alimentares (Brown, 1984; Ribeiro et al., 2011), tendo em vista que roedores herbívoros podem apresentar áreas de vida mais amplas e com maior sobreposição ante baixas densidades de alimento (South, 1999), causando maior adensamento de indivíduos.

Embora a massa corporal seja considerada um fator mais importante na predição da variação na densidade populacional em mamíferos terrestres (Silva et al., 2001), nossos resultados indicaram que esse fator não foi determinante para os valores estimados de área de vida. Como a distribuição espacial de recursos, como alimento e abrigos pode ser determinante na distribuição de fêmeas e consequentemente, dos machos (Birney et al., 1976; Ostfeld, 1985; Clutton-Brock, 1989), essa maior densidade e aumento na sobreposição das áreas de vida, encontrados durante a estação seca, pode ocorrer devido a uma possível mudança temporária dos indivíduos das áreas centrais dos afloramentos, em direção às bordas, para forragear na mata semidecídua, onde a densidade dos recursos é maior durante essa estação. Porém, os dados de telemetria foram obtidos a partir de indivíduos residentes na borda dos afloramentos e portanto, não esclarecem essa questão. Entretanto, mesmo observando mais indivíduos durante a seca e apesar de a vegetação ser menos densa durante essa estação, possibilitando assim, enxergar objetos a uma distância maior, a probabilidade de detecção foi maior durante a estação chuvosa ( $\mathrm{p}=$ $0,42)$ e a taxa de encontro permaneceu igual em ambas as estações ( $E R=0,004)$, evidenciando que o adensamento da vegetação não foi determinante na detecção dos mocós.

A quantidade total de mocós observados na mata decídua foi maior do que na semidecídua e isso provavelmente deve-se ao fato de que a primeira ocorre sobre os 
afloramentos, ambiente do qual são especialistas e cujas locas e tocas esses animais buscam abrigo e nidificam (Moojen et al., 1997; Bonvicino et al., 2008). Entretanto, durante a estação seca foram registrados mais indivíduos na mata semidecídua, provavelmente devido à maior densidade de recursos vegetais e oferta de folhas frescas nesse ambiente durante esse período. Por outro lado, na estação chuvosa, em que diversos recursos vegetais estão disponíveis em ambos os ambientes, foram observados mais indivíduos na mata decídua, localizada sobre os afloramentos, que possuem os abrigos que essa espécie utiliza.

Os indivíduos de $K$. acrobata foram encontrados em grande parte dos fragmentos da área de estudo, porém foram mais facilmente observados em locais onde os afloramentos de calcário eram mais elevados e ocorreram mais desmoronamentos. Além da diferença no tipo de vegetação, as observações de campo sugerem que os afloramentos rochosos habitados pelo mocó acrobata na área deste estudo são maiores do que os ocupados por K. rupestris na região estudada por Lacher Jr (1981), que os descreve como "pilhas de rochas". Com isso, aparentemente, o tamanho das áreas de vida pode ser mais flexível e o estabelecimento e a defesa de territórios (Burt, 1943) ocorre de forma diferente, já que indivíduos de $K$. acrobata foram observados realizando marcações por urina e esfregando regiões de glândulas em diferentes substratos, mas principalmente em rochas, ao contrário do observado para seu congênere (Lacher Jr, 1981). Além disso, ao observar os dados obtidos por telemetria, os indivíduos de K. acrobata aparentemente evitaram as áreas de pasto circundantes. Como consequência, as populações residentes em afloramentos inseridos em matrizes compostas por pastos podem diminuir em abundância e até se extinguirem, caso este ambiente alterado se configure em uma barreira para a dispersão, gerando isolamento das populações e comprometendo o fluxo gênico, pois análises sobre as consequências da endogamia materna em K. rupestris indicaram efeitos negativos na sobrevivência de neonatos (Ballou, 1997). Além disso, um distúrbio no ecossistema por si só, como a fragmentação, ou a supressão da vegetação, afetam em primeiro lugar, a densidade populacional de animais (Makarieva et al., 2005). Por outro lado, animais que habitam fragmentos de tamanho maior, ou igual à sua área de vida, podem sobreviver em grandes densidades, porém rapidamente se extinguem, caso fiquem concentrados em áreas significativamente menores que suas áreas de vida naturais (Makarieva et al., 2005), fato comum a grandes predadores, geralmente os maiores afetados pela perda de habitat natural na região do Cerrado. 
Espécies em que machos possuem áreas de vida maiores do que as fêmeas, englobando duas ou mais dessas áreas e defendendo um território, ou recursos dentro deste, podem apresentar um sistema de acasalamento poligínico (Wolff, 2007). Embora as estimativas das áreas de vida dos machos de $K$. acrobata, em relação às fêmeas, tenham sido um pouco maiores, elas não diferiram significativamente. Entretanto, isso pode ter ocorrido devido ao baixo número de indivíduos amostrados e sob a influência de variações individuais, pois a sobreposição média das áreas de vida entre sexos e entre jovens foi maior do que entre indivíduos do mesmo sexo e entre adultos. Os jovens de Kerodon apresentaram as menores áreas de vida e os maiores valores de sobreposição média destas, permanecendo no mesmo local durante todo o período de amostragem, mesmo após o desmame, o que pode estar relacionado ao maior tempo de desenvolvimento dos indivíduos desse gênero em relação a outros da subfamília Caviinae (Roberts et al., 1984), ou à forma com que estabelecem seus territórios (Solomon \& Keane, 2007), aparentemente próximos e com alguma sobreposição ao de seus genitores. Apesar de os tamanhos estimados das áreas de vida não diferirem entre as estações, curvas baseadas no esforço pelo tamanho da área de vida, indicaram que nem todos os indivíduos tiveram suas áreas estabilizadas dentro de cada estação amostrada, embora todas tenham se estabilizado ao contabilizar-se o período inteiro em que cada animal foi monitorado.

O mocó acrobata, embora seja um especialista em hábitats rochosos, também explora, do chão à copa da floresta semidecídua em seu entorno, e utiliza recursos presentes nesse ambiente, principalmente durante a estação seca. Porém, devido ao fato de que este estudo se concentrou principalmente na borda e no entorno dos afloramentos rochosos, a investigação dos hábitos de indivíduos estabelecidos mais ao centro dos afloramentos se mostra necessária, principalmente para verificar se existe uma mudança sazonal para o entorno e se isso ocorre, como ela se dá. Além disso, devido à degradação ambiental da região de ocorrência de $K$. acrobata, os efeitos sobre as populações dessa espécie, resultantes da completa remoção das florestas semideciduais do entorno dos afloramentos rochosos que habitam, devem ser investigados, pois se trata de um roedor amplamente caçado e que possui distribuição restrita, sendo endêmico do Brasil e por isso, encontra-se classificado como "Vulnerável” pelas autoridades brasileiras. 


\subsection{Referências}

Alcock, J. 2010. Comportamento Animal - Uma abordagem evolutiva. 9a Ed. Editora Artmed. Porto Alegre. 606p.

Anderson, D.R.; Laake, J.L.; Crain, B.R. \& Burnham, K.P. 1979. Guidelines for Line Transect Sampling of Biological Populations. The Journal of Wildlife Management, 43(1): 70-78.

Ballou, J.D. 1997. Ancestral inbreeding only minimally affects inbreeding depression in mammalian population. Journal of Heredity 88: 169-178.

Bates, D.; Maechler, M; Bolker, B; Walker, S.; Christensen, R.H.B.; Singmann, H. \& Dai, B. 2014. lme4: Linear mixed-effects models using Eigen and S4. R-package Version 1.1-7. Comprehensive $\mathrm{R}$ Archive Network. http:// cran.rproject.org/package=lme4.

Birney, E.C.; Grant, W.E. \& Baird, D.D. 1976. Importance of vegetative cover to cycles of Microtus populations. Ecology 57(5): 1043-1051.

Brown, J.H. 1984. On the relationship between abundance and distribution of species. The American Naturalist 124(2): 255-279.

Buckland, S.T.; Anderson, D.R.; Burnham, K.P. \& Laake, J.L. 1993. Distance Sampling: Estimating Abundance of Biological Populations. Chapman and Hall, Londres. 446pp.

Buckland, S.T.; Anderson, D.R.; Burnham, K.P.; Laake, J.L.; Borchers, D.L. \& Thomas, L. 2001. Introduction to Distance Sampling. Oxford University Press, Oxford. 432pp.

Burt, W.H. 1943. Territoriality and home range concepts as applied to mammals. Journal of Mammalogy 24(3): 346-352.

Clutton-Brock, T.H. 1989. Mammalian mating systems. Proceedings of the Royal Society of London, Series B 236: 339-372.

Crawley, M.J. 2007. The R Book. John Wiley \& Sons Ltd. West Sussex, Inglaterra. 942p. 
Deitloff, J.; Falcy, M.R.; Krenz, J.D. \& McMillan, B.R. 2010. Correlating small mammal abundance to climatic variation over twenty years. Journal of Mammalogy 91(1): 193-199.

Desbiez, A. \& Tomas, W.M. 2003 Aplicabilidade do método de amostragem de distâncias em levantamentos de médios e grandes vertebrados no Pantanal. Boletim de Pesquisa e Desenvolvimento 53. Embrapa Pantanal, Corumbá. 16p.

Emmons, L.H. 2009. Long-term variation in small mammal abundance in forest and savanna of Bolivian Cerrado. Biotropica 41(4): 493-502.

Hothorn, T.; Zeileis, A.; Farebrother, R.W.; Cummins, C. Millo, G \& Mitchell, D. 2014. lmtest: Testing Linear Regression Models. R-package Version 0.9-33. Comprehensive R Archive Network. http://cran.r-project.org/package=lmtest.

Kelt, D.A. \& Van Vuren, D.H. 2001. The ecology and macroecology of mammalian home range area. The American Naturalist 157(6): 637-645.

Kenward, R.E.; Walls, S.S.; South, A.B. \& Casey, N.M. 2008. Ranges8: For the analysis of tracking and location data. Online manual. Anatrack Ltd. Wareham, Reino Unido.

Lacher Jr, T.E. 1981. The comparative social behavior or Kerodon rupestris and Galea spixii and the evolution of behavior in the Caviidae. Bulletin of Carnegie Museum of Natural History 17: 1-71.

Makarieva, A.M.; Gorshkov, V.G. \& Li, B. 2005. Why do population density and inverse home range scale differently with body size? Implications for ecosystem stability. Ecological Complexity 2: 259-271.

Moojen, J.; Locks, M. \& Langguth, A. 1997.A new species of Kerodon Cuvier, 1825 from the State of Goiás, Brazil (Mammalia, Rodentia, Caviidae).Boletim do Museu Nacional do Rio de Janeiro, Série Zoologia 377: 1-10.

Moraes Jr, E.A. \& Chiarello, A.G. 2005. A radio tracking study of home range and movements of the marsupial Micoureus demerarae (Thomas) (Mammalia, Didelphidae). Revista Brasileira de Zoologia 22(1): 85-91.

Nowak, R.M. 1999. Walker's Mammals of the World. Volume II. 6 a edição. The Johns Hopkins University Press. Baltimore e Londres. 1.100p. 
Ostfeld, R.S. 1985. Limiting Resources and Territoriality in Microtine Rodents. The American Naturalist 126(1): 1-15.

Pinheiro, J.; Bates, D.; DebRoy, S. \& Sarkar, D. 2015. nlme: Linear and Nonlinear Mixed Effects Models. R-package Version 3.1-121. Comprehensive R Archive Network. http://cran.r-project.org/web/packages/nlme.

R Core Team. 2014. R: A Language and Environment for Statistical Computing. R Foundation for Statistical Computing. Vienna, Áustria. http://www.R-project.org

Ribeiro, R. \& Marinho-Filho, J. 2005. Estrutura da comunidade de pequenos mamíferos (Mammalia, Rodentia) da Estação Ecológica de Águas emendadas, Planaltina, Distrito Federal, Brasil. Revista Brasileira de Zoologia 22(4): 898-907.

Ribeiro, R.; Rocha, C.R. \& Marinho-Filho, J. 2011. Natural history and demography of Thalpomys lasiotis (Thomas, 1916), a rare and endemic species from the Brazilian savanna. Acta Theriologica 56(3): 275-282.

Roberts, M.; Maliniak, E. \& Deal, M. 1984. The reproductive biology of the rock cavy, Kerodon rupestris, in captivity: a study of reproductive adaptation in a trophic specialist. Mammalia 48(2): 253-265.

Rooney, S.M.; Wolfe, A. \& Hayden, T.J. 1998. Autocorrelated data in telemetry studies: time to independence and the problem of behavioural effects. Mammalian Review 28(2): 89-98.

Silva, M.; Brimacombe, M. \& Downing, J.A. 2001. Effects of body mass, climate, geography, and census area on population density of terrestrial mammals. Global Ecology \& Biogeography 10: 469-485.

Solomon, N.G. \& Keane, B. 2007. Reproductive strategies in female rodents. Pp. 42-56. In: Wolff, J.O. \& Sherman, P.W. (Eds.) Rodent societies: an ecological \& evolutionary perspective. The University of Chicago Press, Chicago, EUA. 610p.

South, A. 1999. Extrapolating from individual movement behaviour to population spacing patterns in a ranging mammal. Ecological Modelling 117: 343-360.

Thomas, L.; Laake, J.L.; Rexstad, E.; Strindberg, S.; Marques, F.F.C.; Buckland, S.T.; Borchers, D.L.; Anderson, D.R.; Burnham, K.P.; Burt, M.L.; Hedley, S.L.; Pollard, J.H.; Bishop, J.R.B. \& Marques, T.A. 2009. Distance 6.0. Release 2. Research Unit 
for Wildlife Population Assessment, University of St. Andrews, UK. http://www.ruwpa.st-and.ac.uk/distance/

Vieira, M.V. 1997. Dynamics of a rodent assemblage in a Cerrado of Southeast Brazil. Revista Brasileira de Biologia 57(1): 99-107.

White, G.C. \& Garrot, R.A. 1990. Analysis of Wildlife Radio-tracking Data. Academic Press, San Diego. 383p.

Wolff, J.O. 2007. Social biology of rodents. Integrative Zoology 2(4): 193-204.

Zuur, A.F.; Ieno, E.N.; Walker, N.J.; Saveliev, A.A. \& Smith, G. 2009. Mixed Effects Models and Extensions in Ecology with R. Springer, Nova York. 574p. 
Anexo 1 - Descrição dos modelos testados e valor de $\mathrm{p}$, para verificar padrões de autocorrelação temporal no número de mocós observados em Monte Alegre de Goiás, de novembro de 2011 a outubro de 2012, por meio da comparação da qualidade do ajuste dos modelos que consideram a campanha de coleta como variáveis aleatórias.

\begin{tabular}{llc}
\hline \multicolumn{1}{c}{ Modelos } & Teste & p \\
\hline m1.glmer <-glmer (nmocos $~$ cobertura * estacao + & & \\
(1|censo), family = poisson) & & \\
m2.glmer <-glmer (nmocos $\sim$ cobertura * estacao + & m1.glmer, & $<0,001$ \\
$(1 \mid$ censo / campanha), family = poisson) & m2.glmer & \\
\hline
\end{tabular}

Anexo 2 - Descrição dos modelos testados e valor de p, para verificar se as variáveis estação e cobertura são significativas para a variação no número de mocós registrados em Monte Alegre de Goiás, de novembro de 2011 a outubro de 2012.

\begin{tabular}{llc}
\hline \multicolumn{1}{c}{ Modelos } & Teste & p \\
\hline m2.glmer <- glmer (nmocos $\sim$ cobertura * estacao + & & \\
(1|censo / campanha), family = poisson) & & \\
m3.glmer <- glmer (nmocos $\sim$ cobertura + estacao + & m2.glmer, & 0,002 \\
$(1 \mid$ censo / campanha), family = poisson) & m3.glmer & \\
\hline
\end{tabular}

Anexo 3- Descrição dos modelos testados e valor de p, utilizados para comparar o modelo inicial (GLS) com o modelo que considera o indivíduo como fator aleatório (LME), para verificar se há variação nas estimativas do tamanho das áreas de vida (AV) em cada uma das três estações amostradas, em Monte Alegre de Goiás, de fevereiro a dezembro de 2013.

\begin{tabular}{lccc}
\hline \multicolumn{1}{c}{ Modelos } & LRT & Teste & p \\
\hline $\mathrm{m} 1<-$ gls $(\mathrm{AV} \sim$ estacao $*$ npontos $)$ & & & \\
$\mathrm{m} 0<-$ lme $(\mathrm{AV} \sim$ estacao $*$ npontos, random $=$ & 0,606 & $\mathrm{~m} 1, \mathrm{~m} 0$ & 0,436 \\
$(\sim 1$ individuo $))$ & & & \\
\hline
\end{tabular}


Anexo 4- Valor médio estimado para o número de indivíduos de Kerodon acrobata, erro padrão e valores de z e p encontrados para o modelo selecionado (nmocos estacao * cobertura).

\begin{tabular}{lcccc}
\hline & Estimativa & Erro padrão & $\mathbf{z}$ & $\mathbf{p}$ \\
\hline Intercepto - MD chuva & 0,9674 & 0,4192 & 2,308 & 0,021 \\
Cobertura MS & $-2,8792$ & 0,2594 & $-11,098$ & $<0,001$ \\
Estação seca & $-0,2513$ & 0,1732 & $-1,451$ & 0,146 \\
Cobertura MS : estação seca & 0,9468 & 0,3186 & 2,972 & 0,003 \\
\hline
\end{tabular}

Anexo 5 - Descrição dos modelos testados e valor de p, para verificar se as variáveis estação e número de pontos influenciam no tamanho das áreas de vida (AV) de mocós estimadas de fevereiro a dezembro de 2013, em Monte Alegre de Goiás.

\begin{tabular}{lccc}
\hline \multicolumn{1}{c}{ Modelos } & LRT & Teste & p \\
\hline m1<-gls (AV estacao * npontos, method = "ML") & & & \\
m2<-gls (AV estacao + npontos, method = "ML") & 0,289 & $\mathrm{~m} 1, \mathrm{~m} 2$ & 0,866 \\
m3<-gls (AV estacao, method = "ML") & 2,362 & $\mathrm{~m} 2, \mathrm{~m} 3$ & 0,124 \\
m4<-gls (AV npontos, method = "ML") & 0,148 & $\mathrm{~m} 2, \mathrm{~m} 4$ & 0,929 \\
\hline
\end{tabular}




\section{APÊNDICE}
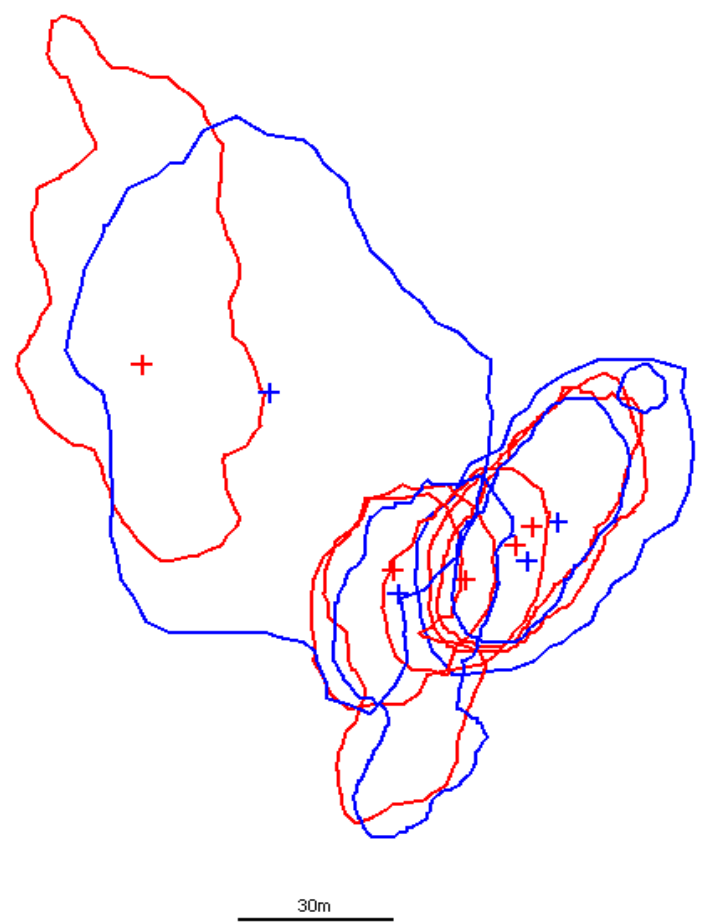

Figura 22 - Áreas de vida estimadas por Kernel-fixo 95\% para machos (azul) e fêmeas (vermelho) de K. acrobata monitorados em 2013 em Monte Alegre de Goiás - GO.
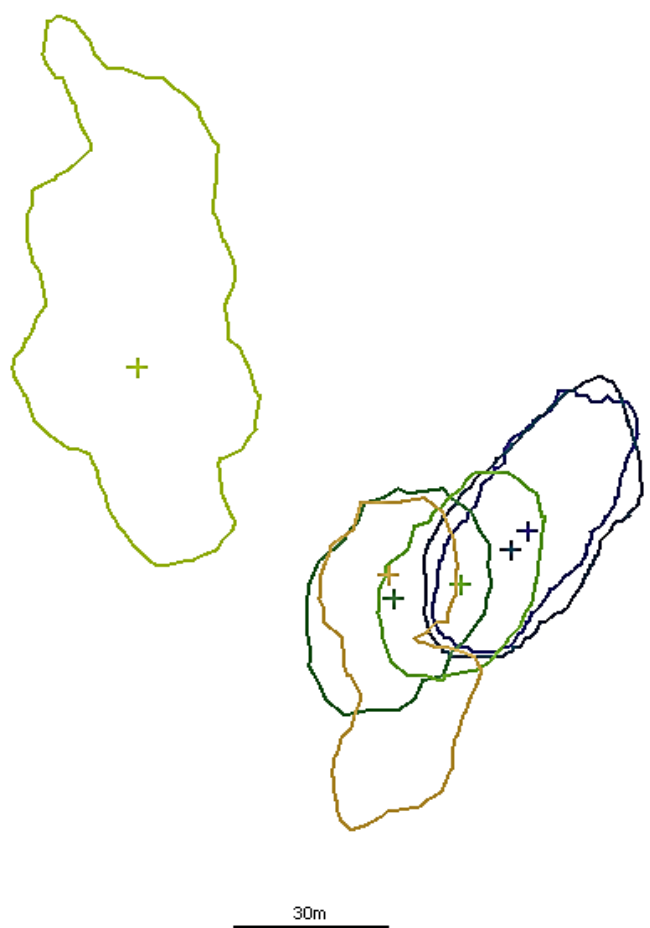

Figura 23 - Áreas de vida estimadas por Kernel-fixo 95\% para fêmeas (cada indivíduo, uma cor diferente) de K. acrobata monitoradas em 2013 em Monte Alegre de Goiás GO. 


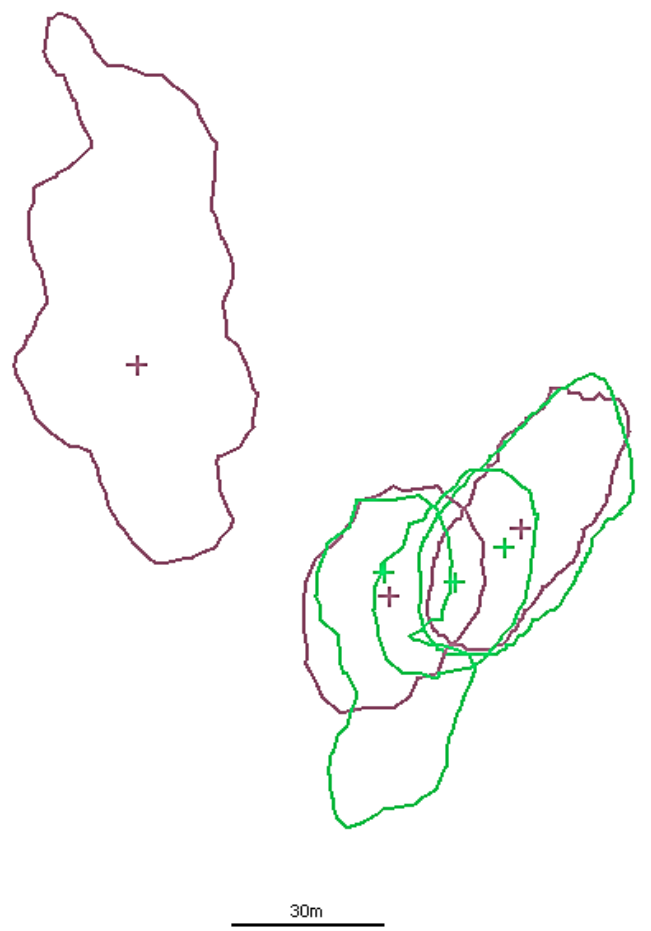

Figura 24 - Áreas de vida estimadas por Kernel-fixo 95\% para fêmeas adultas (roxo) e jovens (verde) de K. acrobata monitoradas em 2013 em Monte Alegre de Goiás - GO.
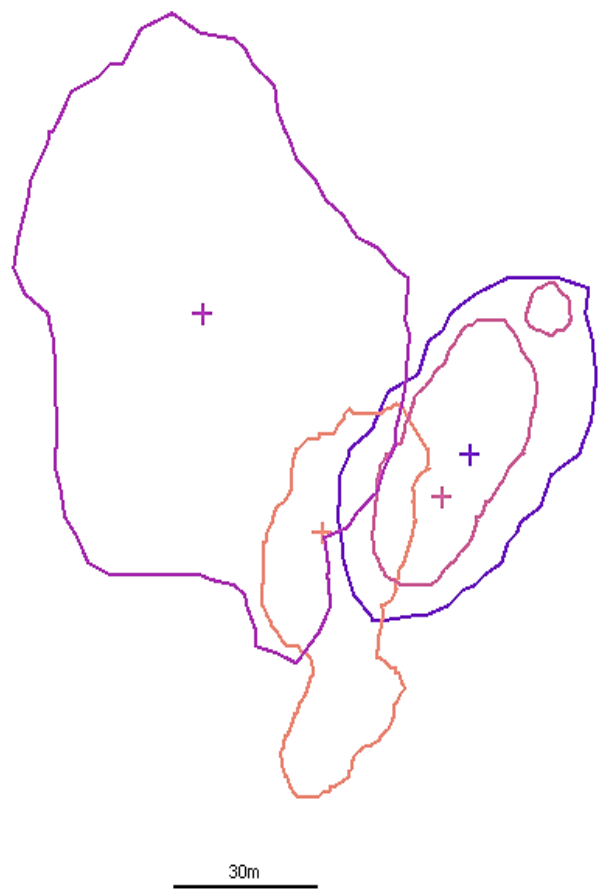

Figura 25 - Áreas de vida estimadas por Kernel-fixo 95\% para machos (cada indivíduo, uma cor diferente) de K. acrobata monitorados em 2013 em Monte Alegre de Goiás. 


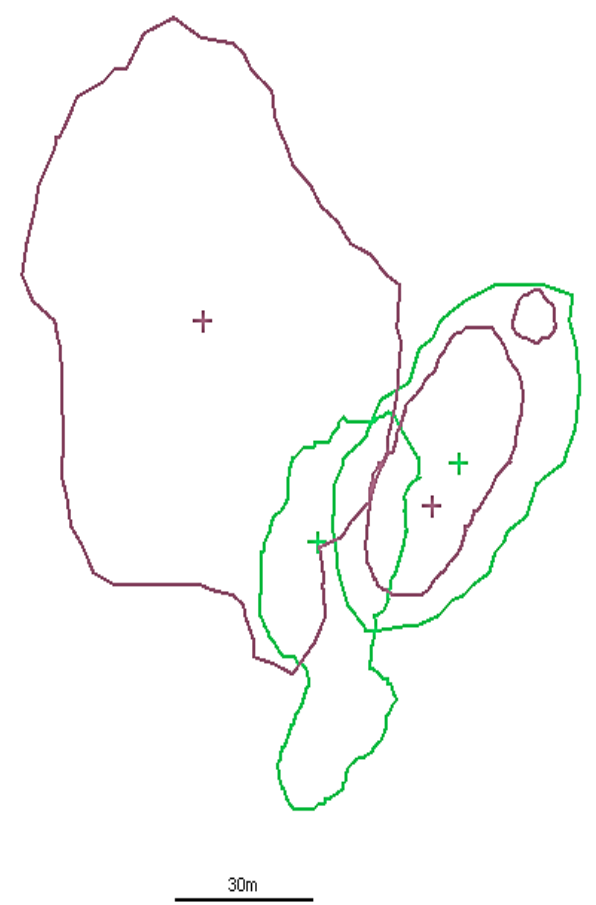

Figura 26 - Áreas de vida estimadas por Kernel-fixo 95\% para machos adultos (roxo) e jovens (verde) de K. acrobata monitorados em 2013 em Monte Alegre de Goiás.
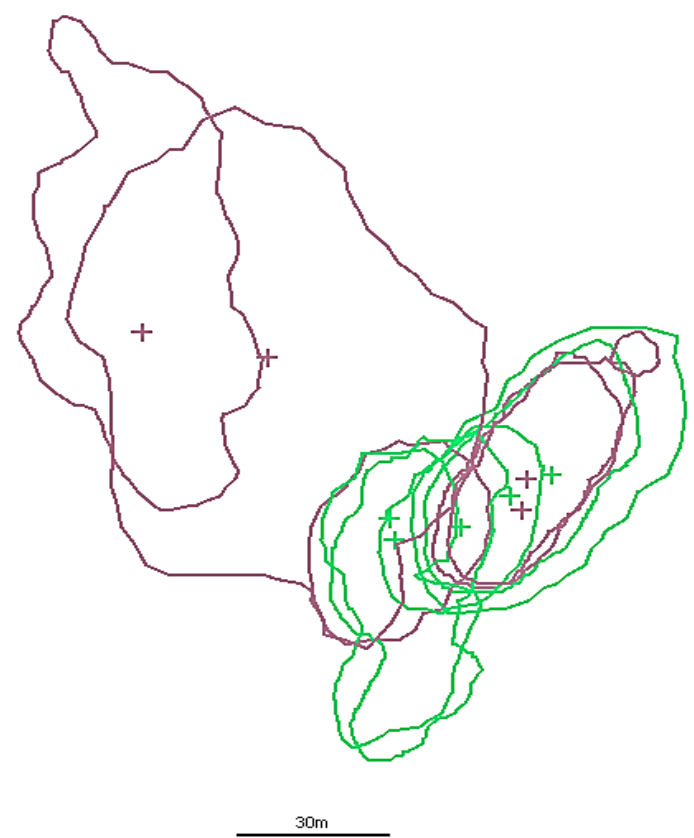

Figura 27 - Áreas de vida estimadas por Kernel-fixo 95\% para adultos (roxo) e jovens (verde) de K. acrobata monitorados em 2013 em Monte Alegre de Goiás - GO. 


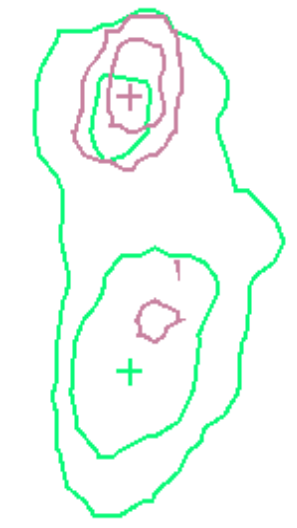

$30 \mathrm{~m}$

(a) Indivíduo 1, fêmea jovem, frequência 174.304.

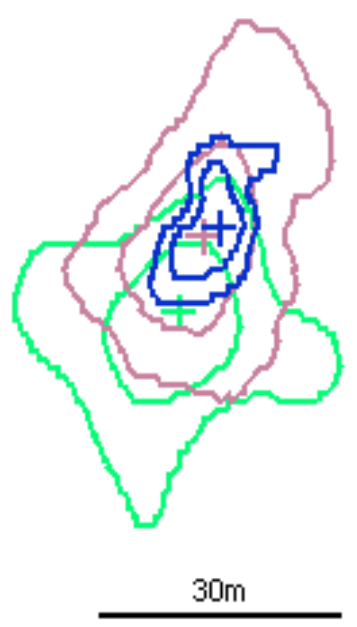

(c) Indivíduo 3, fêmea adulta, frequência 174.636.

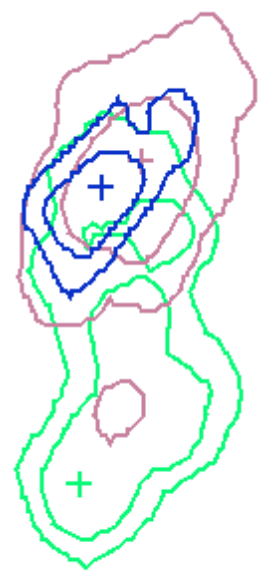

$30 \mathrm{~m}$

(b) Indivíduo 2, macho jovem, frequência 174.990.

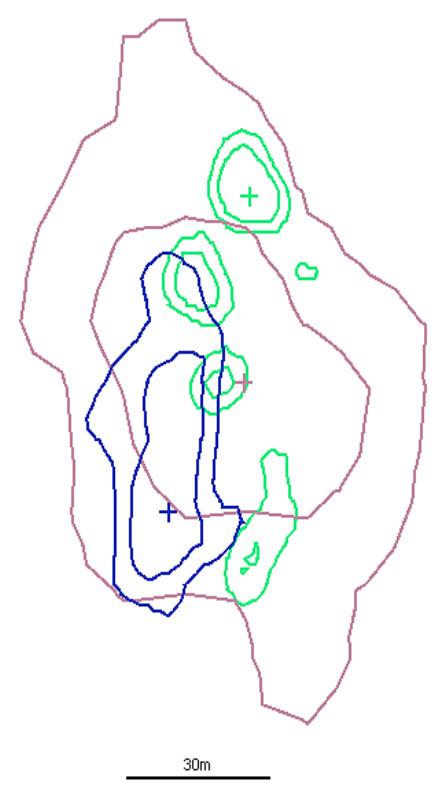

(d) Indivíduo 4, macho adulto, frequência 174.714 . 


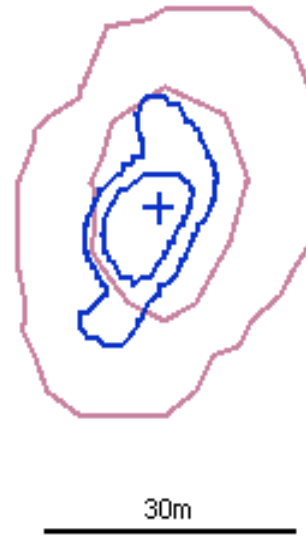

(e) Indivíduo 5, fêmea adulta, frequência 174.545.

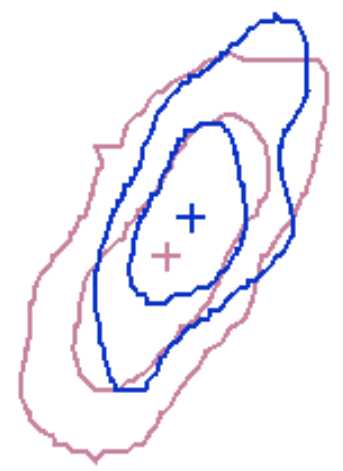

$30 \mathrm{~m}$

(g) Indivíduo 7, fêmea adulta, frequência 148.460.

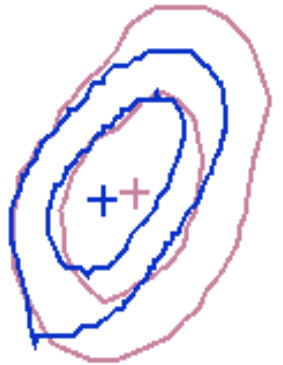

$30 \mathrm{~m}$

(f) Indivíduo 6, fêmea jovem, frequência 174.616.

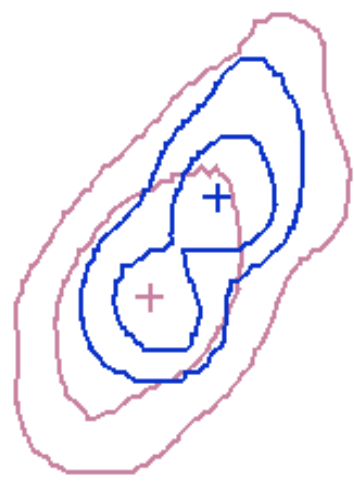

$30 \mathrm{~m}$

(h) Indivíduo 8, fêmea jovem, frequência 148.420. 


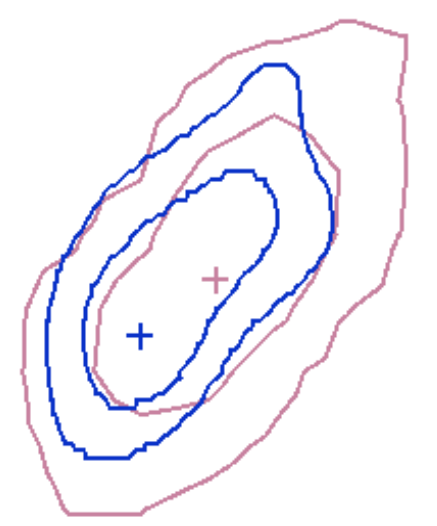

$30 \mathrm{~m}$

(i) Indivíduo 9, macho jovem, frequência 148.520.

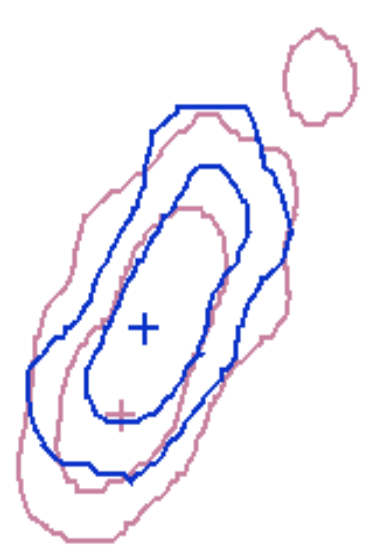

$30 \mathrm{~m}$

(j) Indivíduo 10, macho adulto, frequência 148.260.

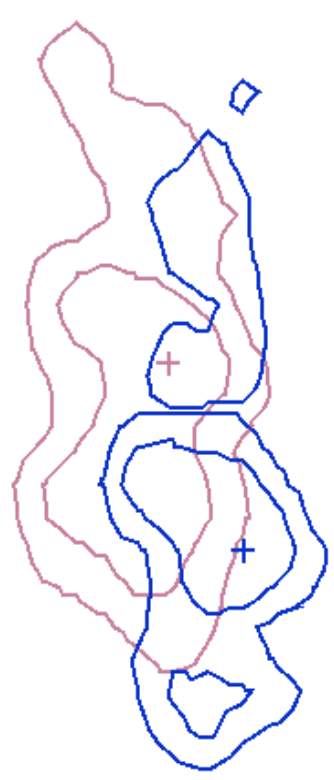

$\diamond$

(k) indivíduo 11, fêmea adulta, frequência 148.181.

Figura 28 - Áreas de vida estimadas por Kernel-fixo 50 e 95\% dos indivíduos de Kerodon acrobata monitorados em 2013 no município de Monte Alegre de Goiás GO: (a) 1, (b) 2, (c) 3, (d) 4, (e) 5, (f) 6, (g) 7, (h) 8, (i) 9, (j) 10 e (k) 11, para a primeira estação chuvosa (verde), a seca (vermelho) e a segunda estação chuvosa (azul), quando houver. Sinal (+): estimativa do centro da área de vida. 


\section{Capítulo 3 - Dieta e amplitude do nicho alimentar de Kerodon acrobata}

\subsection{Introdução}

O alimento é uma das dimensões mais importantes do nicho e a análise da dieta está intimamente relacionada às especificações do nicho de uma espécie (Krebs, 1999). Além disso, a amplitude de nicho é, aparentemente, um fator decisivo na tolerância de uma espécie à perda e fragmentação do habitat e a habilidade de explorar uma ampla variedade de alimentos e habitats é associada à tolerância às alterações antrópicas do ambiente (Swihart et al., 2003). O tipo de recurso ingerido reflete as estratégias de alimentação adotadas pelos animais, pode variar entre diferentes estações e populações (Sassi et al., 2011) e incluir seleção inter e intraespecífica dos recursos (Freeland, 1974; Glander, 1977; Stephens et al., 2006), direcionada pela composição nutricional e concentração de metabólitos secundários da folhagem dos indivíduos vegetais (Moore et al., 2010; Marsh et al., 2014).

Durante períodos de escassez de folhas (e.g., inverno com neve ou estação seca), algumas espécies de mamíferos folívoros podem optar por consumir a casca de plantas lenhosas, utilizando-a junto com a seiva, aparentemente como um recurso de emergência para suprir carências nutricionais ou de água (Baxter \& Hansson, 2001). Nesse caso, pode haver seleção de espécies vegetais e ainda, dos indivíduos em que a concentração desses nutrientes na casca seja maior (Stephens et al., 2006). Entretanto, o aumento no consumo dessas plantas disponíveis durante períodos de escassez de outros recursos, pode levar à redução da reprodução desses browsers (herbívoros cuja dieta é composta por $>50 \%$ de folhas e ramos (Roberts et al., 1984)), devido ao acúmulo em seu organismo, de substâncias tóxicas presentes nas resinas dessas plantas (DeAngelis et al., 2015).

Os danos nas plantas podem ser influenciados pela densidade de animais e pela qualidade do ambiente, incluindo a presença, ou ausência de outras espécies vegetais (Gill, 1992). Galhos roídos podem influenciar negativamente sua sobrevivência e a produção de estruturas reprodutivas, afetando assim, o fitness da planta consumida (Campos et al., 2006), enquanto que tal comportamento aplicado ao caule pode causar a morte do indivíduo consumido (Gill, 1992).

Mamíferos especialistas em ambientes rochosos são fundamentalmente herbívoros, alimentam-se da vegetação usualmente associada ao microhabitat rochoso e tendem a escalar árvores (Mares \& Lacher, 1987). Em regiões altamente sazonais do 
Brasil, como na Caatinga e no Cerrado, os roedores caviídeos do gênero Kerodon estão fortemente associados a tais ambientes. Este gênero é atualmente composto por duas espécies, o mocó $K$. rupestris (Wied, 1820) e o mocó do Cerrado K. acrobata. O roedor caviídeo K. rupestris (Wied, 1820), possui habilidade para escalar rochas, árvores e arbustos e forrageia tanto no chão, quanto em diferentes alturas em árvores (Lacher, 1981; Streilen, 1982; Nowak, 1999), por isso pode ser considerado escansorial (Smythe, 1986), embora alguns autores considerem que as duas espécies do gênero ( $K$. acrobata e $K$. rupestris) apresentem apenas locomoção terrestre (Oliveira \& Bonvicino, 2006; Paglia et al., 2012). Essa espécie forrageia principalmente no final da tarde ou começo da noite, percorrendo os afloramentos rochosos ou escalando árvores (Nowak, 1999) e alimentase de folhas tenras, sendo caracterizada como browser (Roberts et al., 1984), mas também ingere flores e cascas de plantas (Lacher, 1981). Um estudo conduzido por Lacher et al. (1982), visou testar a teoria de forrageamento ótimo, oferecendo a indivíduos cativos espécies de plantas da sua região de ocorrência na Caatinga. Os resultados demonstraram que pode haver uma ordenação no consumo de espécies vegetais em relação à oferta destes recursos. Entretanto, o estudo não conseguiu demonstrar a preferência por um item, como um fenômeno completo ou consistente, pois ao aumentar igualitariamente a quantidade de folhas ofertadas, a ordenação variou (Lacher et al., 1982). Em outro estudo, foi observado que a seleção de itens alimentares por K. rupestris aparentemente está relacionada com a presença de nitrogênio, cálcio, potássio e sódio nas folhas das espécies vegetais disponíveis, com o sódio podendo ser importante para a manutenção do balanço hídrico no ambiente árido que habita (Willig \& Lacher 1991).

A outra espécie do gênero Kerodon, K. acrobata, ocorre em áreas de afloramentos calcários que podem estar associados à vegetação de mata seca (floresta estacional) ou cerrado sensu stricto, onde se alimenta basicamente de folhas (Moojen et al., 1997; Bezerra et al., 2010). Não existem, no entanto, estudos detalhados sobre a dieta de $K$. acrobata na natureza. São conhecidas apenas as observações gerais sobre o uso da vegetação, como Cactaceae e folhas de outras espécies nativas e de mandioca (Manihot sp.) (Moojen et al. 1997). Essa espécie é considerada vulnerável no Brasil (MMA, 2014) e sofre ameaças pela perda do seu habitat e por intensa pressão de caça devido ao seu tamanho grande $(\sim 1 \mathrm{Kg})$ e pela qualidade de sua carne (Bezerra et al., 2010). Pouco se sabe sobre a biologia desse roedor e por isso, o seu estado de conservação segundo a International Union for Conservation of Nature (IUCN) é classificado na categoria "dados insuficientes" (DD) (Langguth \& Reis, 2008). Kerodon acrobata é uma espécie 
especialista em relação ao uso de hábitats rochosos e por esse ser um tipo de hábitat menos comum em sua área de distribuição, é aparentemente rara.

Como as outras formações vegetais associadas ao Cerrado, a mata seca está sujeita a intensa variação climática sazonal, pois nesse bioma há estações de chuva e seca anuais bem demarcadas (Nascimento et al., 2004; Felfili et al., 2007). Isso resulta em diversos níveis de caducifólia durante a estação seca nesse tipo de mata, pois apesar de ocorrer em solos geralmente mais ricos em nutrientes, esses estão localizadas sobre terrenos bem drenados (Ribeiro \& Walter, 1998). Sabe-se que florestas estacionais localizadas sobre afloramentos de rochas perdem, quase que totalmente, as folhas durante a estação seca e são denominadas florestas estacionais decíduas, enquanto que parte das que ocorrem em solos planos mantêm 50\% ou mais de cobertura, sendo denominadas semideciduais (Felfili et al., 2005). Esse tipo de ambiente, se não estiver associado a um curso d'água, pode apresentar características xéricas, contando inclusive, com a presença de cactáceas. Portanto, o conhecimento das variações sazonais no comportamento alimentar de herbívoros em florestas secas, onde a disponibilidade e qualidade dos recursos vegetais podem variar drasticamente ao longo do ano, pode ser crucial para a compreensão da ecologia desses herbívoros e sua conservação. A ecologia alimentar de pequenos mamíferos que habitam outros ambientes áridos, como o deserto, é bastante diversa ao redor do mundo. Enquanto mamíferos de pequeno e médio portes que habitam essas áreas na América do Sul adotam primariamente, estratégias tróficas de onivoria e herbivoria, respectivamente, na África do Sul esse grupo é predominantemente herbívoro, na América do Norte e em Israel é granívoro e na Austrália é onívoro e insetívoro (Campos et al., 2001). Dentro desse contexto de ambientes xéricos, os caviomorfos (Hystricognathi da América do Sul) são todos herbívoros (Ojeda et al., 2000). As variações nas estratégias de comportamento alimentar podem ser cruciais para a colonização e sobrevivência de pequenos mamíferos em ambientes xéricos ou que passam por gargalos nutricionais ao longo do ano, como em ambientes quem possuem uma estação seca marcada (Sassi et al., 2007; Sassi et al., 2011).

Não existem estudos direcionados sobre a dieta de $K$. acrobata na natureza e sobre a existência, ou não, de variação sazonal na composição desta. São conhecidas apenas as observações gerais sobre o uso da vegetação, como Cactaceae e folhas de outras espécies nativas e de mandioca (Manihot sp.), realizadas por Moojen et al. (1997).

No presente estudo, investiguei a dieta e o comportamento alimentar do raro mocó K. acrobata, em áreas de mata seca no ambiente de Cerrado do Brasil central. Os 
objetivos foram identificar os itens consumidos e investigar possíveis variações sazonais no comportamento alimentar dessa espécie ao longo do ano, descrevendo os itens consumidos em cada estação (seca e chuvosa). Para tanto, foram testadas as seguintes hipóteses:

1) O nicho alimentar de K. acrobata varia entre as estações. Em decorrência da diminuição da oferta de folhas frescas, como consequência da perda de folhas das espécies caducifólias e da maior oferta de outros itens vegetais sazonais (e.g. flores, frutos) durante a seca, suponho que a amplitude de nicho aumente nessa estação.

2) Mesmo no caso da manutenção da amplitude de nichos alimentares semelhantes em ambas as estações, $K$. acrobata pode explorar diferentes recursos alimentares em cada estação. Devido à variação sazonal na oferta de itens de origem vegetal, espero que $K$. acrobata exiba uma plasticidade alimentar, mudando o seu comportamento alimentar durante o ano.

\subsection{Materiais e métodos}

\subsection{1 Área de estudo}

Idem item 1.2.1.

\subsubsection{Coleta de dados}

Investiguei o comportamento alimentar de Kerodon acrobata por meio de observação ad libitum de indivíduos forrageando na área de estudo, com auxílio de binóculo (modelo Action, 10 x 50 mm (ampliação x abertura) - Nikon Inc., El Segundo, CA, USA). Classifiquei os itens alimentares observados sendo ingeridos em categorias (Tabela 7), sem levar sua taxonomia em conta (Krebs, 1999), pois não foi possível identificar a espécie vegetal de grande parte desses recursos durante as observações de campo (e.g. plântulas e folhas e outros recursos caídos na serrapilheira).

As espécies vegetais que puderam ter amostras coletadas foram classificadas no menor nível taxonômico possível. Coletei amostras contendo galhos, folhas e quando possível, flores e frutos, com o auxílio de tesoura de poda, ou podão, as quais foram acomodadas em prensas para secagem e posterior identificação. A identificação das amostras se deu a partir de consulta ao material de referência do herbário da Universidade 
de Brasília e com auxílio de especialistas. Para cada amostra foram registrados dados de coordenadas geográficas, data, tipo de substrato e de cobertura vegetal.

Tabela 7 - Classe e descrição dos itens vegetais consumidos por Kerodon acrobata observados durante as campanhas de coleta de dados em área de Floresta Seca em Monte Alegre de Goiás - GO, no Cerrado do Brasil central, de novembro de 2011 a novembro de 2013.

\begin{tabular}{ll}
\hline \multicolumn{1}{c}{ Classe } & \multicolumn{1}{c}{ Descrição } \\
\hline Folhas & Folhas consumidas diretamente de plantas. \\
Folhas caídas & Folhas secas encontradas sobre solo ou rochas. \\
Flores & Flores consumidas diretamente de plantas. \\
Flores caídas & Flores encontradas sobre o solo ou rochas. \\
Frutos & Frutos consumidos diretamente de plantas. \\
Frutos caídos & Frutos encontrados sobre o solo ou rochas. \\
Frutos de Manga & Frutos da espécie exótica Mangifera indica L. \\
Recursos caídos não identificados & Recursos consumidos da serrapilheira, \\
& encontrados sobre o solo, ou rochas, que não \\
puderam ser observados durante a ingestão e não \\
puderam ser classificados nas demais categorias.
\end{tabular}

\subsubsection{Análises dos dados}

Para estimar a amplitude do nicho alimentar de $K$. acrobata foi utilizado o índice de diversidade de Shannon-Wiener (H') (Krebs, 1999). Posteriormente comparei estes índices utilizando o teste t de Hutchenson (Zar, 1999). Ambas as análises foram realizadas no programa PAST versão 2.17 (Hammer et al., 2001). O índice de Shannon inclui uma 
correção de viés e pode diferir levemente das estimativas não corrigidas calculadas em outros módulos do PAST, ao menos para amostras pequenas. Com: $p_{i}$ a proporção (0-1) do táxon $i, \mathrm{~S}$ o número de táxons e $\mathrm{N}$ o número de indivíduos, o estimador do índice é:

$$
H^{\prime}=-\sum_{i=1}^{S} p_{i} \ln p_{i}-\frac{S-1}{2 N}
$$

Verifiquei se existiu diferença sazonal no comportamento alimentar, comparando as frequências observadas dos itens consumidos entre as duas estações, realizando o testeg, utilizando as categorias de itens da Tabela 7.

\subsection{Resultados}

Realizei, no total, 342 observações de mocós consumindo recursos alimentares durante a estação seca e 343 observações durante a chuvosa. Dois registros foram descartados das análises, um em cada estação, pois consistiram no consumo de brotos de ramos e de cascas de plantas, os quais foram descartados, pois foram observados uma única vez cada. Observei os mocós consumindo itens vegetais variados, obtidos de plântulas até indivíduos adultos e desde o sub-bosque até o dossel. Eles consumiram folhas, flores, frutos, brotos de ramos e cascas de plantas e também forragearam em busca de folhas, flores e frutos da serrapilheira (Figura 29), encontrados sobre o solo e os afloramentos rochosos. Considerando os indivíduos marcados e os diferentes pontos em que realizei as observações, estimo que ao menos 125 indivíduos foram observados se alimentando na estação chuvosa e 96 na seca.

Em apenas $26 \%$ das observações foi possível determinar um nível taxonômico dos recursos consumidos $(\mathrm{n}=97)$. Registrei mocós consumindo 22 espécies vegetais, distribuídas em 16 famílias, incluindo a exótica Mangifera indica L., que teve seus frutos consumidos (Tabela 8). Levantamentos não-padronizados identificaram ao menos 42 famílias de plantas na área de estudo. Dentre as espécies nativas, 12 foram identificadas ao nível de espécie e uma delas encontra-se presente na Lista Nacional das Espécies da Flora Brasileira Ameaçadas de Extinção (MMA, 2008), a aroeira (Myracrodruon urundeuva Allemão). 
A amplitude de nicho, calculada pelo índice de diversidade de Shannon, foi de H' = 1,192 na estação chuvosa e H' = 1,276 na estação seca, porém esta diferença não foi significativa $(\mathrm{t}=-1,195 ; \mathrm{g} .1 .=677,05 ; \mathrm{p}=0,23)$. Todas as classes de recursos foram observadas sendo exploradas durante as duas estações, exceto as flores caídas, que não tiveram o consumo registrado durante a estação chuvosa (Figura 31). Essa diferença foi causada principalmente pelo aumento nos itens (folhas e flores) consumidos da serapilheira na estação seca, ao passo que mais itens retirados de plantas foram consumidos durante a estação chuvosa. Os itens mais frequentemente observados sendo consumidos foram folhas (70\%), seja diretamente de plantas (38\%) ou da serrapilheira (32\%) (Figura 29). Flores (Figura 30) compreenderam o segundo item mais consumido (6\%), seguidas por frutos e manga (analisada separadamente, por ser uma espécie exótica). Aproximadamente 52\% $(\mathrm{n}=359)$ dos itens que os mocós foram observados consumindo, foram de recursos obtidos da serrapilheira (caídos sobre o solo ou afloramentos rochosos), os quais não seria possível identificar o táxon por meio de observações à distância (i.e. folhas e outros recursos caídos). 


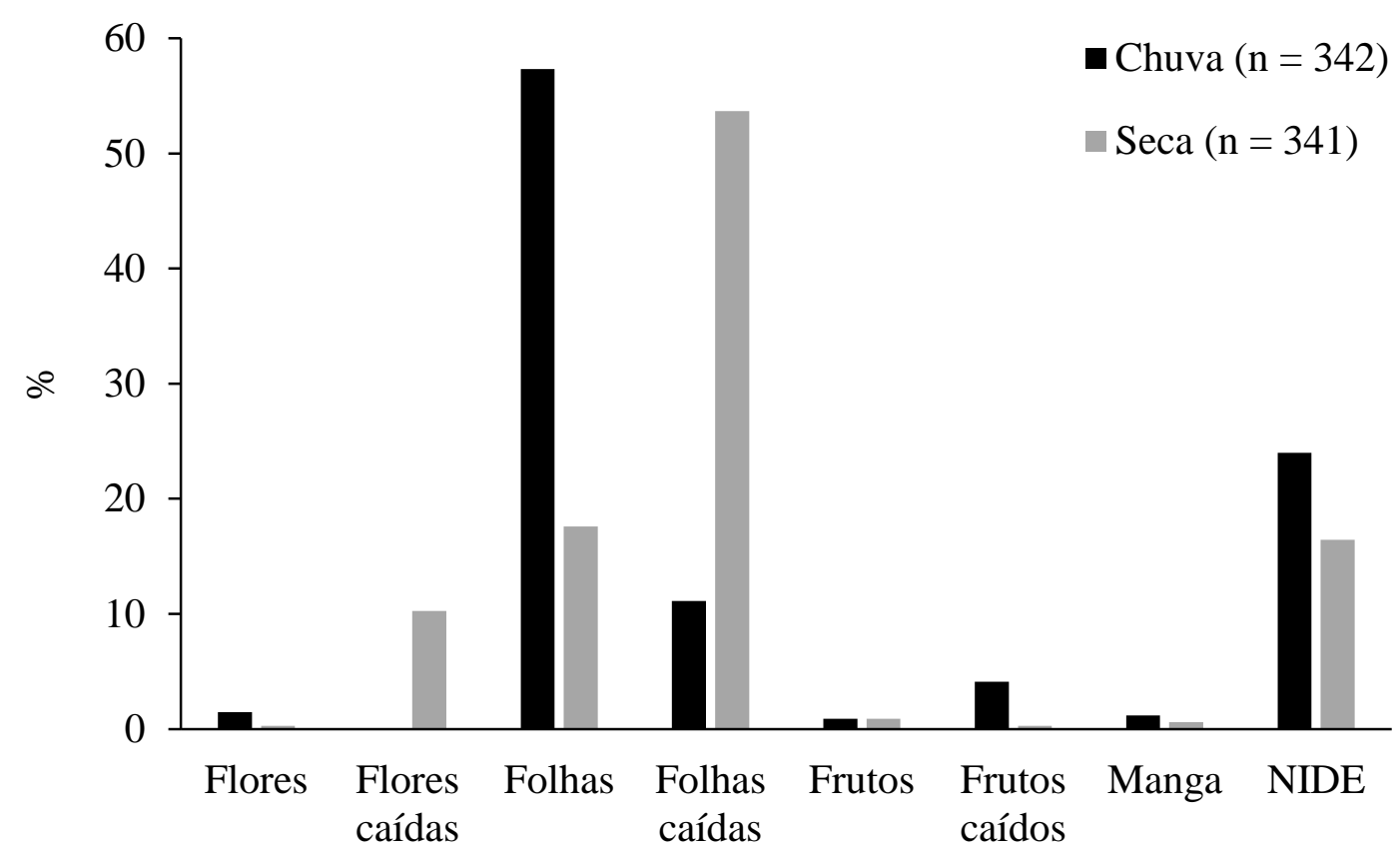

Categorias de itens alimentares

Figura 29 - Porcentagem de itens alimentares consumidos por Kerodon acrobata nas estações seca e chuvosa, de novembro de 2011 a novembro de 2013, no município de Monte Alegre de Goiás, Goiás, Brasil. NIDE: itens não-identificados coletados a partir da serrapilheira. 


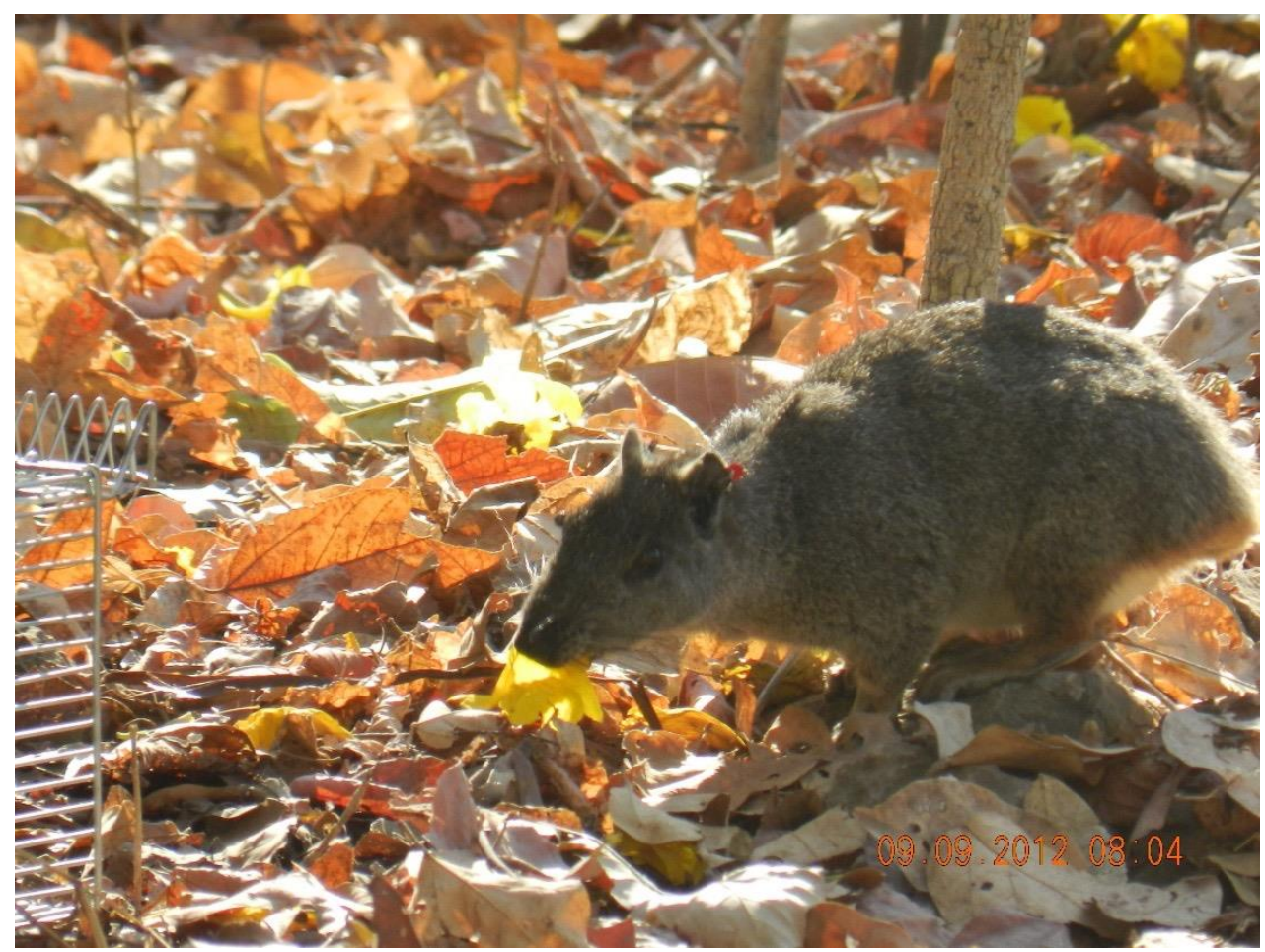

Figura 30 - Indivíduo de Kerodon acrobata alimentando-se de flor de Handroanthus serratifolius encontrada sobre a serrapilheira, em Monte Alegre de Goiás, GO.

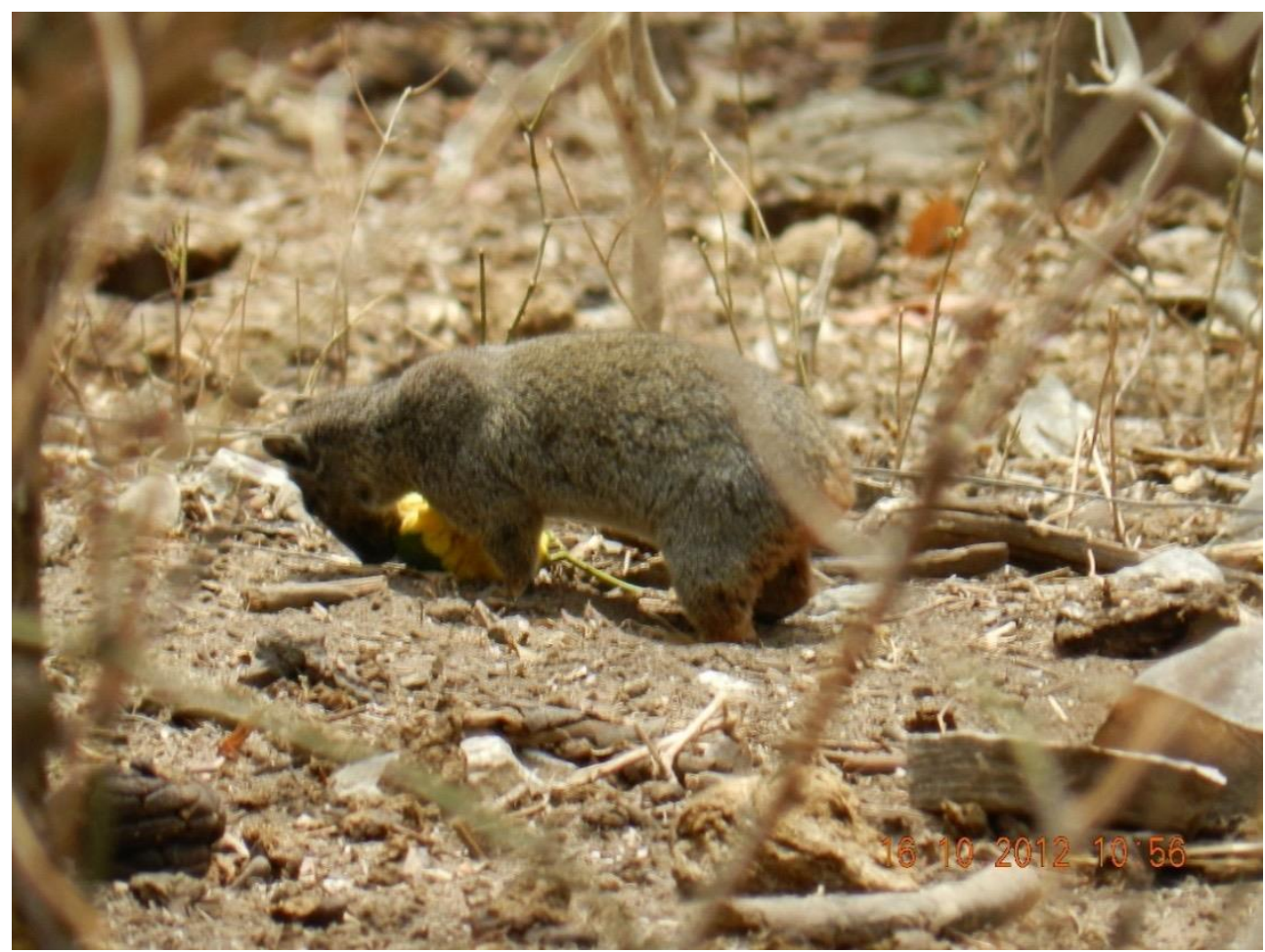

Figura 31 - Indivíduo de Kerodon acrobata alimentando-se de fruto caído de Mangifera indica em Monte Alegre de Goiás, GO. 
Tabela 8 - Lista de espécies vegetais observadas sendo consumidas por Kerodon acrobata, por estação, em Monte Alegre de Goiás - GO, de novembro de 2011 a novembro de 2013 e que puderam ser classificadas em algum nível taxonômico.

\begin{tabular}{|c|c|c|c|c|c|}
\hline \multirow{2}{*}{ Família } & \multirow{2}{*}{ Espécie } & \multirow{2}{*}{ Nome popular } & \multirow{2}{*}{$\begin{array}{c}\text { Itens } \\
\text { ingeridos }\end{array}$} & \multicolumn{2}{|c|}{ Estação } \\
\hline & & & & Chuva & Seca \\
\hline Anacardiaceae & Mangifera indica* & Mangueira & Frutos & 4 & 2 \\
\hline Anacardiaceae & Myracrodruon urundeuvat & Aroeira & Folhas e frutos & 4 & 1 \\
\hline Anacardiaceae & Spondias mombi & Cajazinho, taperebá & Folhas e frutos & 12 & 0 \\
\hline Apocynaceae & Aspidosperma sp. & - & Folhas & 1 & 0 \\
\hline Bignoniaceae & Handroanthus serratifolius & Ipê-amarelo & Flores & 0 & 26 \\
\hline Bignoniaceae & Jacaranda brasiliana & Jacarandá-boca-de-sapo & Folhas & 1 & 0 \\
\hline Bignoniaceae & Tabebuia roseoalba & $\begin{array}{l}\text { Ipê-branco, ipê-do- } \\
\text { cerrado }\end{array}$ & Folhas & 1 & 0 \\
\hline Boraginaceae & - & - & Folhas & 1 & 0 \\
\hline Cannabaceae & Celtis sp. & - & Folhas & 11 & 12 \\
\hline Caricaceae & Jacaratia corumbensis & Mamãozinho-de-veado & Folhas & 0 & 1 \\
\hline Cucubitaceae & - & - & Folhas & 1 & 0 \\
\hline Fabaceae & Bauhinia sp. & Pata-de-vaca & Folhas & 0 & 1 \\
\hline Fabaceae & $\begin{array}{c}\text { Enterolobium } \\
\text { contortisiliquum }\end{array}$ & Orelha-de-macaco & Frutos & 5 & 0 \\
\hline Malpighiaceae & - & - & Folhas & 1 & 0 \\
\hline Malvaceae & Ceiba speciosa & Paineira, barriguda & Flores & 0 & 5 \\
\hline Moraceae & Ficus sp. & - & Folhas & 0 & 1 \\
\hline Phyllanthaceae & Margaritaria nobilis & Figueirinha & Folhas & 1 & 0 \\
\hline Piperaceae & Piper sp. & Jaborandi & Folhas e frutos & 14 & 4 \\
\hline Polygonaceae & Triplaris gardneriana & Pajaú, pau-formiga & Folhas & 0 & 1 \\
\hline Sapindaceae & Dilodendron bipinnatum & Mamoninha & Folhas & 1 & 2 \\
\hline Sapindaceae & Serjania sp. & Cipó & Folhas & 3 & 1 \\
\hline Sterculiaceae & Guazuma ulmifolia & Mutamba & Folhas & 1 & 2 \\
\hline
\end{tabular}

Legenda: * Espécie exótica. ${ }^{\dagger}$ Espécie ameaçada. 


\subsection{Discussão}

Os mocós acrobatas podem ser classificados como herbívoros generalistas, já que foram observados consumindo folhas, flores, frutos, brotos de ramos e cascas de plantas. A amplitude de nicho alimentar de K. acrobata não diferiu entre as estações. Apesar de as observações indicarem que os mocós exploram as classes de recursos alimentares em quantidade diferente entre as estações, indicando uma diferença sazonal na frequência de consumo dos itens, estes são praticamente os mesmos, exceto as flores caídas, que não foram registras sendo consumidas durante a estação chuvosa. Porém, é possível perceber que a dieta dos mocós do Cerrado é influenciada pela queda das folhas e flores durante a seca, na serrapilheira, onde esses animais passaram a concentrar mais as suas atividades de forrageio. Portanto, o mocó acrobata não amplia seu repertorio comportamental de forrageio na seca, mas sim, muda sazonalmente a sua estratégia de exploração dos recursos, alterando a proporção em que os consome.

Os resultados obtidos indicam que mais de $50 \%$ da dieta de $K$. acrobata foi composta por folhas e por isso, esse roedor pode ser considerado um browser, assim como K. rupestris (Roberts et al., 1984). A maioria dos mamíferos folívoros não apresenta especialização na dieta, explorando mais de uma espécie, possivelmente para evitar uma limitação relacionada à demanda de nutrientes essenciais (Westoby, 1978), ou devido à incapacidade fisiológica de desintoxicação frente a elevadas concentrações de metabólitos secundários (toxinas) com composição química semelhante, que se encontram nas folhas de uma única espécie e em congêneres (Freeland \& Janzen, 1974; Dearing et al., 2000; Wiggins, et al., 2006). Por exemplo, na Costa Rica, bandos de Alouatta paliata (Gray, 1849), um primata folívoro, foram observados selecionando espécies vegetais menos abundantes, cujas folhas contêm menor concentração de alcaloides tóxicos e tanino, além de maiores concentrações de proteína e em alguns casos ingeriram apenas o pecíolo, descartando a folha laminar (Glander, 1977). Mesmo entre as espécies selecionadas, esse primata pode se alimentar somente dos indivíduos com as menores concentrações destas substâncias nas folhas. Apesar de viverem cercados por folhas, estes animais forrageiam cuidadosamente, aumentando o tempo e o custo energético dessa atividade (Glander, 1977). Em ambientes áridos, a quantidade de folhas verdes ingeridas por roedores foi positivamente correlacionada com a reprodução desses animais (Reichman \& Van de Graaff, 1975). Por outro lado, o aumento na densidade de pequenos mamíferos herbívoros pode exaurir os recursos alimentares preferenciais e 
consequentemente forçar os indivíduos a consumirem espécies vegetais tóxicas, o que pode resultar no aumento da mortalidade desses animais (Freeland, 1974).

Uma estratégia alimentar oportunista, baseada na plasticidade do fenótipo de comportamento alimentar, pode se manifestar em caviídeos, como no caso de Microcavia australis em que diferentes populações apresentam desde uma dieta especialista, com maior concentração de metabólitos secundários, até a generalista com baixas doses de diferentes compostos secundários (Sassi et al., 2011). Nossos resultados indicaram que $K$. acrobata também apresenta dieta generalista em relação ao consumo de folhas, com ao menos, 15 famílias nativas consumidas. Entretanto, os mocós também aparentam exibir preferência alimentar, ao menos sazonal. Mas não foi possível determinar se essa preferência é inter ou intraespecífica. Por exemplo, dentre os indivíduos vegetais registrados tendo as folhas consumidas, um indivíduo de aroeira (M. urundeuva) cuja exploração foi intensa, resultou em galhos com poucas folhas, localizadas apenas nas extremidades dos ramos, o que não ocorreu com as outras árvores em sua vizinhança, as quais não aparentavam desfolhação. Essa sobre-exploração com uma aparente seleção, pode ser o reflexo de uma melhor composição nutricional em suas folhas, menor concentração de metabólitos secundários, ou maior palatabilidade destas (Moore et al., 2010; Marsh et al., 2014). Entretanto, os mocós foram observados alimentando-se frequentemente, não somente de folhas retiradas diretamente de plantas, mas também de folhas da serrapilheira. Os indivíduos observados consumindo folhas, aparentemente não fizeram distinção entre ingerir somente pecíolo, ou lâmina foliar e somente em uma oportunidade, um único indivíduo foi registrado comendo apenas pecíolos de algumas folhas da serrapilheira.

Diversos mocós foram observados alimentando-se de frutos, tanto na estação seca, quanto na chuvosa, embora não houvesse, até o momento, informações sobre este comportamento na literatura. O consumo dos frutos de cajazinho (Spondias mombi) foi intenso durante a frutificação observada em 2012, com observações de mocós se alimentando e diversos registros de frutos roídos (obs. pessoal). Em 2013, não houve tais registros e os frutos da serrapilheira, diferentemente do ano anterior, não apresentavam sinais característicos da dentição dos mocós. Frutos de orelha-de-macaco (Enterolobium contortisiliquum) foram observados sendo consumidos, porém não suas sementes e somente na frutificação de 2012. Entretanto, em 2013, não houve tais registros. Estes frutos são indeiscentes e possuem sementes zoocóricas que podem medir de 1,05 a 1,64 cm de comprimento e de 0,64 a 1,10 cm de largura (Stefanello et al., 2009; Barreto \& 
Ferreira, 2011). O consumo dos frutos de manga (Mangifera indica) indica uma adaptação à oferta dessa abundante fonte de alimento sazonal introduzida pelo homem e sua influência no fitness reprodutivo de $K$. acrobata poderia ser investigada.

Embora Moojen et al. (1997) tenham relatado o consumo de cactos por $K$. acrobata, nenhum mocó foi registrado alimentando-se desse tipo de vegetal na área de estudo, apesar dele ser frequentemente encontrado sobre os morros, nem sinais evidentes deste comportamento foram observados. Somente em uma oportunidade, um indivíduo foi observado alimentando-se de ramos verdes, do cipó Serjania sp., embora esse comportamento deva se manifestar mais frequentemente.

Apesar de diversas plantas terem sido observadas com as cascas roídas e muitas das marcas presentes nos caules e galhos se assemelharem à dentição de K. acrobata, somente um indivíduo foi observado roendo a casca de uma planta. Porém esse item alimentar não foi incluído nas análises, pois não foi possível precisar quando os outros eventos ocorreram. Além disso, tal comportamento também foi observado uma outra vez, porém fora da área de estudo, em uma área de mata decídua em Aurora do Tocantins, TO, quando um indivíduo roeu a casca do caule de um cipó (obs. pessoal). O comportamento de roer o caule de plantas também foi relatado por Lacher (1981) para K. rupestris, e relatos anedóticos de visitantes da ilha de Fernando de Noronha, onde foi introduzido (Olson, 1981), apontam o consumo desse recurso, colocando em risco a sobrevivência de algumas árvores exploradas. As cascas de árvores são consumidas por diversos mamíferos, principalmente em situações críticas, como durante a seca e provavelmente, em busca de determinados nutrientes, como cálcio, potássio ou sódio e também, água (Baxter \& Hansson, 2001; Stephens et al., 2006). Pequenos mamíferos herbívoros ao removerem a casca de uma planta, completando um anel no tronco, podem causar a morte desta e a prevenção dos estragos e prejuízos que podem ser causados em reflorestamentos e plantações comerciais de espécies lenhosas não é considerada uma tarefa simples (Gill, 1992; Baxter \& Hansson, 2001). A crescente conversão das matas semidecíduas que circundam os afloramentos habitados por K. acrobata, em pastos (Bianchi \& Haig, 2013), diminuindo a oferta de folhas, flores e outros recursos durante a estação seca, pode influenciar a dieta desse roedor, aumentando o consumo de casca dos caules de plantas nas matas decíduas e consequentemente, afetando a sobrevivência de plântulas e indivíduos adultos.

O mocó $K$. acrobata, durante suas atividades de forrageio, escala os afloramentos rochosos e os arbustos e árvores, habilmente passando de uma planta a outra, movendo- 
se pela copa. Adicionalmente, explora o solo no entorno dos afloramentos em busca de alimento, assim como seu congênere K. rupestris (Lacher, 1981) e, portanto, pode ser considerado um animal escansorial (Smythe, 1986) e não somente de locomoção terrestre, como descrito em algumas revisões literárias (Oliveira \& Bonvicino, 2006; Paglia et al., 2012). Entretanto, nenhum mocó foi observado forrageando, ou deslocando-se, fora dos fragmentos de mata seca, seja na matriz de pastos, ou estradas adjacentes e somente foram vistos deslocando-se até a borda da floresta semidecídua. Embora habite fragmentos de mata seca, degradados em diversos locais e isolados por pastos, a amplitude do nicho alimentar do mocó do Cerrado (ao menos 16 famílias vegetais exploradas) pode ser um fator que possibilita sua persistência nesses ambientes alterados, já que a largura de nicho é positivamente relacionada à tolerância de espécies de mamíferos à alteração do habitat (Swihart et al., 2003). Embora $K$. acrobata seja um animal especialista em habitats rochosos, esse relevo rugoso dificulta a exploração, pelo homem, de plantas nativas que servem de alimento para esse roedor. Por outro lado, dependendo da intensidade das alterações antrópicas, a estreita relação dessa espécie com ambientes rochosos e com os fragmentos florestais estudados, pode tornar esses animais vulneráveis às ações que ameaçam a integridade desses ambientes, como a mineração e o fogo, amplamente utilizado pela população rural no manejo das terras cultivadas. 


\subsection{Referências bibliográficas}

Barreto, S.S.B. \& Ferreira, R.A. 2011. Aspectos morfológicos de frutos, sementes, plântulas e mudas de Leguminosae Mimosoideae: Anadenanthera colubrina (Vellozo) Brenan e Enterolobium contortisiliquum (Vellozo) MORONG. Revista Brasileira de Sementes 33(2): 223-232.

Baxter, R. \& Hansson, L. 2001. Bark consumption by small rodents in the northern and southern hemispheres. Mammal Review 31(1): 47-59.

Bezerra, A.M.R.; Bonvicino, C.R.; Menezes, A.A.N. \& Marinho-Filho, J. 2010. Endemic climbing cavy Kerodon acrobata (Rodentia: Caviidae: Hydrochoerinae) from dry forest patches in the Cerrado domain: new data on distribution, natural history, and morphology. Zootaxa 2724: 29-36.

Bianchi, C.A. \& Haig, S.M. 2013. Deforestation trends of tropical dry forests in Central Brazil. Biotropica 45(3): 395-400.

Campos, C.; Ojeda, R.; Monge, S. \& Dacar, M. 2001. Utilization of food resources by small and medium-sized mammals in the Monte Desert biome, Argentina. Austral Ecology 26(2): 142-149.

Campos, C.M.; Borghi, C.E.; Giannoni, S.M.; Mangeaud, A. \& Tognelli, M.F. 2006. Bark consumption of creosote bush (Larrea cuneifolia) by cuises (Microcavia australis): effect on branch survival and reproduction. Ecología Austral 16(1): 1-6.

DeAngelis, D.L.; Bryant, J.P.; Liu, R.; Gourley, S.A.; Krebs, C.J. \& Reichardt, P.B. 2015. A plant toxin mediated mechanism for the lag in snowshoe hare population recovery following cyclic declines. Oikos 124(6): 796-805.

Dearing, M.D.; Mangione, A.M. \& Karasov, W.H. 2000. Diet breadth of mammalian herbivores: nutrient versus detoxification constraints. Oecologia 123(3): 397-405.

Felfili, J.M.; Carvalho, F.A. \& Haidar, R.F. 2005. Manual para o monitoramento de parcelas permanentes nos biomas Cerrado e Pantanal. Departamento de Engenharia Florestal, Universidade de Brasília, Distrito Federal. 60p.

Felfili, J.M.; Nascimento, A.R.T.; Fagg, C.W. \& Meirelles, E.M. 2007. Floristic composition and community structure of a seasonally deciduous forest on limestone outcrops in Central Brazil. Revista Brasileira de Botânica 30(4): 611-621.

Freeland, W.J. 1974. Vole Cycles: Another Hypothesis. The American Naturalist 108(960): 238-245.

Freeland, W.J. \& Janzen, D.H. 1974. Strategies in herbivory by mammals: the role of plant secondary compounds. The American Naturalist 108(961): 269-289. 
Gill, R.M.A. 1992. A review of damage by mammals in North Temperate Forests. 2. Small Mammals. Forestry 65(3): 281-308.

Glander, K.E. 1977. Poison in a monkey's garden of Eden. Natural History 86(3): 34-41.

Hammer, O; Harper, D.A.T. \& Ryan, P.D. 2001. PAST: Paleontological Statistics software package for education and data analysis. Palaeontologia Electronica 4(1): $9 \mathrm{p}$.

Krebs, C.J. 1999. Ecological Methodology. 2nd. Ed. Addison-Wesley Educational Publishers, Inc. New York. USA. 624p.

Lacher Jr., T.E. 1981. The comparative social behavior or Kerodon rupestris and Galea spixii and the evolution of behavior in the Caviidae. Bulletin of Carnegie Museum of Natural History 17: 1-71.

Lacher Jr., T.E.; Willig, M.R. \& Mares, M.A. 1982. Food preference as a function of resource abundance with multiple prey types: an experimental analysis of optimal foraging theory. The American Naturalist 120(3): 297-316.

Mares, M.A. \& Lacher Jr., T.E. 1987. Ecological, morphological and behavioral convergence in rock-dwelling mammals. Pp: 307-348. In: Genoways, H.H. Current Mammalogy, Vol. I. Plenum Publishing Corporation. 520p.

Marsh, K.J.; Moore, B.D.; Wallis, I.R. \& Foley, W.J. 2014. Feeding rates of a mammalian browser confirm the predictions of a "foodscape" model of its habitat. Oecologia 174(3): 873-882.

MMA - Ministério do Meio Ambiente. 2008. Lista Nacional das Espécies da Flora Brasileira Ameaçadas de Extinção. Instrução Normativa MMA nº 06, de 23 de setembro de 2008.

Moojen, J.; Locks, M. \& Langguth, A. 1997. A new species of Kerodon Cuvier, 1825 from the State of Goiás, Brazil (Mammalia, Rodentia, Caviidae). Boletim do Museu Nacional do Rio de Janeiro, Série Zoologia 377: 1-10.

Langguth, A. \& Reis, M. 2008. Kerodon acrobata. In: IUCN 2010. IUCN Red List of Threatened Species. Version 2010.1. Disponível em: www.iucnredlist.org. Acessado em $01 / 01 / 2015$.

Moore, B.D.; Lawler, I.R.; Wallis, I.R.; Beale, C.M. \& Foley, W.J. 2010. Palatability mapping: a koala's eye view of spatial variation in habitat quality. Ecology 91(11): 3165-3176.

Nascimento, A.R.T.; Felfili, J.M. \& Meirelles, E.M. 2004. Florística e estrutura da comunidade arbórea de um remanescente de Floresta Estacional Decidual de encosta, Monte Alegre, GO, Brasil. Acta Botanica Brasilica 18(3): 659-669. 


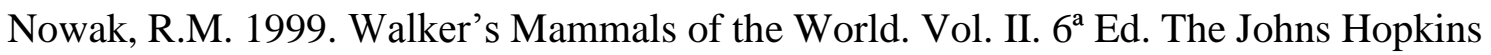
University Press. Baltimore, USA and London, UK. 1.100p.

Ojeda R.A.; Blendinger P.G. \& Brandl, R. 2000. Mammals in South American drylands: faunal similarity and trophic structure. Global Ecology and Biogeography 9(2): 11524.

Oliveira, J.A. \& Bonvicino, C.R. 2006. Ordem Rodentia. Pp: 347-406. In: Reis, N.R.; Peracchi, A.L.; Pedro, W.A.; Lima, I.P. (Eds.) Mamíferos do Brasil. Universidade Estadual de Londrina. Londrina, PR. 437p.

Olson, S.L. 1981. Natural history of vertebrates on the Brazilian islands of the Mid-South Atlantic. National Geographic Society Research Reports 13: 481-492.

Paglia, A.P.; Fonseca, G.A.B.; Rylands, A.B.; Herrmann, G.; Aguiar, L.M.S.; Chiarello, A.G.; Leite, Y.L.R.; Costa, L.P.; Siciliano, S.; Kierulff, M.C.M.; Mendes, S.L.; Tavares, V.C.; Mittermeier, R.A. \& Patton J.L. 2012. Lista Anotada dos Mamíferos do Brasil - $2^{\text {a }}$ Edição / Annotated Checklist of Brazilian Mammals - $2^{\text {nd }}$ Edition. Occasional Papers in Conservation Biology, No. 6. Conservation International, Arlington, VA. USA. 76p.

R Core Team. 2014. R: A Language and Environment for Statistical Computing. R Foundation for Statistical Computing. Vienna, Áustria. http://www.R-project.org.

Reichman, O.J. \& Van de Graaff, K.M. 1975 Association between ingestion of green vegetation and desert rodent reproduction. Journal of Mammalogy 56(2): 503-506.

Ribeiro, J.F. \& Walter, B.M.T. 1998. Fitofisionomias do bioma Cerrado. Pp: 89-166. In: Sano, S.M. \& Almeida, S.P. Cerrado: ambiente e flora. EMBRAPA. Planaltina, DF. $556 \mathrm{p}$.

Roberts, M.; Maliniak, E. \& Deal, M. 1984. The reproductive biology of the rock cavy, Kerodon rupestris, in captivity: a study of reproductive adaptation in a trophic specialist. Mammalia 48(2): 253-265.

Sassi, P.L.; Borghi, C.E. \& Bozinovic, F. 2007. Spatial and seasonal plasticity in digestive morphology of cavies (Microcavia australis) inhabiting habitats with different plant qualities. Journal of Mammalogy 88(1): 165-172.

Sassi, P.L.; Borghi, C.E.; Dacar, M.A. \& Bozinovic, F. 2011. Geographic and seasonal variability in feeding behaviour of a small herbivorous rodent. Acta Theriologica 56(1): 35-43.

Smythe, N. 1986. Competition and resource partitioning in the guild of Neotropical terrestrial frugivorous mammals. Annual Review of Ecology and Systematics 17: 169-188. 
Stefanello, D.; Fernandes-Bulhão, C. \& Martins, S.V. 2009. Síndrome de dispersão de sementes em três trechos de vegetação ciliar (nascente, meio e foz) ao longo do rio Pindaíba, MT. Revista Árvore 33(6): 1051-1061.

Stephens, S.A.; Salas, L.A. \& Dierenfeld, E.S. 2006 Bark consumption by the painted ringtail (Pseudochirulus forbesi larvatus) in Papua New Guinea. Biotropica 38(5): 617-624.

Streilen, K.E. 1982. The ecology of small mammals in the semiarid Brazilian Caatinga, III. Reproductive Biology and population ecology. Annals of the Carnegie Museum 51: 251-269.

Swihart, R.K.; Gehring, T.M.; Kolozsvary, M.B. \& Nupp, T.E. 2003. Responses of resistant vertebrates to habitat loss and fragmentation: the importance of niche breadth and range boundaries. Diversity and Distributions 9(1): 1-18.

Westoby, M. 1978. What are the biological bases of varied diets? The American Naturalist 112(985): 627-631.

Wiggins, N.L.; McArthur, C. \& Davies, N.W. 2006. Diet switching in a generalist mammalian folivore: fundamental to maximising intake. Oecologia 147(4): 650-657.

Willig, M.R. \& Lacher Jr., T.E. 1991. Food selection of a tropical mammalian folivore in relation to leaf-nutrient content. Journal of Mammalogy 72(2): 314-321.

Zar, J.H. 1999. Biostatistical analysis. Prentice Hall. New Jersey, USA. 663 p. 


\section{Considerações finais}

O mocó acrobata é um roedor herbívoro, um browser, de distribuição restrita, endêmico do Cerrado brasileiro e aparentemente raro, por ser especialista em habitats rochosos. Estudos recentes, incluindo o presente, têm contribuído para a ampliação da área de ocorrência da espécie, porém seus atuais limites de distribuição precisam ser determinados, incluindo uma melhor investigação em seu limite norte, na região entre Taguatinga do Tocantins e Ponte Alta do Bom Jesus, no mesmo estado, onde aparentemente, a espécie parece ser substituída por outra, que apresenta coloração e vocalizações distintas.

Atualmente, $K$. acrobata encontra-se ameaçada de extinção, pois assim como seu congênere, também é amplamente caçada e além disso, seu habitat encontra-se ameaçado por atividades antrópicas, que aparentemente dificultam, ou podem até mesmo impossibilitar sua dispersão entre os fragmentos de habitat favoráveis. Porém, em ambientes protegidos, as populações desse mocó talvez possam prosperar, pois é uma espécie que explora uma ampla gama de recursos vegetais, exibindo plasticidade no seu comportamento alimentar. Esse foi o caso da população de K. rupestris, que prosperou após ser introduzida no arquipélago de Fernando de Noronha, onde não existem predadores naturais dessa espécie. Além disso, apesar de não ter sido observada consumindo gramíneas, nem naturais, nem em áreas de pasto, estudos sobre a dieta desse mocó, utilizando métodos de análise micro-histológica das fezes (ideal para gramíneas), podem contribuir para o aumento do conhecimento da riqueza de espécies consumidas e da importância de cada espécie vegetal, considerando-se a proporção de ingestão de cada uma delas.

Embora o padrão de atividade pareça ser regulado pela atividade de predadores carnívoros, como Leopardus pardalis, um aspecto importante que não pôde ser observado nesse estudo, foi sobre o comportamento dos indivíduos de $K$. acrobata dentro de seus abrigos. Portanto, estudos com indivíduos em cativeiro, também devem ser conduzidos, para melhor entendermos como se desenvolvem os comportamentos reprodutivo e de cuidado parental. $\mathrm{O}$ estudo de comportamento em cativeiro também pode contribuir com conhecimentos valiosos para uma eventual criação comercial da espécie, ação que poderia gerar empregos, renda e diminuir a pressão de caça sobre a espécie, ao menos em algumas partes de sua distribuição geográfica. 
Os fragmentos de vegetação remanescentes, associados aos afloramentos rochosos, especialmente os cársticos, têm servido como refúgios para a mastofauna local, comportando além de roedores, espécies de primatas, marsupiais e carnívoros, incluindo predadores de topo de cadeia. Entretanto, estudos focando os efeitos da fragmentação do habitat sobre a variabilidade genética das populações remanescentes de mocós devem ser conduzidos, devido à pequena área de vida e ao comportamento territorialista dos indivíduos e à natureza de habitar "ilhas", pela espécie. Estudos metapopulacionais devem ser conduzidos e os mecanismos de dispersão precisam ser elucidados. Deve-se averiguar quais são as condições desfavoráveis para a dispersão, como e quando ela ocorre, se atualmente é satisfatória, ou se é necessário criar corredores, ou realizar algum tipo de manejo, incluindo translocações, para manter uma boa variabilidade genética das populações remanescentes. Também se mostra necessário, investigar se e onde houveram extinções locais e quais os seus motivos, a exemplo dos relatos desse tipo de ocorrido em populações de $K$. rupestris na Caatinga. 
